Balanceamento e sequenciamento de linhas de produção multi-modelo com trabalhadores deficientes 



\title{
Balanceamento e sequenciamento de linhas de produção multi-modelo com trabalhadores deficientes ${ }^{1}$
}

\author{
Pâmela Michele Cândida Cortez
}

Orientador: Prof. Dr. Alysson M. Costa

\begin{abstract}
Dissertação apresentada ao Instituto de Ciências Matemáticas e de Computação - ICMC-USP, como parte dos requisitos para obtenção do título de Mestre em Ciências - Ciências de Computação e Matemática Computacional. VERSÃO REVISADA
\end{abstract}

USP - São Carlos

Abril de 2012

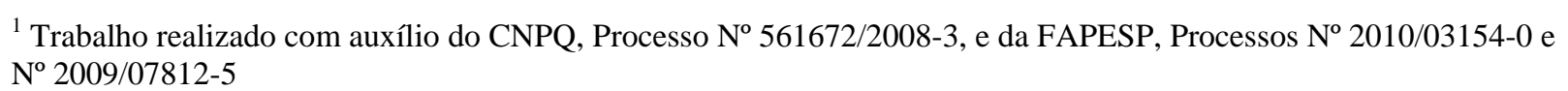


Ficha catalográfica elaborada pela Biblioteca Prof. Achille Bassi e Seção Técnica de Informática, ICMC/USP, com os dados fornecidos pelo(a) autor(a)

Cortez, Pâmela M. C.
Balanceamento e sequenciamento de linhas de
produção multi-modelo com trabalhadores deficientes /
Pâmela M. C. Cortez; orientador Alysson M. Costa. --
São Carlos, 2012.
73 p.
Dissertação (Mestrado - Programa de Pós-Graduação en
Ciências de Computação e Matemática Computacional) --
Instituto de Ciências Matemáticas e de Computação,
Universidade de São Paulo, 2012.
1. Pesquisa Operacional. 2. Sequenciamento. 3.
Heuristicas. I. Costa, Alysson M., orient. II. Título.


A Deus, por ser Deus,

À minha mãe, por ser uma guerreira,

Ao Alysson, por ser um anjo. 


\section{Agradecimentos}

Gostaria de agradecer a Deus pela oportunidade de ter estado aqui. Não raro, penso o quanto poderia ser mais feliz se estivesse na minha cidade, com minha família, trabalhando em algo que eu pudesse ajudar mais. Mas tudo isso só seria possível se a Pâmela de 2004 fosse uma pessoa bem menos arrogante. Mais que estudar na melhor universidade do país, que infelizmente nada me ensinou além da técnica, são os momentos de dificuldade que eu tanto agradeço.

Noites em que a Tininha batia à porta do meu quarto e me oferecia um encontro com o Homem que me ama. Só assim pude suportar as tardes que passei chorando no banheiro do IFSC, seja por não conseguir entender nada da aula de Física Clássica I, seja pelo meu professor de Física Matemática me perguntar: "Como você não sabe isso, isso é trivial, você é burra?". Depois, para alegria do coordenador da graduação em Física, transferi para Ciências de Computação.

Aqui aprendi que, se no mercado você vale o quanto traz de lucro à empresa, aqui na USP você vale sua média ponderada. Ainda bem que na computação a minha foi alta, ainda que por pura Providência. Artur e Diogo, os dois lados do meu cérebro, muito obrigada por toda paciência e humildade. Se metade das pessoas do mundo fossem como vocês, a Terra seria o Céu.

E graças a esses dois irmãos maravilhosos que Deus colocou no meu caminho, e aquele lindo do Fernando que tive oportunidade de conviver desde meu nascimento, terminei a graduação e aqui estou, terminando o mestrado.

Conheci pessoas incriveis no LOt, e descobri através delas que toda regra tem mesmo sua exceção. É maravilhoso estar em um lugar onde as pessoas se preocupam, se ajudam, se amam. E isso não é mérito só dos alunos, o fato de todos os professores do LOt serem pessoas boas, que desejam ao outro o que desejam a si, é o grande responsável por tudo isso. Exemplo é tudo! Como foi fácil passar naquelas disciplinas cheias de teoremas... Gabis, Poullet, Lucas Vendramin, muito obrigada! Rafa, é com grande carinho que lembro nossas 
aulas com a Professora Vitória, nossos trabalhos, foi tudo perfeito!

Obrigada Mayron, por ter me ajudado mesmo antes de sermos oficialmente "irmãos". Obrigada Felipe pela calma e piadas. Obrigada Aline (credu), Claudinha, Marcos, Marcio, Murilo, Pedrinho e Tamara pelas conversas, festas e (é melhor não falar). Léo! eu tava quase esquecendo de você, mas a culpa é sua... só fica com o pessoal do LCAD! Muito bom poder contar com você e Marcão sempre que algo está dando errado... seja lá o que estiver errado.

Alysson, se eu não tivesse um orientador tão paciente, talvez não tivesse escrevendo essa dissertação. Desculpe por ser tão inconstante e agitada. Eu realmente não gostaria de ter uma aluna chata assim, ainda me pergunto como você aguentou? Obrigada por tudo que me ensinou, e muito obrigada por ter me dado apoio quando quis trabalhar, assim vi que sim, PO tem muita aplicação! Mas como todo emprego, só ajudamos a enriquecer quem já é rico. Logística humanitária, arranjo dos painéis no container (empacotamento)... muitos doces, e agora que sei que nada sei, está muito difícil escolher. Melhor esperar eu ser uma aluna menos chata, porque é injusto um professor tão perfeito como você precisar ter tanta "psicologia infantil". Brincamos que somos "irmãos”, então você é nosso super pai! Se hoje alguém me perguntasse o que quero ser quando crescer? O Professor Alysson. 


\section{Resumo}

Este trabalho lida com o problema de balanceamento e sequenciamento de linhas de produção multi-modelo com trabalhadores deficientes, uma generalização de dois importantes problemas da literatura de linhas de produção: o Problema de Balanceamento de Linhas de Produção Multi-Modelo (MALBP) e o Problema de Balanceamento e Designação de Trabalhadores em Linhas de Produção (ALWABP). O MALBP tem sido particularmente importante nas últimas décadas, onde, em um cenário de maior competividade, cresce a necessidade de produção em larga escala de produtos customizados. O ALWABP, por sua vez, é de grande importância em Centros de Trabalhadores com Deficiências (CTD's), onde é necessário considerar as competências individuais de cada trabalhador, que se revelam nos diferentes tempos de execução de uma tarefa, segundo o trabalhador escolhido. Ao nosso conhecimento, nenhum estudo se dedicou a resolver estes dois problemas conjuntamente. Nesta dissertação, propomos modelos lineares para os problemas de balanceamento e sequenciamento de linhas de produção multi-modelo em CTD's. Para o problema de sequenciamento, limitantes inferiores e superiores e métodos heurísticos de resolução são desenvolvidos e discutidos. Testes computacionais foram efetuados e os resultados sugerem que os métodos desenvolvidos são eficientes. 


\section{Abstract}

This study addresses the Mixed Assembly Line and Worker Assignment Balancing Problem, which generalizes two classical problems in the assembly line literature: the Mixed Assembly Line Balancing Problem (MALBP) and the Assembly Line Worker Assignment and Balacing Problem (ALWABP). The MALBP has been considered particularly important in the last two decades, when, in the context of more competitive scenarios, there is a growing need of producing customized products in large scale. On the other hand, the ALWABP is of interest in Sheltered Work centers for the Disabled (SWD). In this situation, we must consider each worker individual abilities, which results in task duration times that are dependent on the workers selected for their execution. To the best of our knowledge, there has been no effort to solve these problems jointly. We propose linear models for both balancing and sequencing multimodels assembly lines commonly found in SWD. Lower and upper bounds and also heuristic methods are proposed and discussed for the sequencing problem. The results obtained by computational experiments suggest the heuristic methods can efficiently solve the MALWABP. 


\section{Sumário}

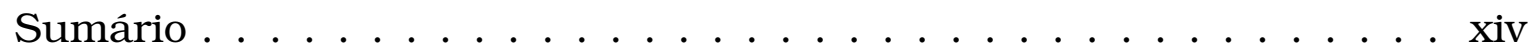

Lista de Figuras . . . . . . . . . . . . . . . $\ldots_{\mathrm{xv}}$

Lista de Tabelas . . . . . . . . . . . . . . . . . xvii

Lista de Algoritmos . . . . . . . . . . . . . . . xix

Lista de Abreviaturas . . . . . . . . . . . . . . . . xix

1 Introdução 1

2 Definição dos Problemas Clássicos e Modelagem Matemática 5

2.1 Definições e Notação . . . . . . . . . . . . . . . . 5

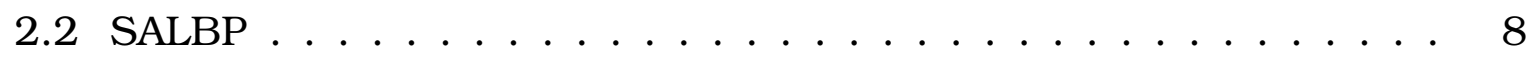

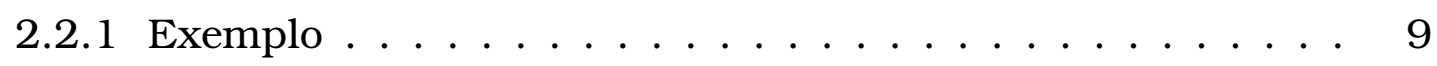

2.2 .2 Modelo matemático . . . . . . . . . . . . 10

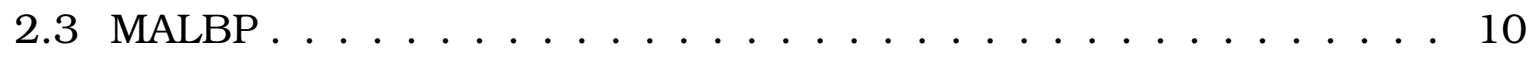

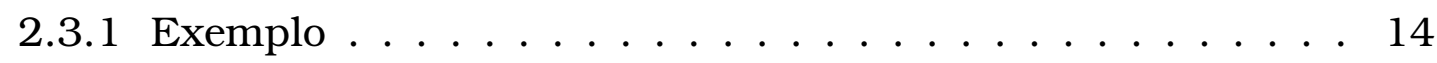

2.3.2 Modelo matemático para o balanceamento MALBP . . . . 15

2.3.3 Modelo matemático para o sequenciamento MALBP . . . . 17

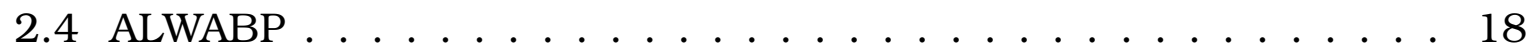

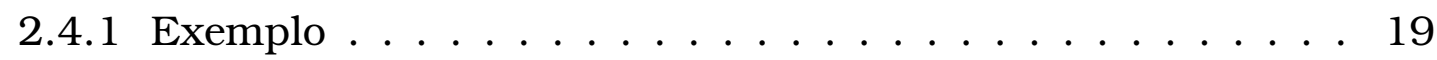

2.4 .2 Modelo matemático . . . . . . . . . . . . 20

3 Revisão Bibliográfica 23

3.1 Problema de Balanceamento de Linhas de Produção Multi-Modelo 23

3.1.1 Literatura sobre o balanceamento multi-modelos . . . . . 23

3.1.2 Literatura sobre o problema de sequenciamento . . . . . 28

3.2 Problema de Balanceamento e Designação de Trabalhadores em Linhas de Produção . . . . . . . . . . . . . . . . . . . . . 29

4 Formalização do problema e modelos matemáticos 31

4.1 Problema de balanceamento MALWABP . . . . . . . . . . . 31

4.2 Problema de sequenciamento MALWABP . . . . . . . . . . . 32 
4.2.1 Modelo matemático para o sequenciamento MALWABP . . 33

4.2.2 Reformulação do modelo matemático para o sequenciamento MALWABP . . . . . . . . . . . . . . 35

4.2.3 Limitantes para o sequenciamento MALWABP . . . . . . . 37

5 Heúristicas para o sequenciamento MALWABP 39

5.1 Heurística construtiva . . . . . . . . . . . . . . . . . . 39

5.1 .1 Exemplo . . . . . . . . . . . . . . . 41

5.2 Busca Local . . . . . . . . . . . . . . . . . . . . . . . . . 43

5.2 .1 Função de avaliação exata . . . . . . . . . . . . 43

5.2.2 Função de avaliação aproximada . . . . . . . . . . . 46

5.2.3 Método de busca local com mais de uma função de avaliação 48

5.3 Vizinhança MIP . . . . . . . . . . . . . . . . . . . . 49

6 Experimentos 51

6.1 Geração de instâncias para o MALWABP . . . . . . . . . . . 51

6.2 Resultados computacionais . . . . . . . . . . . . . 52

6.2 .1 Qualidade dos limitantes . . . . . . . . . . . . 53

6.2.2 Testes iniciais: $\mathrm{LS}^{1}$ e $\mathrm{LS}^{2} \ldots \ldots \ldots \ldots$. . . . . . . . . . . 53

6.2.3 Comparação entre as heurísticas construtivas . . . . . . . 56

6.2 .4 Busca Local . . . . . . . . . . . . . . . . . . . . 56

6.2 .5 Vizinhança MIP . . . . . . . . . . . . . . . . 58

6.2.6 Comparação com o CPLEX . . . . . . . . . . . . . 61

6.3 Sumário dos resultados . . . . . . . . . . . . . . . . . . 62

7 Conclusões e Trabalhos Futuros $\quad 63$

$\begin{array}{ll}\text { Referências } & 73\end{array}$ 


\section{Lista de Figuras}

2.1 Grafo (rede) de precedências $\ldots \ldots \ldots \ldots \ldots$

2.2 Solução do Exemplo 1 para $|K|=5 \ldots \ldots \ldots \ldots$

2.3 Multi-Model Assembly Line Balancing Problem . . . . . . . . . . 11

2.4 Mixed Assembly Line Balancing Problem . . . . . . . . . . . . . 11

2.5 Exemplo de relação de precedência cíclica . . . . . . . . . . . . 11

2.6 Eliminação da relação de precedência cíclica . . . . . . . . . . . 11

2.7 Diagrama de movimento do operador e trabalhador de apoio em uma estação . . . . . . . . . . . . . . . . . 14

2.8 Grafos de precedência para os modelos 1,2 e 3, respectivamente 15

2.9 Grafo de precedência unificado . . . . . . . . . . . . . 15

2.10 Diagrama de movimento para o exemplo da Tabela $2.5 \ldots \ldots$

2.11 Grafo de precedência para os trabalhadores 1 e $2 \ldots \ldots$

4.1 Tarefas que compõem os conjuntos $N_{k}^{*}$ e $N_{k}^{\star} \ldots \ldots \ldots$. . . 37

5.1 Vetor solução de uma sequência . . . . . . . . . . . . . . . . 44

5.2 Diagrama de movimento para o exemplo da Tabela $2.5 \ldots \ldots 5$ 


\section{Lista de Tabelas}

2.1 Notação para o problema de balanceamento SALBP . . . . . . . 6

2.2 Notação para o problema de sequenciamento MALBP . . . . . . . 6

2.3 Notação para o problema de balanceamento ALWABP . . . . . . . 7

2.4 Versões do SALBP . . . . . . . . . . . . . . . 8

2.5 Tempo de execução dos modelos em cada estação . . . . . . . . 16

5.1 Heurísticas construtivas . . . . . . . . . . . . . . . . 42

5.2 Tempo de execução dos modelos em cada estação . . . . . . . . . 43

6.1 Características das instâncias utilizadas . . . . . . . . . . 51

6.2 Qualidade dos limitantes propostos . . . . . . . . . . . . 53

6.3 Qualidade das soluções e tempo computacional . . . . . . . . 53

6.4 Comparação entre as heurísticas construtivas . . . . . . . . . . 54

6.5 Comparação entre os métodos de busca local . . . . . . . . . . . 55

6.6 Porcentagem de soluções ótimas $(\%)$. . . . . . . . . . . . . . 55

6.7 Comparação entre as heurísticas construtivas, comparando-se as soluções após a mip $p_{1, L S_{P}, 180}$. . . . . . . . . . . . . . 56

6.8 Comparação entre os métodos de busca local (valores em \% e tempo em s) . . . . . . . . . . . . . . . . 57

6.9 Comparação entre as estratégias híbridas de busca local mip $p_{2}$ (valores em \% e tempo em s) . . . . . . . . . . . . . . 59

6.10 Comparação entre as estratégias híbridas de busca local mip $p_{1,180}$ para diferentes soluções iniciais (valores em \% e tempo em s) . . . 60

6.11 Comparação entre as estratégias híbridas de busca local mip $p_{1, L S_{P}}$ para diferentes limites de tempo por iteração (valores em \% e tempo em s) . . . . . . . . . . . . . . . . . 60

6.12 Comparação com a solução obtida pelo CPLEX após 2 dias de execução ........................ 61 


\section{Lista de Algoritmos}

1 Heurística construtiva $\mathrm{HC} 4 \ldots \ldots$. . . . . . . . . . . 40

2 Heurística construtiva HC3 . . . . . . . . . . . . . . . . . 42

3 Busca Local . . . . . . . . . . . . . . . . . . . . . . 45 


\section{Lista de Abreviaturas}

ALB Balanceamento da Linha de Produção (Assembly Line Balancing)

SALBP Problema Simples de Balanceamento da Linha de Produção (Simple Assembly Line Balancing Problem)

MALBP Problema de Balanceamento de Linhas de Produção Multi-Modelo (Mixed Assembly Line Balancing Problem)

ALWABP Problema de Balanceamento e Designação de Trabalhadores em Linhas de Produção (Assembly Line Worker Assignment and Balacing Problem)

MALWABP Balanceamento de Linhas de Produção Multi-Modelo com Trabalhadores Deficientes (Mixed Assembly Line and Worker Assignment Balancing Problem)

MIP Programação Inteira Mista (Mixed Integer Programming)

CTD Centro de Trabalhadores com Deficiências (Sheltered Work Center for Disabled - SWD)

LP Problema Linear (Linear Problem)

LS Busca Local (Local Search)

LB Limitante Inferior (Lower Bound)

UB Limitante Superior (Upper Bound)

NP Tempo polinomial não determinístico (Non-deterministic polynomial time) 
Xxii 


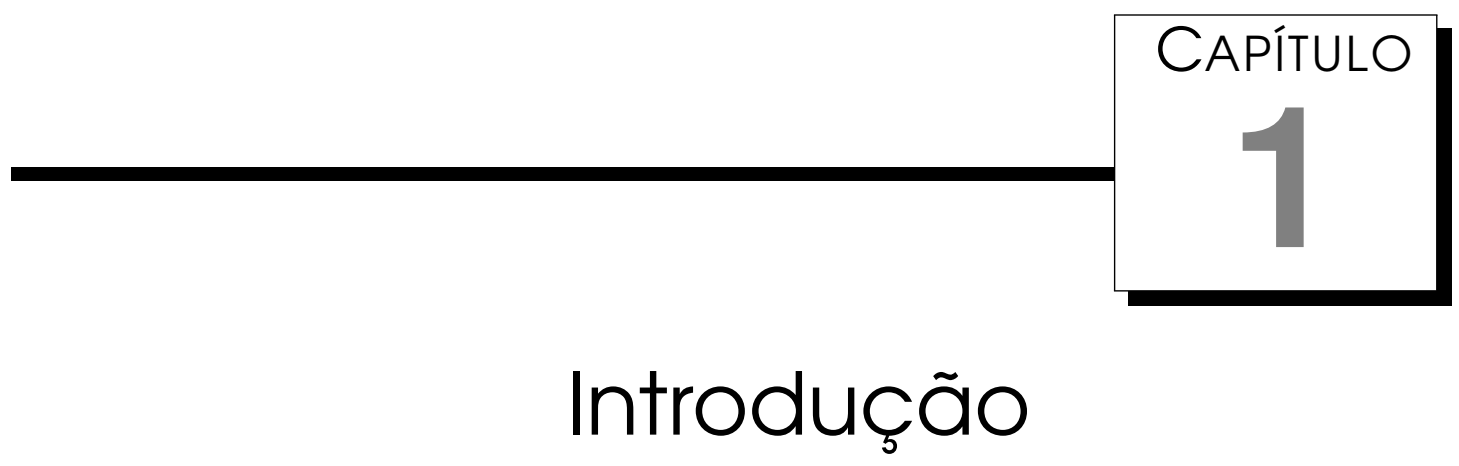

No mundo, segundo a OMS, há 600 milhões de pessoas portadoras de deficiência. No Brasil, segundo o Instituto Brasileiro de Geografia e Estatística (IBGE, 2000), 24,6 milhões de brasileiros são portadores de deficiência. Infelizmente, a taxa de desemprego desta parcela da população é muito maior do que a encontrada entre os trabalhadores sem deficiência. Este fato, motiva estudos e ações que visem aumentar a inclusão destes cidadãos no mercado de trabalho.

Os resultados computacionais de Moreira et al. (2009) sugerem que com um bom planejamento é possível não ter perda significativa de eficiência em linhas de produção que empregam trabalhadores com deficiências, evidenciando que uma suposta incapacidade produtiva destes trabalhadores não se sustenta como justificativa válida para as altas taxas de desemprego encontradas. Esta conclusão é reforçada pelos dados da Bureau of Labor Statistics (2010) dos Estados Unidos: 86,2\% dos trabalhadores com deficiências daquele país estão empregados, e da Office for National Statistics Labour Force Survey (2009): 80\% dos portadores de deficiências em idade ativa no Reino Unido estão trabalhando. Tais dados levam a crer que, no Brasil, o preconceito, a falta de informação e de políticas públicas de capacitação e inserção são os fatores determinantes para termos menos de $40 \%$ destes trabalhadores em idade ativa exercendo atividade produtiva no mercado formal (IBGE, 2005).

Este problema é também evidenciado pela maneira como as empresas lidam com a Lei Federal 8213/91 (conhecida como Lei de Cotas), que obriga empresas com mais de 100 empregados a preencher seu quadro de funcionários com dois a cinco por cento de trabalhadores com deficiências. É comum estas empresas fazerem altas exigências para as vagas destinadas a portadores de deficiências, visando restringir a ocupação dos cargos por elas "dispo- 
nibilizados” para atender a Lei de Cotas (Jaime e Carmo, 2005).

Apesar disso, o profissional portador de deficiência é capaz de agregar tanto valor ao seu trabalho que algumas grandes empresas têm hoje mais empregados portadores de deficiência do que a lei determina, pois tais empresas garantem que os esforços para adaptação são largamente compensados (Bissoli, 2005).

Indústrias são as maiores responsáveis por disponibilizar vagas para deficientes. No município de São Carlos, por exemplo, 90\% das vagas se encontram em tais ambientes (Simonelli et al., 2006). Recentemente, a indústria vem se transformando, impulsionada por clientes cada vez mais exigentes e maior concorrência. Neste contexto, a customização em massa e produção por demanda (Cohen e Pine II, 2007) tem exigido maior flexibilidade nas linhas de produção, visando atender as necessidades de um público mais diverso. Esta diversidade é claramente observada na indústria automobilística, onde um produto pode apresentar mais de $10^{6}$ modelos (Boysen et al., 2009a) (originados pelos diferentes "opcionais" que o cliente pode requisitar independentemente). Portanto, o desenvolvimento de métodos que visam otimizar a produção destes diferentes modelos tem grande importância prática.

Motivado pela necessidade de incorporar os trabalhadores com deficiências na indústria, que necessita atender ao mercado no contexto atual de produção customizada em larga escala, este trabalho visa obter um método de otimizar linhas de produção multi-modelo operadas por trabalhadores com deficiências. Nosso interesse principal está em empresas, criadas pela iniciativa governamental de alguns países, onde todos os trabalhadores da linha de produção possuem alguma deficiência. Estes Centros de Trabalho para Deficientes (CTD's) têm grande importância para integração inicial destes trabalhadores, que podem iniciar sua vida profissional em empresas que, por serem sem fins lucrativos, têm outros objetivos além da maximização da produção, como por exemplo, permitir que um trabalhador possa ter contato com várias atividades diferentes, aumentando a sua qualificação.

O restante deste documento está organizado da seguinte maneira: no Capítulo 2 descrevemos os problemas clássicos dos quais derivam o problema deste trabalho. No Capítulo 3, apresentamos um resumo da literatura sobre trabalhadores com deficiências em linhas de produção e sobre a extensão do problema de balanceamento quando se devem produzir diversos modelos de um mesmo produto. No Capítulo 4, é definido formalmente e fornecido um modelo matemático para o problema proposto neste trabalho. As heurísticas desenvolvidas para o problema de sequenciamento são discutidas no Capítulo 5. No Capítulo 6 são mostrados os testes computacionais obtidos através das resoluções exata e heurística do problema e, finalmente, no Capítulo 7 
são apresentadas as conclusões e os trabalhos que podem dar continuidade a este estudo. 


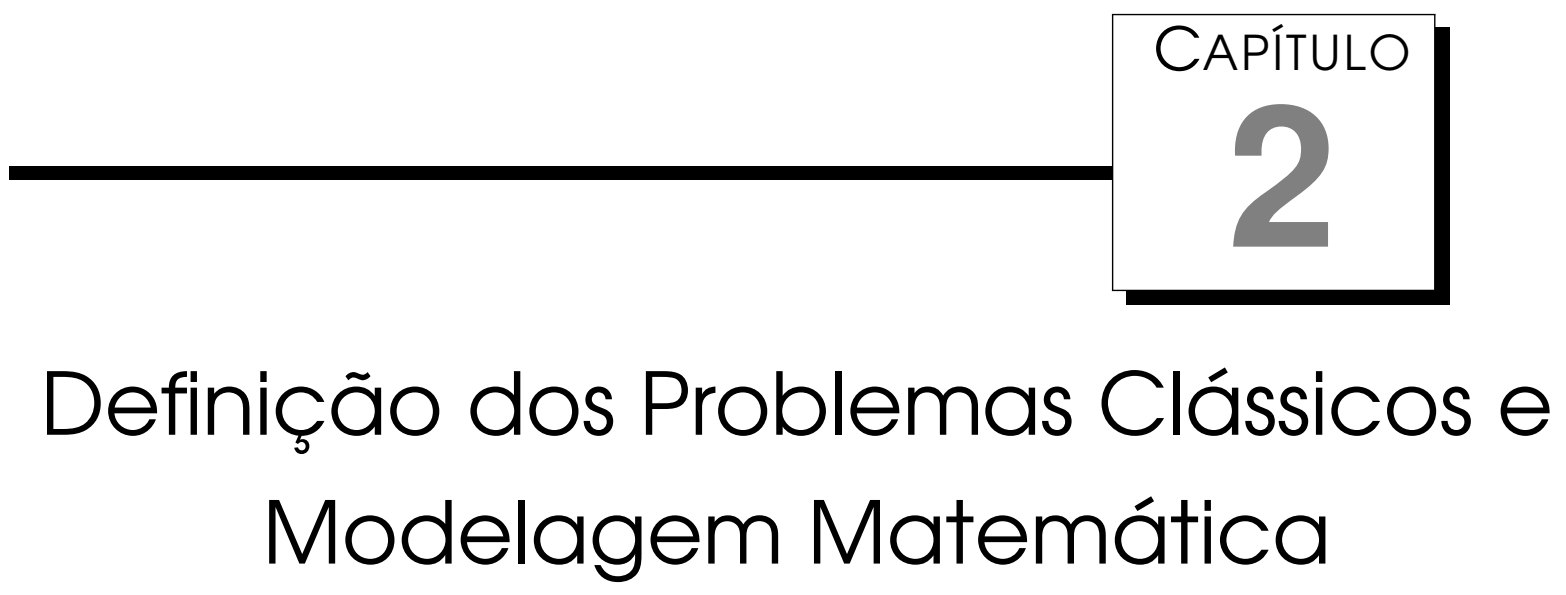

A primeira parte deste capítulo dedica-se à apresentação das notações e definições necessárias para a descrição dos problemas envolvidos neste trabalho. Apresentamos também descrições, exemplos e modelagens matemáticas dos problemas clássicos da área nas seções seguintes.

\subsection{Definições e Notação}

Nesta seção, apresentamos as notações e definições utilizadas neste trabalho. Os conceitos utilizados são em grande parte retirados da obra de Scholl (1999). A notação adotada para representar o Problema Simples de Balanceamento da Linha de Produção (SALBP, do inglês Simple Assembly Line Balancing Problem) encontra-se na Tabela 2.1. A Tabela 2.2 refere-se a notação do Problema de Balanceamento de Linhas de Produção Multi-Modelo (MALBP, do inglês Mixed Assembly Line Balancing Problem). Notações adicionais necessárias ao Problema de Balanceamento e Designação de Trabalhadores em Linhas de Produção (ALWABP, do inglês Assembly Line Worker Assignment and Balacing Problem) podem ser obtidas na Tabela 2.3.

Definição 1 (Relação de Precedência Direta) Uma tarefa $i$, que deve ser executada antes da tarefa $j$, é denominada predecessora de $j$, enquanto $j$ é uma sucessora de $i$. A relação de precedencia entre duas tarefas i e $j$ é dita direta ou imediata se nenhuma das tarefas que sucedem i é predecessora de $j$. 


\begin{tabular}{|ll|}
\hline$i, j$ & indice para tarefas $(i, j=1, \cdots,|N|)$ \\
$k$ & indice para estações $(k=1, \cdots,|K|)$ \\
$K$ & conjunto de estações, \\
$N$ & conjunto de tarefas, \\
$|K|$ & número de estações, \\
$|N|$ & quantidade de tarefas, \\
$N_{k}$ & conjunto de tarefas alocadas a estação $k$, \\
$D_{j}$ & conjunto de tarefas imediatamente precedentes à tarefa $j$, \\
$F_{j}$ & conjunto de tarefas imediatamente sucessoras à tarefa $j$, \\
$A$ & conjunto de relações de precedência diretas $\left(\mathrm{A}=\left\{(i, j): i \in N\right.\right.$ e $\left.\left.j \in F_{i}\right\}\right)$, \\
$D_{j}^{*}$ & conjunto de predecessores imediatos e transitivos à tarefa $j$, \\
$F_{j}^{*}$ & conjunto de sucessores imediatos e transitivos à tarefa $j$, \\
$A^{*}$ & conjunto de todas as relações de precedência $\left(A^{*}=\left\{(i, j): i \in N\right.\right.$ e $\left.\left.j \in F_{i}^{*}\right\}\right)$. \\
$C$ & tempo de ciclo, \\
$t_{j}$ & tempo de processamento da tarefa $j$, \\
$t_{s u m}$ & somatório dos tempos gastos na execução de todas as tarefas $\left(t_{s u m}=\sum_{j \in N} t_{j}\right)$ \\
$t_{k}$ & tempo necessário à estação $k$ para operar as tarefas do conjunto $N_{k}$, \\
\hline
\end{tabular}

Tabela 2.1: Notação para o problema de balanceamento SALBP

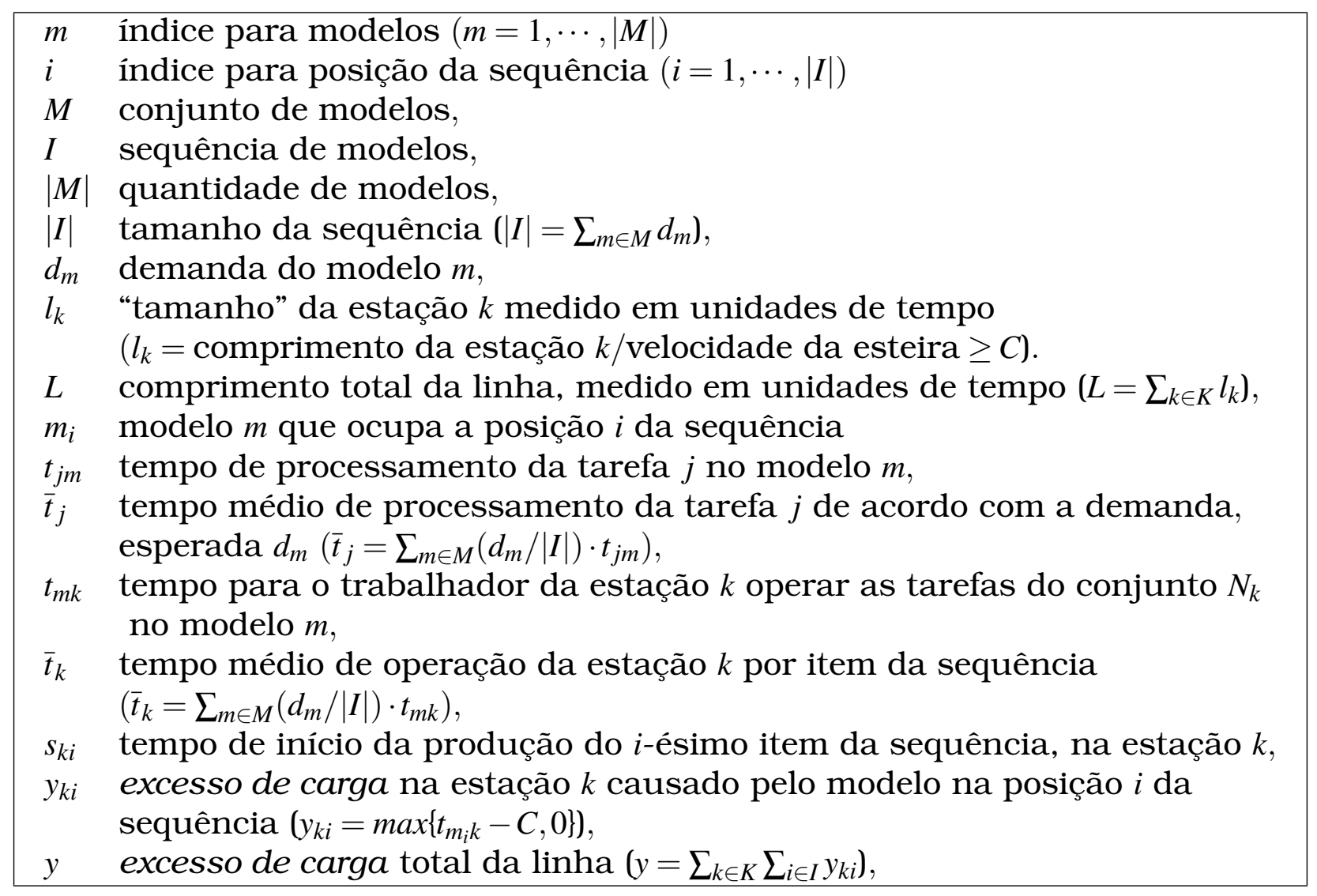

Tabela 2.2: Notação para o problema de sequenciamento MALBP

Definição 2 (Relação de Precedência Transitiva) Uma relação de precedência transitiva $(i, k)$ envolve nós $i, j, k$ tal que $i \in D_{j}, i \in D_{k}$ e $j \in D_{k}^{*}$, ou seja, $i$ é predecessor direto de $j$ e $k$ e $j$ é predecessor direto ou indireto de $k$. 


\begin{tabular}{|ll|}
\hline$w$ & índice para trabalhadores $(w=1, \cdots,|W|)$, \\
$w_{k}$ & trabalhador alocado para operar a estação $k$, \\
$W$ & conjunto de trabalhadores, \\
$|W|$ & quantidade de trabalhadores $(|W|=|K|)$, \\
$N_{w}^{\infty}$ & conjunto de tarefas que o trabalhador w não é capaz de executar, \\
$t_{\text {max }}$ & maior tempo gasto na execução de uma tarefa $\left(t_{\max }=\max \left\{t_{j}: j=1, \ldots,|N|\right\}\right)$ \\
$t_{\min }$ & menor tempo gasto na execução de uma tarefa $\left(t_{\min }=\min \left\{t_{j}: j=1, \ldots,|N|\right\}\right)$ \\
$t_{j w}$ & tempo necessário ao trabalhador $w$ executar a tarefa $j$ \\
& $\left(t_{j w} \rightarrow \infty\right.$ se o trabalhador não é apto a executar a tarefa $\left.j\right)$, \\
\hline
\end{tabular}

Tabela 2.3: Notação para o problema de balanceamento ALWABP

Definição 3 (Relação de Precedência Cíclica) Uma relação de precedência cíclica envolve nós $i$ e $j$, tal que $i \in D_{j}^{*}$ e $i \in F_{j}^{*}$.

Definição 4 (Grafo (rede) de Precedências (Moreira, 2011)) Um grafo de precedência $G=(N, A)$ é um dígrafo não-cíclico com um conjunto $N=\{1, \ldots, n\}$ de nós e um conjunto $A=\left\{(i, j): i \in N\right.$ e $\left.j \in F_{i}\right\}$ de arcos. Os nós representam as tarefas e os arcos representam precedências diretas não transitivas. O peso no nó $j$ representado por $t_{j}$ corresponde ao tempo de execução dessa tarefa. O nó correspondente a uma tarefa sem predecessores (sucessores) é chamado de origem (sumidouro).

A precedência reversa $G^{r}$ do grafo é obtida revertendo a orientação de todos os arcos de G. Origens tornam-se sumidouros, predecessores tornam-se sucessores, e vice-versa.

Exemplo 1 (Grafo de Precedências) A Figura 2.1 representa um grafo de precedência com 11 tarefas. A tarefa $C$, por exemplo, deve ser executada antes de seus sucessores diretos, as tarefas $F$ e G, e indiretos, $H, I, J$ e K.

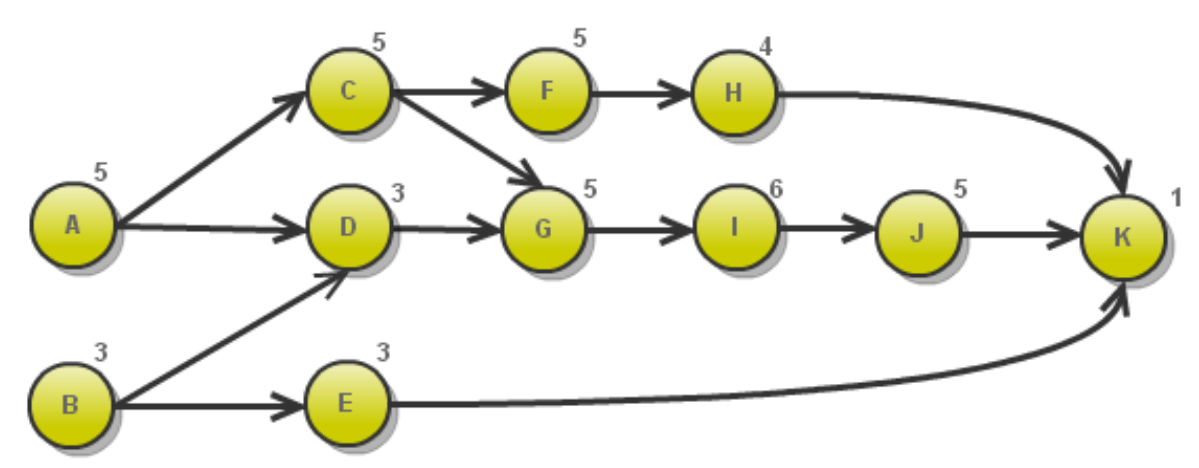

Figura 2.1: Grafo (rede) de precedências (Scholl, 1999)

Definição 5 (Balanceamento de Linha (Moreira, 2011)) A partição do conjunto $N$ de todas as tarefas em $|K|$ subconjuntos disjuntos ordenados $N_{k}$, com $k=$ $1, \ldots,|K|$ é chamada de designação (ou alocação) de tarefas se $i \in N_{k_{1}}$ e $j \in N_{k_{2}}$, 
com $k_{1} \leq k_{2}, \forall(i, j) \in A$. Em outras palavras, cada tarefa $i$ é designada a exatamente uma estação de trabalho e seus sucessores não devem ser designados a estações anteriores. Uma alocação de tarefas é factível para um dado tempo de ciclo $C$ se o valor de $t_{k}$ para todas as estações é menor ou igual a $C$. Uma alocação de tarefas factível é denominada balanceamento de linha. Portanto, uma condição necessária para a existência de um balanceamento de linha é $C \geq t_{\max }$, dado que as tarefas são indivisíveis.

Definição 6 (Linha ritmada) Em linhas do tipo ritmada (paced line), os produtos são movidos a velocidade constante, ou em intervalos fixos de tempo, de uma estação $k$ à próxima estação.

Definição 7 (Eficiência da linha) Uma medida de eficiência da linha, E, pode ser definida da seguinte forma:

$$
E=t_{\text {sum }} /(|K| \cdot C)
$$

Em uma linha perfeitamente balanceada $E=1$, ou seja, $t_{k}=C, \forall k \in K$. Outras medidas de desempenho, tais como fluxo da linha de produção e smoothness index podem ser encontradas em Scholl (1999). Observe que devido a indivisibilidade das tarefas entre as estações, raramente é possível obter um balanceamento perfeito.

\section{$2.2 S A L B P$}

O SALBP é o problema mais clássico em linhas de produção e consiste em alocar as tarefas relacionadas à produção de um item de forma a balancear a carga entre as diversas estações, respeitando as relações de precedência entre as tarefas. A otimização pode ter diferentes objetivos: minimizar o número de estações $|K|$ dado um tempo de ciclo (SALBP-1), minimizar o tempo de ciclo $C$, ou seja, o tempo de operação da estação com maior carga dado o número de estações da linha (SALBP-2) ou minimizar o produto entre o tempo de ciclo e o número de estações (SALBP-E), como mostra a Tabela 2.4. O problema SALBP-F refere-se a um problema de decisão: dados $|K|$ e $C$ deve-se verificar se existe uma alocação de tarefas factível.

\begin{tabular}{clcc}
\cline { 3 - 3 } & & \multicolumn{2}{c}{ Tempo de ciclo $C$} \\
& & conhecido & a ser minimizado \\
\hline \hline $\mathrm{n}^{0}$ estações & conhecido & SALBP-F & SALBP-2 \\
$|K|$ & a ser minimizado & SALBP-1 & SALBP-E \\
\hline \hline
\end{tabular}

Tabela 2.4: Versões do SALBP (Scholl e Becker, 2006) 
Excluindo-se as restrições sobre a precedência das tarefas, o SALBP-F é equivalente a um problema de partição, sendo, portanto, um problema NPCompleto. Assim, as versões SALBP-1, SALBP-2 e SALBP-E, que constituem problemas de otimização que podem ser resolvidos iterativamente analisando diversas instâncias do SALBP-F, são classificados como NP-difíceis (Scholl e Becker, 2006).

Segundo Scholl (1999), as principais características do SALBP são:

1. produção em massa de um único produto, através da execução de $|N|$ tarefas;

2. tempos de execução das tarefas determinísticos e inteiros;

3. linhas com tempo de ciclo $C$ fixo (tipo paced line);

4. nenhuma restrição de designação além das restrições de precedência;

5. estações em apenas um lado da linha serial (one-sided stations);

6. estações igualmente equipadas nos quesitos estrutural e de trabalhadores;

7. o item em produção é continuamente transferido de uma estação à próxima, permanecendo em cada estação durante um intervalo de tempo fixo dado por $C$ (tempo de ciclo).

\subsubsection{Exemplo}

Considere o grafo de precedências mostrado na Figura 2.1. Seja $|K|=5$ o número de estações de trabalho disponíveis. Para obter a máxima eficiência nesta linha, deve-se minimizar o tempo de ciclo, ou seja, o tempo de execução das tarefas na estação com maior carga deve ser o menor possível. Para alcançar este objetivo, deve-se dividir as tarefas em 5 conjuntos, como mostra a Figura 2.2, obtendo tempo de ciclo $C=10$.

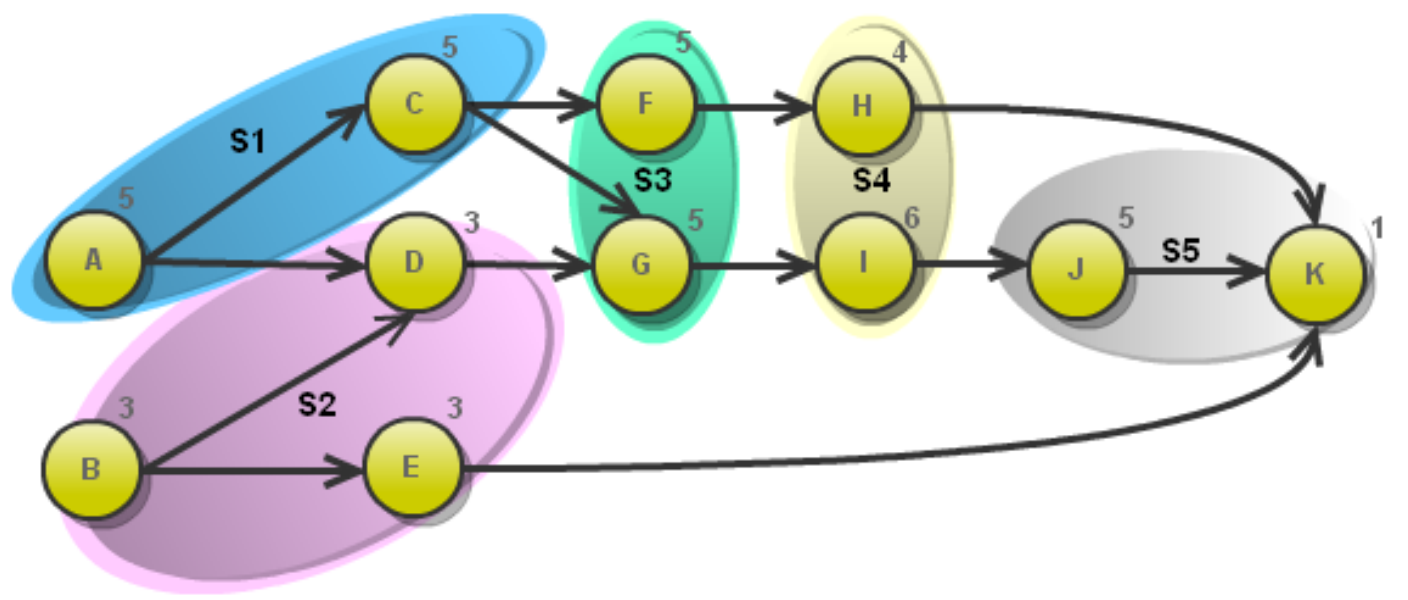

Figura 2.2: Solução do Exemplo 1 para $|K|=5$ (Scholl, 1999) 


\subsubsection{Modelo matemático}

Mostraremos apenas o modelo matemático do SALBP-2, por ser a versão do SALBP que mais interessa ao nosso estudo. Dentre as várias formulações propostas, apresentaremos uma simplificação do modelo proposto por Patterson e Albracht (1975). As variáveis de decisão são definidas da seguinte forma:

$$
x_{i k}=\left\{\begin{array}{ll}
1 & \text { se a tarefa } i \text { é alocada a estação } k \\
0 & \text { caso contrário }
\end{array}\right\} \text { para } i \in N \text { e } k \in K
$$

Min $C$

sujeito a

$$
\begin{aligned}
\sum_{k \in K} x_{i k}=1, & i \in N, \\
\sum_{i \in N} t_{i} \cdot x_{i k} \leq C, & k \in K, \\
\sum_{k \in K} k \cdot x_{i k} \leq \sum_{k \in K} k \cdot x_{j k}, & \forall(i, j) \in A, \\
x_{i k} \in\{0,1\} & \forall i \in N \text { e } \forall k \in K .
\end{aligned}
$$

O objetivo do SALBP-2 é, dado um número de estações disponíveis $|K|$, minimizar o tempo de ciclo. Equivalentemente, deseja-se maximizar a eficiência da linha. As restrições (2.4) garantem que cada tarefa é executada em uma única estação. As restrições (2.5) garantem que o tempo gasto em cada estação será, no máximo, igual ao tempo de ciclo $C$. Finalmente, as restrições (2.6) impedem que uma tarefa $j$ seja executada em uma estação anterior à alocada para uma tarefa precedente $i$, respeitando-se, assim, as relações de precedência.

\section{$2.3 \quad M A L B P$}

No Problema de Balanceamento de Linhas de Produção Multi-Modelo, diversas versões de um mesmo produto (modelos) são produzidas, mas o tempo para adequar a linha de produção entre os diferentes modelos (tempo de setup) é irrelevante. Quando esta hipótese não é válida, os diferentes modelos precisam ser operados em lotes, como exemplificado na Figura 2.3. Neste caso, chamado Multi-Model Assembly Line Balancing Problem, deve-se decidir o tamanho de cada lote, para que os custos de produção e estocagem sejam minimizados (van Zante-de Fokkert e de Kok, 1997). Sendo os custos de setup irrelevantes, podem-se produzir os diversos modelos conjuntamente, 
como mostrado na Figura 2.4, atendendo à atual necessidade da indústria em produzir sob demanda.

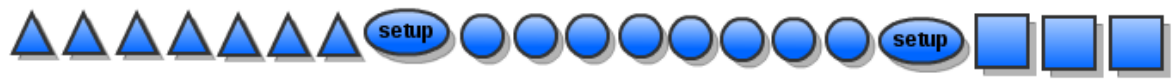

Figura 2.3: Multi-Model Assembly Line Balancing Problem (Scholl, 1999)

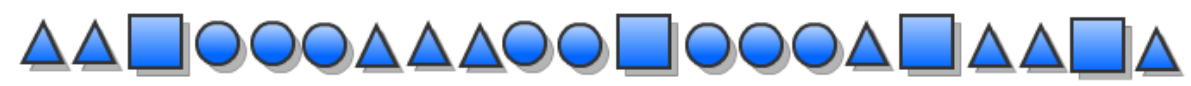

Figura 2.4: Mixed Assembly Line Balancing Problem (Scholl, 1999)

Formalmente, pode-se definir o MALBP como: dada as redes de precedência de cada modelo, em que os nós ponderados representam as tarefas a serem executadas e o peso representa o tempo de execução desta tarefa, desejase atribuir tarefas às estações de forma que a rede de precedência de cada modelo seja respeitada e alguma medida de performance seja otimizada (Erel e Gökçen, 1999).

A transformação do MALBP em uma instância do SALBP, através da unificação das redes de precedência, é a forma de resolução mais empregada na literatura para o problema de balanceamento. A construção do grafo unificado inicia-se adicionando nós com peso nulo aos grafos de precedência de cada modelo, de forma que cada grafo apresente todas as tarefas. Então, agrupam-se todas as tarefas em um único grafo, onde cada nó $j$ possui peso (tempo de processamento) dado por $\bar{t}_{j}$.

A união de todas as tarefas em um único grafo pode levar a relações de precedência transitivas e cíclicas (ver Definições 2 e 3). Portanto, de acordo com a Definição 4, um grafo assim gerado não pode ser considerado um grafo de precedência. Uma relação de precedência transitiva pode ser eliminada sem perda de informação. Já a eliminação de uma relação de precedência cíclica envolve um processo mais complicado em que é necessário a duplicação de nós.

A unificação dos grafos das Figuras 2.5(a) e 2.5(b) resulta em uma relação de precedência cíclica. Um grafo de precedência unificado válido para este exemplo, com o menor número possível de nós, é mostrado na Figura 2.6, em que a tarefa 2 é explicitada em termos de cada modelo, nos nós 2.1 e 2.2 (os pesos dos nós foram omitidos, por simplicidade).

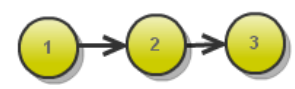

a) modelo 1

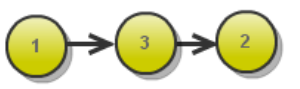

b) modelo 2

Figura 2.5: Exemplo de relação de precedência cíclica

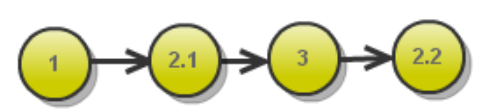

Figura 2.6: Grafo de precedência obtido após a eliminação da relação de precedência cíclica 
Boysen et al. (2009c) classificam as variantes do problema de sequenciamento MALBP, de acordo com as características das estações, da linha de produção e diferentes funções objetivos, representados pela tupla $[\alpha|\beta| \gamma]$. De acordo com essa classificação, este trabalho refere-se a um problema [cc||] cujas principais contribuições são o desenvolvimento de um modelo para um novo problema (M) e de uma heurística para a resolução de um problema de sequenciamento (HI). As considerações [cc||] são as seguintes:

características das estações $(\alpha=c c)$ : são fechadas, com comprimento dado em unidades de tempo igual a $l_{k}$. Se o trabalhador da estação $k$ não puder completar o item $i$ dentro do limite de sua estação, um outro trabalhador (de uma equipe de apoio) irá auxiliá-lo. A indicação ( $c c$ ) reflete a existência deste trabalho concorrente. O tempo de processamento pode ser considerado determinístico; o tempo e o custo de setup são despreziveis; não há paralelismo entre as estações.

características da linha ( $\beta=$ padrão): o número de estações é conhecido $(|K|)$; todas são igualmente capazes de operar qualquer tarefa. A cada intervalo de tempo fixo $(C)$ uma unidade é entregue pela linha; o tempo necessário para um trabalhador iniciar um novo produto, tão logo tenha terminado o anterior, é desprezível. As estações são arranjadas fisicamente uma após a outra. Desta forma, todas as considerações acerca das características da linha são do tipo padrão.

função objetivo ( $\gamma=$ padrão): o objetivo do problema de sequenciamento é a minimização do excesso de carga.

As considerações apresentadas na Seção 2.2 continuam válidas, com exceção das características 1 e 2. Apresentamos algumas considerações adicionais, resultantes do emprego do grafo de precedência unificado (Scholl, 1999):

1. a produção de cada modelo requer a execução de um conjunto de tarefas, relacionadas por um grafo de precedência;

2. um subconjunto de tarefas é comum a todos os modelos;

3. é possível combinar todas as tarefas em um grafo de precedência unificado, eliminando-se as relações de precedência transitivas e cíclicas;

4. as tarefas comuns a vários modelos são executadas na mesma estação, mas podem apresentar tempos de execução diferentes (tempo de execução nulo $\left(t_{j m}=0\right)$ indica que a tarefa $i$ não é necessária para a produção do modelo $m$ );

5. tempo fixo disponível para a produção de toda a demanda durante um horizonte de planejamento;

6. demanda estimada para cada modelo conhecida. 
A característica 4 é muito comum na prática. Sendo assim, se as restrições de tempo de ciclo (conjunto de restrições (2.5)) fossem impostas sobre cada estação e modelo, a eficiência da linha seria baixa. Visando melhor utilização do tempo de trabalho, a restrição de tempo de ciclo recai sobre o tempo médio de execução dos modelos em cada estação, em relação à demanda esperada. Com isso, a execução de um modelo pode ultrapassar o tempo de ciclo na estação, contanto que $\bar{t}_{k} \leq C, \forall k \in K$.

O eventual excesso de carga geralmente é solucionado com o emprego de trabalhadores de apoio. Esses trabalhadores devem deslocar-se constantemente, auxiliando os trabalhadores no processamento dos modelos nas estações onde $t_{m k}>C$. No entanto, a necessidade de intervenção externa pode ser minimizada se parte do tempo excedido por um modelo na posição $i$ da sequência, na estação $k$, puder ser compensado pelo menor tempo do modelo posterior nessa estação. Para tanto, o MALBP apresenta, além do problema de balanceamento de carga, mais um problema de otimização: o sequenciamento dos modelos.

As características adotadas para o problema de sequenciamento são (Bautista e Cano, 2008):

1. Todas as tarefas a serem realizadas estão alocadas às $|K|$ estações;

2. as partes dos produtos a serem fabricados são movidos de uma estação a outra constantemente;

3. a taxa de produção é influenciada pelo tempo de ciclo $C$ e pelo comprimento da linha $L$;

4. tempo de ciclo é conhecido e menor do que $\max \left\{t_{m k}\right\}$ (caso contrário qualquer solução de sequenciamento seria ótima);

5. as estações são fechadas em ambas as extremidades, assim o trabalhador $w_{k}$ não pode operar um item durante um tempo maior que $l_{k}$ (o que é uma limitação prática definida pelo alcance das ferramentas e materiais necessários à estação $k$ );

6. quando $t_{m k}>l_{k}$ um trabalhador de apoio deve intervir na estação $k$;

7. Considera-se que o trabalhador de apoio dobra a eficiência do trabalhador da estação, ou seja, os trabalhadores não se interferem ao produzirem, simultaneamente, o mesmo item.

A importância do sequenciamento deve-se à interdependência entre posições vizinhas da sequência. Isto porque se um trabalhador opera sobre o item $i$ da sequência durante um tempo $C+\Delta_{k i}\left(\Delta_{k i} \leq l_{k}-C\right)$, ele não poderá iniciar a produção do próximo item antes do tempo $\Delta_{k i}$ (relativamente ao início do item $i+1$ na estação $k$ ). A Figura 2.7 mostra um diagrama de movimentação de um trabalhador $w_{k}$ na estação $k=1$. Neste exemplo, considera-se $l_{1}=13$ e $C=10$. As 
linhas preenchidas diagonais representam o tempo/deslocamento do trabalhador $w_{k}$ em função da produção de cada item $i$ da sequência 1,2,1,1,1 em que o tempo de execução dos modelo $\left(t_{m k}\right)$, para $k=1$, é dado por $\left\{t_{11}, t_{21}\right\}=\{12,7\}$. Observe que o primeiro item da sequência não exige a intervenção de um trabalhador de apoio, pois $t_{11}<l_{1}$ (ponto A na figura). Como o próximo item da sequência tem baixa carga, apesar do trabalhador iniciar sua produção duas unidades de tempo atrasado (B), ele ainda consegue terminar sua produção uma unidade de tempo antes do terceiro item entrar em sua estação (C), gerando uma unidade de tempo ocioso (destacado como " $o(2)=1$ ") (D). Porém, como o início do quarto item se dá em $s_{14}=2$ (E), o término deste item necessita da ajuda de outro trabalhador durante pelo menos uma unidade de tempo (representado na figura pelo segmento de reta em negrito $\mathrm{F}$ ), pois $w_{1}$ não pode ultrapassar seu limite $l_{1}$. Para a produção do quinto e último item da sequência, é necessário que o trabalhador de apoio opere durante $l_{1}-s_{15}-t_{11}=2$ unidades de tempo nesse produto (G).

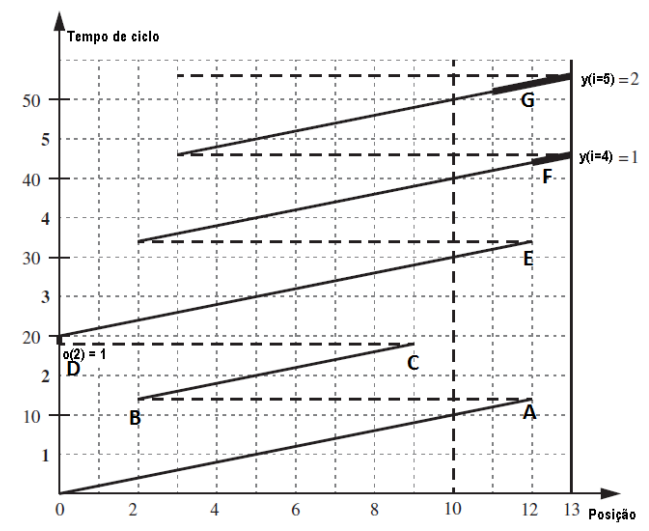

Figura 2.7: Diagrama de movimento do operador e trabalhador de apoio em uma estação (Boysen et al., 2010)

\subsubsection{Exemplo}

A Figura 2.9 exemplifica um grafo unificado gerado a partir dos grafos de precedência de três modelos, sob a demanda $d_{m}=(2,1,1)$. Considere ainda $l_{k}=$ $1,1 C, \forall k \in K$, e uma linha do tipo fechada, ritmada e com um único trabalhador por estação (closed, paced, one-sided).

Note que cada tarefa de um modelo possui tempo de execução inteiro, exatamente como no SALBP, mas o tempo de execução médio dos três modelos nem sempre é inteiro, pois é obtido através da média ponderada dos tempos de execução de cada modelo pelas suas respectivas demandas. Há modelos que não necessitam de todas as tarefas para sua produção, é o caso dos modelos 2 e 3 do exemplo. Tarefas não necessárias a produção de um dado modelo equivalem a nós com peso (tempo de processamento) nulo. Com isso, o tempo 


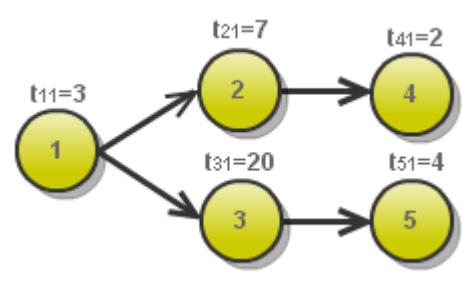

a)

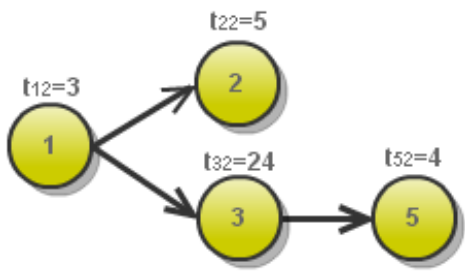

b)

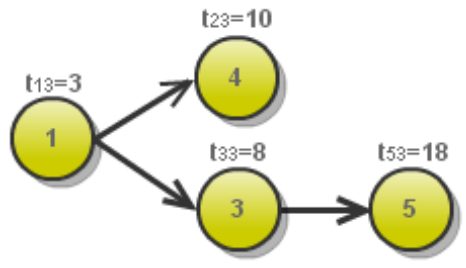

c)

Figura 2.8: Grafos de precedência para os modelos 1, 2 e 3, respectivamente

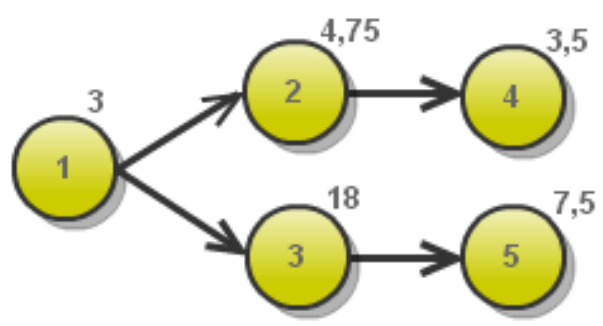

Figura 2.9: Grafo de precedência unificado

de processamento da tarefa 4, por exemplo, pode ser obtida pelo somatório: $\bar{t}_{4}=\sum_{m \in M} t_{4 m} \cdot\left(d_{m} /|I|\right)=2 \cdot 2 / 4+0 \cdot 1 / 4+10 \cdot 1 / 4=3,5$ unidades de tempo.

Uma relação de precedência transitiva, da tarefa 1 para tarefa 4 , é exemplificada nas Figuras 2.8(a) e 2.8(c). A Figura 2.9 mostra que a relação de precedência transitiva pode ser excluída sem perda de informação.

Considerando que há duas estações para produzir a demanda especificada $(|K|=2)$, o menor tempo de ciclo para o problema unificado da Figura 2.9 é obtido particionando-se as tarefas em dois sub-conjuntos: $(1,3)$ e $(2,4,5)$. Assim, o tempo de ciclo é definido pelo tempo médio de operação da estação 1 , e vale 21 unidades de tempo. Em termos de cada modelo, o tempo de ciclo não é respeitado: os modelos 1 e 2 possuem alta carga na estação 1, enquanto o modelo 3 excede em 7 unidades o tempo de ciclo na estação 2, como pode ser visto na Tabela 2.5 .

O menor excesso de carga que precisa ser compensado por trabalhadores de apoio é obtido através da sequência: 2,3,1,1, e vale 13 unidades de tempo, para $l_{k}=23, \forall k \in K$. Parte do excesso de carga do modelo 2 na estação 1 é compensado pelo modelo 3 , que por sua vez é favorecido na estação $2\left(t_{12}<C\right)$. As sequências em que os modelos 1 e 2 são vizinhos tem menor qualidade, pois ambos apresentam alta carga na estação 1. O diagrama de movimento e momentos em que o trabalhor de apoio deve atuar em cada estação são mostrados na Figura 2.10.

\subsubsection{Modelo matemático para o balanceamento MALBP}

Assim como no SALBP, podem-se empregar várias funções objetivo (f.o.), as mais comuns são: minimizar o número de estações $|M|$ (MALBP-1), minimizar o tempo de ciclo $C$ (MALBP-2), minimizar o produto do tempo de ciclo pelo 


\begin{tabular}{c|rr}
\cline { 2 - 3 }$t_{m k}$ & $k_{1}$ & $k_{2}$ \\
\hline \hline$m_{1}$ & 23 & 13 \\
$m_{2}$ & 27 & 9 \\
$m_{3}$ & 11 & 28 \\
\hline \hline
\end{tabular}

Tabela 2.5: Tempo de execução dos modelos em cada estação

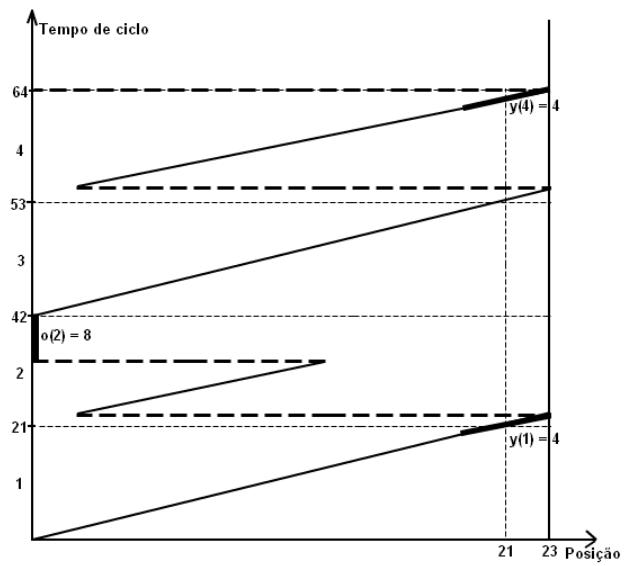

estação 1

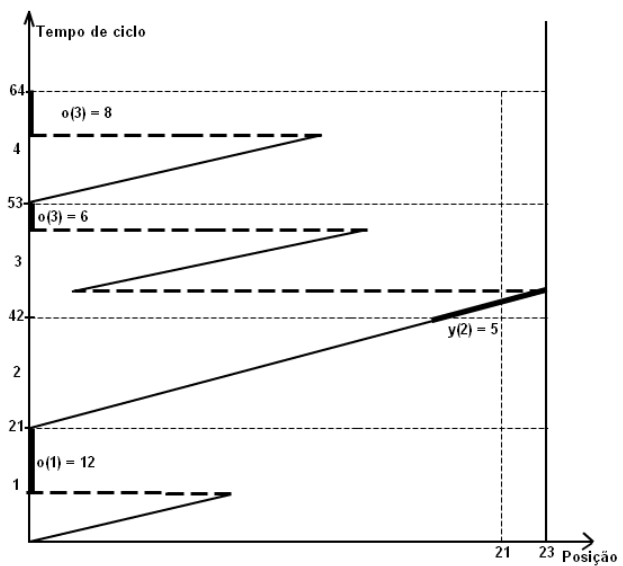

estação 2

Figura 2.10: Diagrama de movimento para o exemplo da Tabela 2.5

número de estações (MALBP-E).

O modelo matemático para o balanceamento MALBP é exatamente igual ao apresentado para o SALBP quando se utiliza o grafo de precedência unificado. Apenas a semântica dos elementos é alterada: o tempo de ciclo $C$ não representa mais o tempo de execução da estação com maior carga. No caso MALBP, o tempo de ciclo é interpretado como a taxa média de produção (Scholl, 1999). Também o tempo de execução de cada tarefa $\left(t_{j}\right)$ é agora o tempo médio ponderado entre todos os modelos $\left(\bar{t}_{j}\right)$, obtido através da demanda esperada.

O modelo de balanceamento MALBP pode ser dado por:

$\operatorname{Min} f . o$.

sujeito a:

O objetivo do MALBP-2 é, dado um número de estações disponíveis $|K|$, minimizar o tempo de ciclo. Pode haver mais de uma função objetivo, visando tornar o tempo de processamento dos modelos mais uniforme, em cada estação. As restrições 2.9 são idênticas às do SALBP-2, substituindo-se $t_{j}$ por $\bar{t}_{j}$.

Muitos trabalhos apresentam mais de um objetivo, visando antecipar características do sequenciamento durante a fase de balanceamento, pois a solução para o problema de sequenciamento depende da alocação de tarefas, 
obtida através do balanceamento (ver Seção 3.1).

\subsubsection{Modelo matemático para o sequenciamento MALBP}

Apresentaremos o modelo de sequenciamento MALBP apresentado em Scholl (1999). As variáveis binárias $x_{m i}$ são definidas como:

$$
x_{m i}=\left\{\begin{array}{ll}
1 & \text { se na posição } i \text { é produzido o modelo } m \\
0 & \text { caso contrário }
\end{array}\right\} \text { para } i \in I \text { e } m \in M
$$

A interdependência entre as posições da sequência, pode ser modelada através de variáveis reais, definidas, recursivamente, da seguinte forma:

$$
\begin{gathered}
s_{k 1}=s_{k,|I|+1}=0, k=1, \cdots,|K| \\
s_{k i}=\max \left\{0, \min \left\{s_{k, i-1}+\sum_{m \in M} \Delta_{m k} \cdot x_{m, i-1}, l_{k}-C\right\}\right\}, k=1, \cdots,|K|, i=2, \cdots,|I|
\end{gathered}
$$

em que $\Delta_{m k}=t_{m k}-C, k=1, \cdots,|K|, m=1, \cdots,|M|$. As restrições (2.11) indicam que cada trabalhador deve iniciar a produção no início de sua estação de trabalho e ter voltado a este início ao final da produção. As restrições (2.12) indicam que o trabalhador $w_{k}$ pode iniciar um novo item tão logo tenha terminado o item anterior, o que acontecerá no tempo $s_{k i}$. Mas o tempo que um trabalhador pode operar sobre um mesmo item é no máximo o "comprimento" de sua estação $\left(l_{k}\right)$, por isso, o atraso máximo é dado por $l_{k}-C$, ainda que o tempo de início mais o tempo de produção do item $i-1$ na estação $k$ seja maior que $l_{k}$.

Para simplificar a apresentação do modelo matemático, definimos o tempo de operação do $i$-ésimo item da sequência, na estação $k$, como:

$$
\rho_{k i}=\sum_{m \in M} t_{m k} \cdot x_{m i}, k=1, \cdots, K, i=1, \cdots, I
$$

Seja $y_{k i}$ o tempo empregado por um trabalhor de apoio na estação $k$ e item $i$. A modelagem do sequenciamento é dada por:

$$
\operatorname{Min} \sum_{k \in K} \sum_{i \in I} y_{k i}
$$

sujeito a 


$$
\begin{aligned}
\sum_{m \in M} x_{m i}=1, & i \in I, \\
\sum_{i \in I} x_{m i}=d_{m}, & m \in M, \\
s_{k, i+1} \geq s_{k i}+\rho_{k i}-y_{k i}-C, & k \in K, i \in I, \\
s_{k i}+\rho_{k i}-y_{k i} \leq l_{k}, & k \in K, i \in I, \\
s_{k 1}=0, s_{k, I+1}=0, & k \in K, \\
s_{k i} \geq 0, y_{k i} \geq 0, & k \in K, i \in I, \\
x_{m i} \in\{0,1\} & m \in M, i \in I .
\end{aligned}
$$

O objetivo do sequenciamento é minimizar o tempo dispendido pelos trabalhadores da equipe de apoio (minimizar o excesso de carga). As restrições (2.15) e (2.16) garantem que cada posição da sequência será ocupada por apenas um modelo e que a demanda será satisfeita, respectivamente. As restrições (2.17) garantem que um item da sequência só será iniciado depois que o item anterior tiver sido finalizado, na mesma estação. As restrições (2.18) impedem que um trabalhador exceda o limite de sua estação. Finalmente, as restrições (2.19) definem que antes do início do primeiro item, e após a produção do último item da sequência, todos os trabalhadores estarão no início de suas respectivas estações; desta forma, o último modelo deve ser produzido dentro do tempo de ciclo, ainda que a última estação tenha comprimento $l_{k}>C$. As restrições (2.17)-(2.19) incluindo o efeito da presença de trabalhadores de apoio modelam de maneira linear as definições (2.11)-(2.12).

\section{$2.4 \quad A L W A B P$}

Tanto no SALBP como no ALWABP, o desafio consiste em atribuir tarefas a cada estação de trabalho respeitando as suas relações de precedência, a fim de otimizar alguma medida de eficiência. Porém, no ALWABP, o tempo de execução de uma tarefa depende do trabalhador que a executa, podendo haver, inclusive, tarefas que alguns trabalhadores não estão aptos a executar. Surge, então, um problema de dupla alocação: alocar as tarefas e os trabalhadores às estações.

De acordo com Miralles et al. (2007), as principais características do ALWABP são:

- os tempos de processamento das tarefas e as relações de precedências entre as tarefas são determinísticos;

- o número de trabalhadores (|W|) é fixo; 
- o tempo de execução de cada tarefa varia de acordo com o trabalhador, uma vez que cada trabalhador possui habilidades e capacidades distintas;

- não há, em geral, trabalhadores mais eficientes (rápidos em todas as tarefas) que outros, mas para cada subconjunto de tarefas, há trabalhadores capazes de executá-las mais eficientemente, e outros que podem, inclusive, não serem aptos a executá-las;

- a cada estação de trabalho deve ser atribuído um único trabalhador;

- assim como no SALBP cada tarefa é atribuída somente a uma estação de trabalho, respeitando-se o grafo de precedência. Além disso, o trabalhador da estação deve ser capaz de executar a tarefa.

Adotam-se as mesmas notações para designar os objetivos mais comuns: o ALWABP-1 também se refere a otimização do número de estações de trabalho e o ALWABP-2 à minimização do tempo de ciclo. Como o ALWABP foi inspirado na otimização de Centros de Trabalhadores com Deficiências (CTD's), em geral, o interesse está no ALWABP-2, pois deseja-se o máximo de eficiência da linha, empregando-se todos os trabalhadores disponíveis.

\subsubsection{Exemplo}

O fato dos trabalhadores possuirem tempos diferentes entre si para a execução de uma tarefa consiste, sem dúvida, em um fator complicador no problema de balanceamento, pois devem-se reunir sub-conjuntos disjuntos de tarefas, de forma que se possa alocar eficientemente um trabalhador para cada sub-conjunto. Além disso, deve-se garantir que nenhum trabalhador $w$ será responsável por uma estação $k$, se $N_{k} \cap N_{w}^{\infty} \neq \varnothing$.

Considere o grafo de precedências ilustrado na Figura 2.11 para dois trabalhadores. Se todos os trabalhadores fossem idênticos, por exemplo, ao trabalhador 1 , a melhor alocação de tarefas seria: $(1,3,5)$ ou $(2,4)$. Porém, observando os tempos de execução para o segundo trabalhador, vemos que este não pode executar nenhum dos sub-conjuntos citados. Logo, esta alocação, apesar de ser ótima para o SALBP, definido apenas com os tempos de execução do trabalhador 1, é infactível para o ALWABP. Observe ainda que a alocação ótima para o ALWABP nem sempre implica em acréscimo do tempo de ciclo. Neste exemplo, é possível alocar as tarefas $(1,2,3)$ para a estação 1 e trabalhador 2 , e as tarefas $(4,5)$ para a segunda estação e primeiro trabalhador, obtendo-se o mesmo tempo de ciclo $(C=11)$ que a solução ótima para o problema SALBP em que os dois trabalhadores são idênticos ao trabalhador 1. 


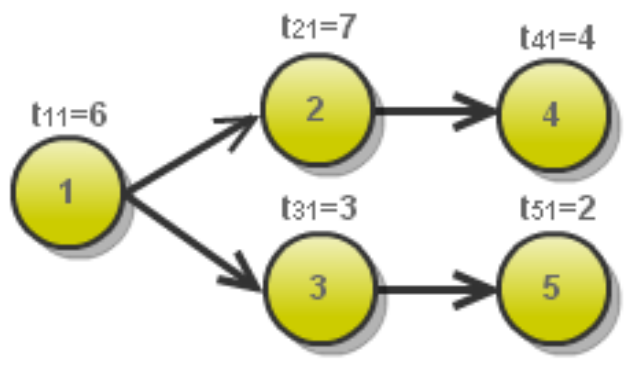

trabalhador 1

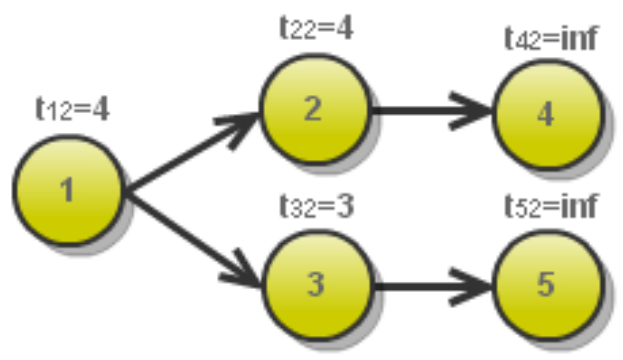

trabalhador 2

Figura 2.11: Grafo de precedência para os trabalhadores 1 e 2

\subsubsection{Modelo matemático}

A minimização de estações e, consequentemente, a minimização de trabalhadores necessários na linha de produção não é o objetivo em CTD's. O objetivo é, dado os trabalhadores disponíveis, otimizar a eficiência da linha. Por este motivo, apresentaremos aqui apenas o modelo para o ALWABP-2. Este modelo foi proposto por Miralles et al. (2007), e é apresentado na forma ligeiramente modificada descrita por Moreira e Costa (2009).

Sejam as variáveis binárias $x_{i k w}$ e $y_{k w}$ :

$$
\begin{gathered}
x_{i k w}=\left\{\begin{array}{ll}
1 & \text { se a tarefa } i \text { é alocada ao } \\
\text { trabalhador } w \text { na estação } k \\
0 & \text { caso contrário }
\end{array}\right\} \forall i \in N, \forall k \in K, \forall w \in W \\
y_{k w}=\left\{\begin{array}{ll}
1 & \text { se o trabalhador } w \text { opera a estação } k \\
0 & \text { caso contrário }
\end{array}\right\} \forall k \in K, \forall w \in W .
\end{gathered}
$$

O modelo pode ser escrito como: 


$$
\begin{aligned}
\sum_{w \in W} \sum_{k \in K} x_{i k w}=1, & \forall i \in N, \\
\sum_{k \in K} y_{k w}=1 & \forall w \in W, \\
\sum_{w \in W} y_{k w}=1 & \forall k \in K, \\
\sum_{w \in W} \sum_{k \in K} k \cdot x_{i k w} \leq \sum_{w \in W} \sum_{k \in K} k \cdot x_{j k w} & \forall j \in N, i \in D_{j}, \\
\sum_{w \in W} \sum_{i \in N} t_{i w} \cdot x_{i k w} \leq C & \forall k \in k, \\
\sum_{i \in N} x_{i k w} \leq|N| y_{k w} & \forall w \in W, \forall k \in K, \\
x_{i k w}=0 & \forall k \in K, \forall w \in W, \forall i \in N_{w}^{\infty}, \\
x_{i k w} \in\{0,1\} & \forall k \in K, \forall w \in W, \forall i \in N-N_{w}^{\infty}, \\
y_{k w} \in\{0,1\} & \forall k \in K, \forall w \in W .
\end{aligned}
$$

A formulação (2.24)-(2.33) visa alocar as tarefas às estações de forma a minimizar o maior dos tempos de operação de uma estação. As restrições (2.25) garantem que todas as tarefas serão realizadas, em exatamente uma estação, por um único trabalhador. Para evitar que tarefas sejam alocadas na mesma estação, com diferentes trabalhadores, ou a estações diferentes com o mesmo trabalhador, são necessárias as variáveis binárias $y_{k w}$. As restrições (2.26) e (2.27) asseguram que cada trabalhador trabalha em exatamente uma estação. O grafo de precedências é respeitado através das restrições (2.28). As restrições (2.29) definem que o tempo de ciclo é, no mínimo, o maior tempo necessário às estações. As restrições (2.30) garantem a coerência entre as restrições (2.25), (2.26) e (2.27), ou seja: uma tarefa só pode ser executada por um trabalhador $w$, em uma estação $k$, se esta é operada por $w$. As restrições (2.31) garantem que uma tarefa não será alocada a um trabalhador que não possa realizá-la. Finalmente, as restrições (2.32) e (2.33) definem o escopo das variáveis de decisão. 


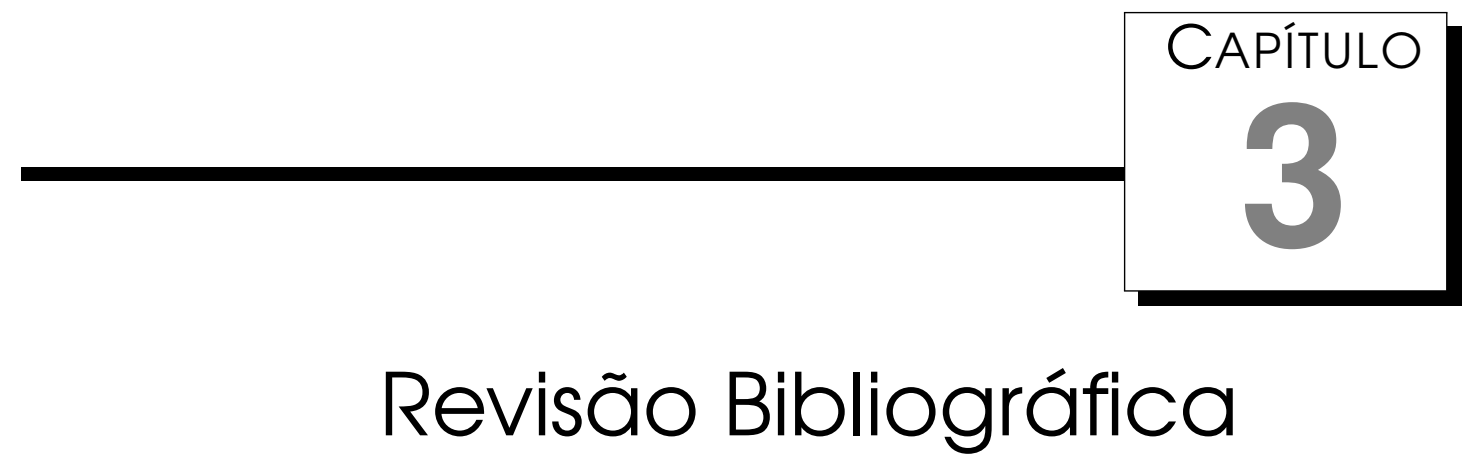

A primeira formulação matemática do problema de alocação de tarefas a estações de trabalho foi realizada por Salveson (1955). Desde então, muito esforço têm sido feito para estender o problema de balanceamento de linhas de produção e encontrar soluções exatas e heurísticas para este problema e para problemas de alocação mais complexos, que envolvem outras restrições, aproximando o modelo matemático dos problemas reais encontrados na indústria.

Neste capítulo revisaremos as publicações sobre os dois problemas mais relevantes para este trabalho, MALBP e ALWABP, nas Seções 3.1 e 3.2, respectivamente.

\section{1 Problema de Balanceamento de Linhas de Pro- dução Multi-Modelo}

A extensão do SALBP em que mais de um modelo do mesmo produto é produzido na mesma linha foi também introduzido por Salveson (1955). Esse problema vem sendo estudado desde então e, recentemente, vem ganhando destaque na literatura devido à necessidade das mais diversas indústrias de adequarem sua produção permitindo a customização em massa dos itens produzidos.

\subsubsection{Literatura sobre o balanceamento multi-modelos}

Roberts e Villa (1970) propuseram uma formulação binária para o MALBP e estenderam, para este problema, o método de resolução do SALBP baseado 
em caminhos mínimos (Gutjahr e Nemhauser, 1964). Através da formulação binária proposta, resolve-se o balanceamento multi-modelos considerando-se $|M|$ instâncias independentes do SALBP. Apesar desta modelagem conduzir a uma boa solução para a alocação das tarefas nas estações, ela permite que tarefas idênticas sejam alocadas a diferentes estações, dificultando o controle da produção e especialização dos funcionários. Além disso, na prática, o número de tarefas e modelos inviabiliza a utilização desta técnica.

Outra estratégia, utilizada em praticamente todos os trabalhos subsequentes da área foi introduzida por Thomopoulos (1970), e consiste na transformação do MALBP em uma instância do SALBP através da unificação das redes de precedência, utilizando uma estimativa da demanda de cada modelo, conforme explicado no Capítulo 2. Assim, tarefas comuns a mais de um modelo são obrigatoriamente executadas na mesma estação e, com isso, o grafo de precedências torna-se muito menor do que aquele gerado pela formulação binária apresentada anteriormente. Esta simplificação, que tira flexibilidade do balanceamento, é justificada, por exemplo, pelo fato da produção de muitas das tarefas comuns entre os modelos exigirem as mesmas matérias primas e equipamentos, sendo portanto, positivo operar tais tarefas na mesma estação.

Erel e Gökçen (1999) também estendem o algoritmo de caminhos mínimos proposto por Gutjahr e Nemhauser (1964), mas utilizando o grafo de precedências unificado. Com isso, obtêm soluções para problemas muito maiores do que aqueles resolviveis com a formulação de Roberts e Villa (1970).

Para construir o grafo unificado, deve-se fazer a média ponderada do tempo de cada tarefa pela demanda esperada. Devido a dificuldade encontrada na obtenção de uma boa estimativa, Boysen et al. (2009a) propõem o cálculo sobre o conjunto de diferentes opções que originam os modelos, ao invés de explicitar todos os diferentes modelos possíveis. A motivação deste trabalho surge da indústria automobilística, onde, segundo as opções ou acessórios escolhidos, um carro pode apresentar uma quantidade extremamente elevada de modelos, havendo apenas poucos modelos sendo vendidos repetidamente. Neste contexto, como não há uma base de dados adequada para estimar a demanda futura de cada modelo, observa-se uma superestimativa dos recursos e tempo necessários para produção. Seus resultados mostram que é possível obter, com a estratégia proposta, estimativas do tempo médio de execução das tarefas $\left(\bar{t}_{j}\right)$ muito mais próximas das reais.

A união de todas as tarefas em um único grafo geralmente leva a relações de precedência transitivas e cíclicas. Portanto, um grafo assim gerado não pode ser considerado um grafo de precedência (ver Definições 2 e 3). Como visto anteriormente, uma relação de precedência transitiva pode ser excluída do grafo unificado sem haver perda de informação, enquanto uma relação de 
precedência cíclica não tem uma resolução trivial. A técnica, discutida na Seção 2.3, de se eliminar as relações de precedência cíclicas via duplicação de nós, de forma que cada tarefa envolvida em um ciclo ocupe nós distintos no grafo unificado, foi proposta por Ahmadi e Wurgaft (1994). Esta técnica envolve um problema de otimização para minimizar o número de nós do grafo resultante.

Na prática, é comum algumas tarefas serem mais demoradas em alguns modelos específicos, por exemplo o tempo de instalação das portas de um carro depende de quantas portas o modelo possui, podendo inclusive não exigir uma determinada tarefa (a instalação de ar-condicionado, por exemplo). Desta forma, impor a restrição de tempo de ciclo sobre cada estação, independentemente do modelo, implicaria em ineficiente utilização da capacidade produtiva da linha. Este problema é trivialmente resolvido através do grafo de precedência unificado, pois a restrição de tempo de ciclo recai sobre o tempo médio de operação das estações entre os diversos modelos.

Com isso, como visto no exemplo da Seção 2.3.1, haverá estações que excederão o tempo de ciclo durante a produção de certos modelos, o que geralmente é solucionado com o emprego de trabalhadores de apoio. Para evitar ao máximo a necessidade desse auxílio, pode-se intercalar os modelos, de forma que um modelo com alta carga em uma estação $k$ seja seguido por outro modelo $m$ tal que $t_{m k}<C$. Disto surge um novo problema: o sequenciamento dos modelos.

Em uma linha de produção adequadamente balanceada, o tempo de ciclo deve ser definido de forma que os trabalhadores estejam ocupados a maior parte do tempo. Se um modelo $m$ exige um tempo menor que o tempo de ciclo para ser produzido em uma determinada estação $k$, então este modelo deve ser precedido por outro modelo $m^{\prime}$ tal que $t_{m^{\prime} k}>C$, pois assim, o trabalhador $w_{k}$ não ficará muito tempo ocioso. Portanto, a qualidade do balanceamento de uma linha de produção só pode ser determinada após definir a sequência em que os modelos serão processados. Por outro lado, o sequenciamento depende do tempo de ciclo e tempo de operação dos modelos em cada estação, conhecido após a designação das tarefas às estações. Assim, é evidente a inerente interdependência dos dois problemas. Este fato, entretanto, não justifica sua resolução simultânea, visto que existe uma grande diferença temporal entre o horizonte de planejamento de cada problema: o balanceamento visa determinar, com base nos recursos financeiros disponiveis, como investir na construção da linha de produção e, portanto, esta fase deve acontecer antes do início da produção. Neste momento não há ainda conhecimento sobre a real demanda de cada modelo, utilizando-se apenas uma estimativa desta. Já o sequenciamento é realizado em tempo de operação, quando a demanda de 
cada modelo é conhecida.

Além disso, resolver os dois problemas simultaneamente implica em otimizar um problema com um número muito grande de variáveis e restrições. Ainda assim, alguns autores trabalham com planejamento simultâneo. Dentre eles: Özcan et al. (2011); Hwang e Katayama (2010); Sawik (2009); Rao et al. (2009); Tseng et al. (2008); Zhang et al. (2008); Kara (2008); Kara et al. (2007); Kim et al. (2006); Bock et al. (2006); Miltenburg (2002).

Alternativamente, se a decisão sobre o balanceamento for realizada sem nenhuma consideração ao sequenciamento, abordagem conhecida como planejamento sucessivo, soluções muito longe do ótimo podem ser obtidas nesta segunda etapa, o que implica em alto custo com trabalhadores capazes de operar sobre qualquer ponto da linha de produção para compensar esse excesso de carga. Por isso, um grande esforço tem sido realizado na procura por funções objetivo para o problema de balanceamento que possibilitem a obtenção posterior de uma boa solução para o problema de sequenciamento, ou seja, dentre as várias soluções para o balanceamento, deseja-se obter aquela que permite um sequenciamento de boa qualidade.

A estratégia de empregar uma otimização multi-objetivo, visando antecipar características do problema de sequenciamento no problema de balanceamento é chamada planejamento antecipativo. Essa estratégia se faz necessária pela própria dependência do sequenciamento em relação ao balanceamento: este restringe o espaço de busca do sequenciamento, visto que as tarefas já estão alocadas às estações.

Merengo et al. (1999) classificam as funções objetivo em duas categorias:

Balanceamento horizontal: simplificadamente, refere-se à diferença no tempo de execução entre os modelos. Não deve haver grande diferença entre a carga de trabalho alocada a cada estação para os diferentes modelos, pois como a sequência de tarefas a ser realizada é fixa, seria possível não encontrar uma sequência de modelos que seja eficiente em todas as estações. Desta forma, a obtenção de uma solução de qualidade para o sequenciamento (com baixo excesso de carga) seria menos provável;

Balanceamento vertical: simplificadamente, refere-se à diferença no tempo de execução entre as estações. O tempo total disponível para a produção de cada item é $|K| \cdot C$, mas como nem todas as estações tem carga média igual a $C$, há um desperdício de tempo dado por $|K| \cdot C-\sum_{k \in K} \sum_{j \in N_{k}} \bar{t}_{j}$. Quanto mais este tempo livre estiver distribuído entre as estações, menor a probabilidade de uma estação não conseguir completar suas tarefas. Além disso, uma boa solução de sequenciamento é mais facilmente obtida, pois uma sequência boa para uma estação também o será para as outras estações. 
Matanachai e Yano (2001) resolvem o problema de balanceamento vertical, em um contexto de multi-modelos, com um algoritmo de Beam Search. Visich et al. (2010) utilizam Busca Tabu para balancear uma linha em formato de U (U-line) e minimizar os desvios em relação ao tempo de ciclo, comparando três objetivos diferentes de antecipação: o desvio absoluto, o desvio máximo (máxima divergência) e a soma dos desvios em relação ao tempo de ciclo. McMullen e Tarasewich (2006) e Vilarinho e Simaria (2006) utilizam algoritmos de colônia de formigas para balanceamento antecipativo em um contexto just-in-time e de paralelismo entre as estações, respectivamente. De maneira diferente, Vilarinho e Simaria (2002) e Pastor et al. (2002) empregam planejamento antecipativo lexicográfico: a melhor solução em relação ao tempo dos modelos é tomada em uma segunda fase da otimização, como um objetivo secundário. Os algoritmos propostos consistem em Simulated Annealing e Busca Tabu, respectivamente.

Emde et al. (2010) fazem um estudo sistemático de 28 funções objetivo que aplicam a estratégia de antecipação, buscando definir quais as melhores funções em comparação à qualidade do sequenciamento obtido pelo planejamento sucessivo. Essas funções foram divididas de acordo com suas similaridades quanto ao tipo de medida e desvio. Guatro medidas são consideradas: somatório dos excessos de carga, distâncias de manhattan e euclidiana, e máxima divergência. Os desvios são considerados em função de quatro argumentos:

a) tempo de processamento de cada modelo vs tempo de ciclo $\left(t_{m k}-C\right)$;

b) tempo de processamento de cada modelo vs tempo médio de processamento de cada modelo $\left(t_{m k}-\bar{t}_{m}\right)$;

c) tempo de processamento de cada modelo us tempo médio de processamento de todos os modelos $\left(t_{m k}-\bar{t}\right)$;

d) tempo médio de processamento em cada estação vs tempo médio de processamento de todos os modelos $\left(\bar{t}_{k}-\bar{t}\right)$;

As funções dos grupos (a), (b) e (c) pertencem a categoria de balanceamento horizontal, enquanto o grupo (d) apenas preocupa-se com o tempo médio em relação às estações, não considerando os desvios em relação aos modelos, referindo-se, portanto, ao balanceamento vertical.

Foi possível concluir que, independentemente da função objetivo aplicada, a antecipação sempre fornece uma solução de melhor qualidade para o sequenciamento. Não foi possível identificar um conjunto de funções que obtivesse melhor desempenho em todas as intâncias testadas, mas pode-se afirmar que o balanceamento horizontal é sempre melhor que o vertical. Além disso, as funções do grupo (a) obtiveram melhor desempenho médio utilizando a distância de manhattan ou o somatório dos excessos de carga. 
Em virtude desta diferença temporal entre a necessidade de uma solução para o balanceamento e a obtenção de uma boa estimativa de demanda, permitindo otimizar o sequenciamento dos modelos, Boysen et al. (2009b) propõem o planejamento hierárquico. O planejamento hierárquico se refere às duas decisões importantes e aos dados necessários que estão disponíveis em cada etapa do processo. Consiste em dividir as etapas de balanceamento e sequenciamento, visando obter boas soluções para cada problema e reotimizar, quando os diferentes modelos e suas respectivas demandas forem conhecidos, caso seja necessário.

\subsubsection{Literatura sobre o problema de sequenciamento}

Métodos exatos, do tipo Branch-and-Bound, foram propostos para resolver o problema de sequenciamento (Xiaobo e Ohno, 1997), mas por não serem aplicáveis a instâncias de grande porte (nos testes dos autores, estabeleceu-se o limite de oito estações e vinte modelos) devido ao grande tempo computacional necessário para resolução, muitos autores têm formulado algoritmos heurísticos.

A maioria dos trabalhos sobre o problema de sequenciamento empregam algoritmos genéticos, dentre eles: Wang (2010); Akgündüz e Tunali (2010); Shao et al. (2010); Mansouri (2005); Ponnambalam et al. (2003); Dong et al. (2002); Hyun et al. (1998); Leu et al. (1996); Kim et al. (1996). Muitos desses autores consideram funções multi-objetivo, visando, além de minimizar o excesso de carga, minimizar também o custo de setup e manter constante o uso de cada matéria prima. Outros algoritmos populacionais, como algoritmos de colônia de formigas, também são empregados no problema de sequenciamento (McMullen, 2001).

Scholl et al. (1998) utilizam geração de colunas para criar bons padrões de sequenciamento, diminuindo consideravelmente o tamanho do problema. Esses padrões são sequenciados por uma heurística construtiva, baseada em uma generalização do problema do Caixeiro Viajante em que as distâncias dependem dos tempos de execução (Gouveia e Voß, 1995). Um algoritmo de Busca Tabu é aplicado para melhorar a solução inicialmente obtida. Instâncias de grande porte (com mais de 500 tarefas) também são resolvidas via Busca Tabu por McMullen e Frazier (2000). Os resultados de McMullen (2010) sugerem que se pode obter melhores resultados com Simulated Annealing em comparação a algoritmos genéticos. Além dessas metaheurísticas, GRASP com path relinking foi empregado recentemente, mostrando-se melhor que Simulated Annealing quando o objetivo é manter constante a utilização das matérias primas (Alpay, 2009).

Boysen et al. (2010) consideram outro objetivo: minimizar a quantidade de intervenções necessárias de um trabalhador de apoio. Considera-se uma 
aproximação muito longe da realidade o fato de trabalhador de apoio e operador da estação poderem trabalhar simultaneamente no mesmo item. Assim, sempre que um item $i$ não puder ser completado em uma estação $k$, ou seja $s_{k i}+t_{m_{i} k} \geq l_{k}$, o trabalhador nem mesmo inicia sua produção, voltando ao início da linha para esperar o próximo item da sequência, deixando o trabalhador de apoio operar sobre todo o $i$-ésimo item. A contribuição deste trabalho consiste na apresentação do modelo matemático, resolução exata via Branchand-Bound, proposta de heurística construtiva baseada nas mesmas regras de prioridade utilizadas no Branch-and-Bound, e no desenvolvimento de um algoritmo de Busca Tabu para melhorar a solução inicialmente obtida pela estratégia gulosa.

\subsection{Problema de Balanceamento e Designação de Trabalhadores em Linhas de Produção}

O Problema de Balanceamento e Designação de Trabalhadores em Linhas de Produção (ALWABP) foi proposto por Miralles et al. (2007). Outros trabalhos considerando diferentes performances entre os trabalhadores já haviam sido propostos (para mais detalhes o leitor deve consultar Miralles et al. (2007, 2008)), mas no caso do ALWABP, a performance de cada trabalhador depende da tarefa: um trabalhador pode ser muito eficiente para executar uma tarefa, mas gastar muito mais tempo em outras, podendo inclusive não estar apto a executar um subconjunto das tarefas. Assim, uma característica deve ser adicionada ao caso SALBP: o tempo de execução de cada tarefa depende do trabalhador que a está executando.

Miralles et al. (2007) propõem um modelo para balancear a carga entre os trabalhadores de forma a maximizar a produção (minimizar o tempo de ciclo), para o caso ALWABP. Os autores propõem um algoritmo de Branchand-bound capaz de resolver pequenas instâncias do problema (Miralles et al., 2008). Para a resolução de instâncias maiores do ALWABP e de variantes dele, heurísticas vêm sendo estudadas na literatura.

Chaves et al. (2009) utilizam o método híbrido iterativo Clustering Search (CS), representando a solução através de dois vetores: um que determina quais estações estão associadas a cada tarefa e o outro, quais estações estão associadas a cada trabalhador. É realizada uma Busca Local Iterativa, obtendo-se soluções intermediárias, que são agrupadas de acordo com uma medida de distância estabelecida, baseada na similaridade entre os vetores que representam a solução e o centro do cluster. Os clusters que atingem um número de soluções armazenadas previamente estabelecido são explorados visando-se obter uma melhor solução através de trocas nos vetores que designam tarefas e trabalhadores, e também associando uma estação diferente 
a uma certa tarefa (move-se uma tarefa para outra estação). Estas heurísticas levam a uma boa solução dentro do cluster que está sendo explorado. Os resultados obtidos foram os melhores até então conhecidos para $98 \%$ das instâncias, comprovando a eficácia do método.

Moreira e Costa (2009) propõem um algoritmo de Busca Tabu para resolver o problema focando no desenvolvimento de um algoritmo com quatro características principais: simplicidade, flexibilidade, precisão e tempo de processamento. Comparando-se com os melhores resultados conhecidos, obtidos por Chaves et al. (2009), obteve-se redução no tempo de ciclo em torno de $20 \%$, para as grandes instâncias, e redução do tempo de processamento de, aproximadamente, $30 \%$ em todas as instâncias testadas. Em um trabalho subsequente, Moreira et al. (2012) ampliam o número de critérios usados nas heurísticas e propõem um algoritmo genético do tipo biased random-key, obtendo vários dos melhores resultados conhecidos atualmente.

Em relação a extensões do problema, Moreira et al. (2009) lidam com o caso em que apenas um trabalhador possui deficiência. A motivação parte do fato de esta ser a situação que mais se aproxima daquela encontrada nas empresas em geral. Uma formulação é desenvolvida para este novo problema, com um número muito menor de variáveis, obtendo-se soluções ótimas em menos de $0,1 \%$ do tempo necessário quando se utiliza a formulação original de Miralles et al. (2007). Este trabalho sugere que com um bom planejamento é possivel não ter perda significativa de eficiência em linhas de produção que empregam trabalhadores com deficiências.

Costa e Miralles (2009) estendem o ALWABP visando favorecer o aprendizado dos trabalhadores de CTD's através da rotação de tarefas. A ideia do trabalho é obter planos de operação distintos que favoreçam o contato dos trabalhadores com tarefas novas.

Araújo et al. (2010) propõem um modelo linear para o caso em que é possivel ter dois ou mais trabalhadores atuando em paralelo, ou seja, operando o mesmo conjunto de tarefas sobre produtos distintos simultaneamente. Este caso é particularmente interessante visto que há trabalhadores que podem apresentar desempenho muito mais lento em todas as tarefas, o que é comum quando o trabalhador está em fase de aprendizado. Como consequência do objetivo de minimizar o tempo de ciclo, estes trabalhadores operariam poucas tarefas distintas, comparativamente aos demais trabalhadores do CTD. Os testes computacionais mostram que, neste caso, é possivel reduzir o tempo de ciclo utilizando paralelismo enquanto se permite que tais trabalhadores possam operar mais tarefas. Não foi possível testar as maiores instâncias conhecidas na literatura devido a grande complexidade do problema, mas heurísticas têm sido estudadas para resolução desta extensão do ALWABP. 
CAPÍTULO

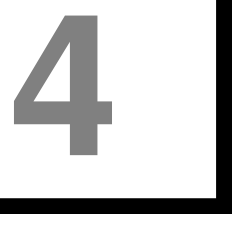

\section{Formalização do problema e modelos matemáticos}

Neste capítulo abordaremos o problema de Balanceamento de Linhas de Produção Multi-Modelo com Trabalhadores Deficientes (MALWABP, do inglês: Mixed Assembly Line and Worker Assignment Balancing Problem). Na Seção 4.1 apresentaremos um modelo matemático para a solução do problema de balanceamento. Na Seção 4.2, além de diferentes modelos matemáticos para o problema de sequenciamento e suas considerações e limitações, apresentaremos limitantes inferior e superior para a resposta do modelo.

\section{1 Problema de balanceamento MALWABP}

Assim como o MALBP foi proposto como uma extensão natural do SALBP utilizando um grafo de precedências unificado, propomos o problema de balanceamento do MALWABP como uma extensão do ALWABP. A única modificação realizada no modelo ALWABP deve-se à dependência do tempo de execução de uma tarefa $j$, por um trabalhor $w$, de acordo com o modelo $m$, ou seja, $t_{j w}$ deve ser substituído por:

$t_{j m w}$ tempo de processamento da tarefa $j$ no modelo $m$, quando executada pelo trabalhador $w$

Sendo conhecido o número de trabalhadores a serem empregados, o objetivo da otimização é produzir o maior número de itens dentro do prazo estabelecido, ou seja, deseja-se minimizar o tempo de ciclo. Apresentamos um 
modelo matemático para o MALWABP, que consiste em uma adaptação do modelo apresentado na Seção 2.4.2:

$\operatorname{Min} C$

sujeito a:

$$
\sum_{j \in N-N_{w}^{\infty}} \sum_{w \in W} \sum_{m \in M}\left(d_{m} /|I|\right) \cdot t_{j m w}^{(25)-(2.28)} \cdot x_{j k w} \leq C, \quad \forall k \in K .
$$

O modelo definido pelas equações (4.1)-(4.4) é o mesmo modelo proposto para o ALWABP-2, com exceção das restrições (2.29), que foram substituídas pelas restrições (4.3), pois, diferentemente do ALWABP e analogamente ao MALBP, o tempo de execução de um item em cada estação não precisa ser menor que o tempo de ciclo. A produção de um modelo pode exceder o tempo de ciclo no contexto de balanceamento multi-modelos, questão que será resolvida no problema posterior de sequenciamento. As restrições (4.3) definem o tempo de ciclo $C$ como a taxa de produção da linha: em média, o tempo de produção de um modelo qualquer do produto é igual a $|K| \cdot C$. Note que o número de restrições e variáveis é igual ao do modelo ALWABP. Assim, não é esperado que este problema de balanceamento apresente complexidade de resolução muito maior que a do problema ALWABP.

É possível contemplar multi-objetivos adicionando uma função de antecipação ao objetivo de minimizar o tempo de ciclo $C$, visando obter um balanceamento mais homogêneo em relação aos modelos. Iniciamos nosso trabalho focando no problema de sequenciamento, assim, a estratégia de balanceamento utilizada neste primeiro momento é a de balanceamento sucessivo.

\subsection{Problema de sequenciamento MALWABP}

Obtida uma solução para o problema de balanceamento, utilizando-se a estratégia antecipativa ou sucessiva, pode-se continuar o estudo do problema de sequenciamento MALWABP. Este segundo problema é particularmente interessante na presença de trabalhadores com deficiências, pois há muitas considerações a serem tomadas em relação à eficiência dos trabalhadores.

Por simplicidade, consideramos que os trabalhadores auxiliares, capazes de operar sobre qualquer estação da linha de produção, são trabalhadores não portadores de deficiência, pois nesse caso, a eficiência dos trabalhadores e a impraticabilidade das tarefas em relação aos auxiliares não precisam ser 
consideradas. Assim, o tempo de execução de um trabalhador de apoio é tomado como o menor tempo dentre todos os trabalhadores deficientes, ou seja, o tempo de execução de uma tarefa $j$ do modelo $m$ para qualquer trabalhador de apoio é dado por:

$$
t_{j m}^{\min }=\min _{w \in W}\left\{t_{j m w}\right\}, \forall j \in N, \forall m \in M
$$

Se o trabalhador de apoio tiver a mesma eficiência que o trabalhador da estação, o tempo por ele empregado em uma estação $k$ e item $i$ estará entre $\left[s_{k i}+t_{m_{i} k}-l_{k}, s_{k i}+t_{m_{i} k}-C\right]$. Portanto, o trabalhador de apoio atuará em um item $i$ durante, no mínimo, o tempo $t_{m k}$ que excede o tempo disponível na estação $\left(l_{k}-s_{k i}\right)$. O trabalhador de apoio pode ser empregado durante um tempo maior, no máximo $s_{k i}+t_{m_{i} k}-C$, possibilitando ao trabalhador da estação iniciar a operação do item $i+1$ em $0 \leq s_{k, i+1}<l_{k}-C$.

Porém, o trabalhador de apoio pode ser mais eficiente que o trabalhador $w_{k}$ se existir pelo menos uma tarefa $j \in N_{k} \mid t_{j m}^{m i n}<t_{j m w_{k}}$. Deste modo, o tempo empregado pelo trabalhador de apoio pode ser menor que $s_{k i}+t_{m_{i} k}-l_{k}$. Para levar em consideração esta importante diferença entre os trabalhadores, propomos dois modelos, sendo o segundo uma simplificação do primeiro.

\subsection{Modelo matemático para o sequenciamento MALWABP}

Primeiramente propomos um modelo linear mais completo, em que se considera que um trabalhador de apoio, quando solicitado, atuará simultaneamente ao operador da estação, realizando uma ou mais tarefas alocadas àquela estação. Seja a variável de decisão:

variável entre 0 e 1 . Representa a porção da tarefa $j$ do modelo

$y_{m i j} m$ que é executada pelo trabalhador de apoio, quando o modelo $m$ está na posição $i$ da sequência.

O modelo proposto é dado por:

$$
\operatorname{Min} \sum_{m \in M} \sum_{i \in I} \sum_{k \in K} \sum_{j \in N_{k}} t_{j m}^{m i n} \cdot y_{m i j}
$$

sujeito a: 


$$
\begin{aligned}
\sum_{m \in M} x_{m i}=1, & i \in I, \\
\sum_{i \in I} x_{m i}=d_{m}, & m \in M, \\
\sum_{j \in N} y_{m i j} \leq|N| x_{m i}, & \forall i \in I, \forall m \in M, \\
s_{k i}+\rho_{k i}-C-\sum_{m \in M} \sum_{j \in N_{k}} t_{j m w_{k}} \cdot y_{m i j} \leq s_{k, i+1}, & \forall i \in I, \forall k \in K, \\
s_{k i}+\rho_{k i}-\sum_{m \in M} \sum_{j \in N_{k}} t_{j m w_{k}} \cdot y_{m i j} \leq l_{k}, & \forall i \in I, \forall k \in K, \\
s_{k 1}=0, s_{k, I+1}=0, & k \in K, \\
s_{k i} \geq 0, & \forall i \in I, \forall k \in K, \\
x_{m i} \in\{0,1\} & m \in M, i \in I, \\
0 \leq y_{m i j} \leq 1 & \forall m \in M, \forall i \in I, \forall j \in N .
\end{aligned}
$$

Como no MALBP, as restrições (4.7)-(4.8) garantem que apenas um modelo será produzido em cada posição da sequência e que a demanda será atendida. As restrições (4.9) garantem que um trabalhador da equipe de apoio pode realizar parte da tarefa $j$ do modelo $m$ na sequência $i$ apenas se o modelo $m$ é o $i$-ésimo a ser produzido, podendo realizar no máximo todas as tarefas existentes. As restrições (4.10) determinam que um trabalhador não pode iniciar o próximo modelo da sequência antes de terminar o modelo atual. As restrições (4.11) determinam o tempo mínimo necessário a ser empregado por um trabalhador de apoio (medido em função do tempo do trabalhador $w_{k}$ ) para que a operação de um modelo não exceda o tamanho da estação. As restrições (4.12) definem que o trabalhador inicia e encerra seu trabalho no início da estação. As restrições (4.13) a (4.15) definem o escopo das variáveis de decisão.

O modelo definido pelas equações (4.6)-(4.15) é uma adaptação do modelo apresentado em Scholl (1999). As adaptações foram realizadas na função objetivo (4.6) e nas restrições (4.10) e (4.11). O excesso de carga na estação $k$ é medido em termos do tempo de execução das tarefas pelo trabalhador $w_{k}$, por isso o tempo retirado deste excesso é expresso em função dos tempos $t_{j m w_{k}}$, apesar do tempo real empregado pelo trabalhador de apoio ser proporcional a $t_{j m}^{m i n}$. Assim, as restrições (4.10) e (4.11) refletem a diferença de eficiência entre os trabalhadores: o tempo que um trabalhador de apoio precisará ajudar é medido em função do tempo necessário ao trabalhador da estação, mas computado na função objetivo em função do tempo real empregado pelo trabalhador de apoio. Note que podemos tornar binárias as variáveis $y_{m i j}$ na equação (4.15). Neste caso, modelamos o problema em que o trabalhador de apoio executa tarefas integralmente sempre que é solicitado. 


\subsubsection{Reformulação do modelo matemático para o sequencia- mento MALWABP}

Pode-se observar que o número de variáveis que designam os trabalhadores de apoio aos itens e estações com excesso de carga, aumentam de $|K| \cdot|I|$ (no modelo original apresentado na Seção 2.3.3) para $|M| \cdot|I| \cdot|N|$ (no modelo definido pelas equações (4.6)-(4.15)). Deste modo, este modelo, apesar de representar adequadamente o problema, não é aplicável na maioria das situações práticas, pois sua complexidade cresce rapidamente com o número de modelos e tarefas.

Por isso, propomos um novo modelo, que fornece o tempo médio necessário de operação dos trabalhadores de apoio.

\section{Modelo matemático simplificado para o sequenciamento MALWABP}

Para simplificar a apresentação do modelo matemático, definimos o parâmetro $\Delta t_{m k}$, que reflete a razão média de eficiência entre o operador da estação $k$ e um trabalhador de apoio, como:

$$
\Delta t_{m k}=t_{m k} / t_{m k}^{\min }, m=1, \cdots,|M|, k=1, \cdots|K|
$$

onde $t_{m k}^{\min }=\sum_{j \in N_{k}} t_{j m}^{\min }$. Devido a definição de $t_{j m}^{m i n}, \Delta t_{m k} \geq 1$.

A variável de decisão $y_{m i j}$ é substituída por:

variável que representa o tempo empregado por um trabalhador de

$y_{k i}$ apoio na estação $k$ durante o processamento do $i$-ésimo item da sequência.

Considerando as definições acima, o modelo proposto é dado por:

sujeito a: $\quad \operatorname{Min} \sum_{i \in I} \sum_{k \in K} y_{k i}$

$(4.7)-(4.8)$

$$
\begin{aligned}
s_{k i}+\rho_{k i}-C-\sum_{m \in M} \Delta t_{m k} \cdot y_{k i} \leq s_{k, i+1}, & \forall i \in I, \forall k \in K, \\
s_{k i}+\rho_{k i}-\sum_{m \in M} \Delta t_{m k} \cdot y_{k i} \leq l_{k}, & \forall i \in I, \forall k \in K,
\end{aligned}
$$

$(4.12)-(4.14)$

$$
y_{k i} \geq 0, \quad k \in K, i \in I .
$$


O modelo definido pelas equações (4.17)-(4.22) é um modelo mais próximo do apresentado por Scholl (1999). Assim, como no modelo MALBP, as variáveis de decisão que designam os trabalhadores de apoio representam o tempo que o trabalhador deve auxiliar em cada estação e item da sequência. As restrições (4.19) e (4.20) são diferentes das respectivas restrições do MALBP e do modelo anteriormente apresentado. Neste modelo aproximado, a razão entre a eficiência do trabalhador comum e de apoio não é considerada em cada tarefa, mas é utilizada uma razão média: $\Delta t_{m k}$, que representa o quanto, em média, o trabalhador de apoio é mais eficiente que o trabalhador $w_{k}$ nas tarefas $N_{k}$.

\section{Limitações do modelo proposto}

O modelo definido em (4.17)-(4.22) tem a mesma ordem de grandeza do modelo de sequenciamento MALBP, o que realça sua importância em relação ao modelo definido em (4.6)-(4.15).

Há uma consideração adicional relevante: em média o trabalhador de apoio é $\Delta t_{m k}$ vezes mais eficiente que o trabalhador $w_{k}$ nas tarefas $N_{k}$. Mas considere a situação em que as tarefas a serem executadas pelo trabalhador de apoio na estação $k$ são aquelas em que o trabalhador $w_{k}$ é tão eficiente quanto o trabalhador de apoio. O fator multiplicador em relação ao tempo empregado pelo trabalhador de apoio deveria ser unitário, ou seja, cada unidade de tempo empregada pelo trabalhador de apoio diminui na mesma quantidade o excesso de carga na estação $k$ e item $i$. Neste caso, este modelo estará subestimando o tempo necessário a ser empregado por trabalhadores auxiliares. O contrário também é valido, se as tarefas que o trabalhador de apoio realizar forem aquelas em que o trabalhador $w_{k}$ é menos eficiente, então o modelo fornecerá uma superestimativa do tempo de auxílio necessário.

Nenhuma destas situações desabona a importância do modelo apresentado, pois como não se tem uma medida precisa da cardinalidade do conjunto de trabalhadores de apoio, nem informações sobre o momento preciso de atuação destes na linha, a utilização de medidas médias de eficiência se justifica.

Porém, se os trabalhadores da equipe de apoio também forem deficientes, essa aproximação será mais grosseira, visto que haverá diferenças entre os trabalhadores de apoio. Não especificando quais tarefas seriam designadas a cada trabalhador de apoio, só seria possivel considerar uma eficiência média entre todos os trabalhadores de apoio e cada trabalhador $w_{k}$. Assim, este modelo não pode ser estendido para a generalização em que todos os trabalhadores possuem deficiências. 


\subsubsection{Limitantes para o sequenciamento MALWABP}

Considerando o esforço computacional necessário para a resolução exata do problema de sequenciamento, é imprescindível o desenvolvimento de métodos heurísticos para sua resolução. Nesta seção, propomos limitantes para este problema. Estes limitantes poderão ser usados, por exemplo, para se tomar conclusões sobre a qualidade dos métodos heurísticos a serem propostos.

\section{Limitante inferior para o sequenciamento MALWABP}

Um limitante inferior (LB, do inglês lower bound) simples para este problema pode ser obtido somando-se todos os excessos que não podem ser compensados, devido a $t_{m k}>l_{k}$. Assim:

$$
L B=\sum_{m \in M} \sum_{k \in K} d_{m} \cdot \max \left\{t_{m k}-l_{k}, 0\right\} / \Delta t_{m k}
$$

Para o problema definido em (4.6)-(4.15), pode-se simplesmente omitir o fator $\Delta t_{m k}$, mas um limitante mais forte, para este caso, é obtido substituindose $\Delta t_{m k}$ por $\sum_{j \in N_{k}^{*}}\left(t_{j m w_{k}} / t_{j m}^{m i n}\right)$, onde o conjunto $N_{k}^{*}$ é formado pelas tarefas em que a eficiência do trabalhador comum é maior do que nas tarefas do conjunto $\overline{N_{k}^{*}}$, como mostra a Figura 4.1(a).

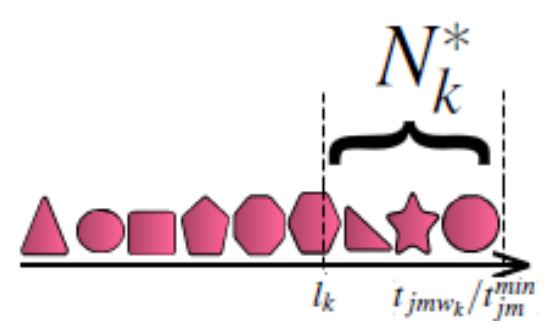

a) conjunto $N_{k}^{*}$

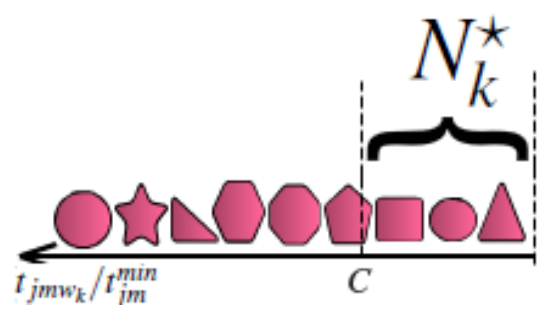

b) conjunto $N_{k}^{\star}$

Figura 4.1: Tarefas que compõem os conjuntos $N_{k}^{*}$ e $N_{k}^{\star}$

\section{Limitante superior para o sequenciamento MALWABP}

Analogamente ao LB, um limitante superior (UB, do inglês upper bound) simples para o modelo (4.17)-(4.22) pode ser obtido somando-se todos os excessos, devido a $t_{m k}>C$, ainda que estes possam ser compensados, ponderados pela eficiência média do trabalhador de apoio comparado ao trabalhador da estação $\left(\Delta t_{m k}^{-1}\right)$. Deste modo:

$$
U B=\sum_{m \in M} \sum_{k \in K} d_{m} \cdot \max \left\{t_{m k}-C, 0\right\} / \Delta t_{m k}
$$

Para o modelo apresentado em (4.6)-(4.15), pode-se substituir $\Delta t_{m k}$ por $\sum_{j \in N_{k}^{\star}}\left(t_{j m w_{k}} / t_{j m}^{\min }\right)$ tal que $N_{k}^{\star}$ contém as tarefas para as quais as relações $t_{j m k} / t_{j m}^{\min }$ 
são as menores possíveis, e em número suficiente para que o tempo de execução pelo trabalhador $w_{k}$ das tarefas restantes não ultrapasse $C$, como mostra a Figura 4.1(b). 


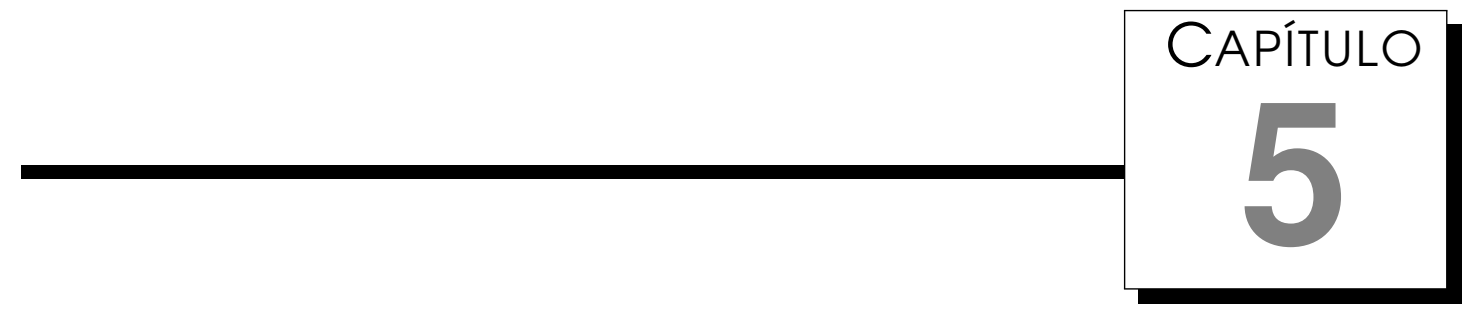

\section{Heúristicas para o sequenciamento MALWABP}

Independentemente do modelo matemático, o problema de sequenciamento dos modelos é de difícil resolução. De fato, para instâncias de médio e grande porte, métodos exatos falham na tentativa de obter soluções para o problema em tempo computacional viável. Por isso, propomos métodos heurísticos formulados para resolver este problema. Na Seção 5.1 são apresentadas quatro heurísticas construtivas, enquanto na Seção 5.2 são apresentados três métodos de busca local. Finalmente, na Seção 5.3 são apresentadas duas heurísticas híbridas que foram testadas como alternativa à busca local e também como métodos para encontrar uma solução de melhor qualidade a partir do mínimo local encontrado pela LS.

\section{1 Heurística construtiva}

A primeira heurística construtiva proposta foi baseada no trabalho de Scholl et al. (1998), em que se busca construir uma primeira solução de sequenciamento de padrões reduzindo-se o problema de sequenciamento ao Problema do Caixeiro Viajante. De fato, introduzindo-se um modelo como nó raiz tal que a distância deste nó a qualquer outro (modelo) seja nula e a distância dos modelos a este nó raiz seja superior ao maior excesso de carga existente entre quaisquer dois modelos, o problema de sequenciamento de modelos é equivalente a minimizar as distâncias de uma rota, considerando-se cada item da demanda como uma cidade a ser visitada. Assim, para agrupar modelos tal que o excesso de carga de um modelo $m_{i}$ e o tempo ocioso do modelo $m_{i+1}$ se 
complementem, busca-se, a cada passo, minimizar a "distância percorrida" associada à sequência de produção. Para isso, define-se a ordem dos itens sequencialmente, usando o seguinte critério guloso:

$$
\text { Min } g_{\text {im }}=\sum_{k \in K} \max \left\{\max \left\{t_{m_{i-1} k}-C, 0\right\}-\max \left\{C-t_{m_{i} k}, 0\right\}, 0\right\}
$$

A construção da solução inicia-se colocando na posição $i=1$ o modelo com menor soma de tempo ocioso nas estações, pois esse tempo ocioso não pode ser utilizado para compensar um item anterior que impôs atraso aos trabalhadores. As sequências posteriores são ocupadas escolhendo-se prioritariamente modelos que minimizam o critério (5.1), que visa compensar o tempo excedido pelo modelo $m_{i-1}$ através do tempo ocioso do modelo $m_{i}$. Quando mais de um modelo é candidato a ocupar a posição $i$, o critério de desempate é o menor tempo ocioso.

Seja $d_{m}^{*}$, a demanda residual do modelo $m$, isto é, a quantidade de unidades do modelo $m$ ainda não sequenciadas. O Algoritmo 1 mostra os passos de construção segundo a heurística adaptada de Scholl et al. (1998).

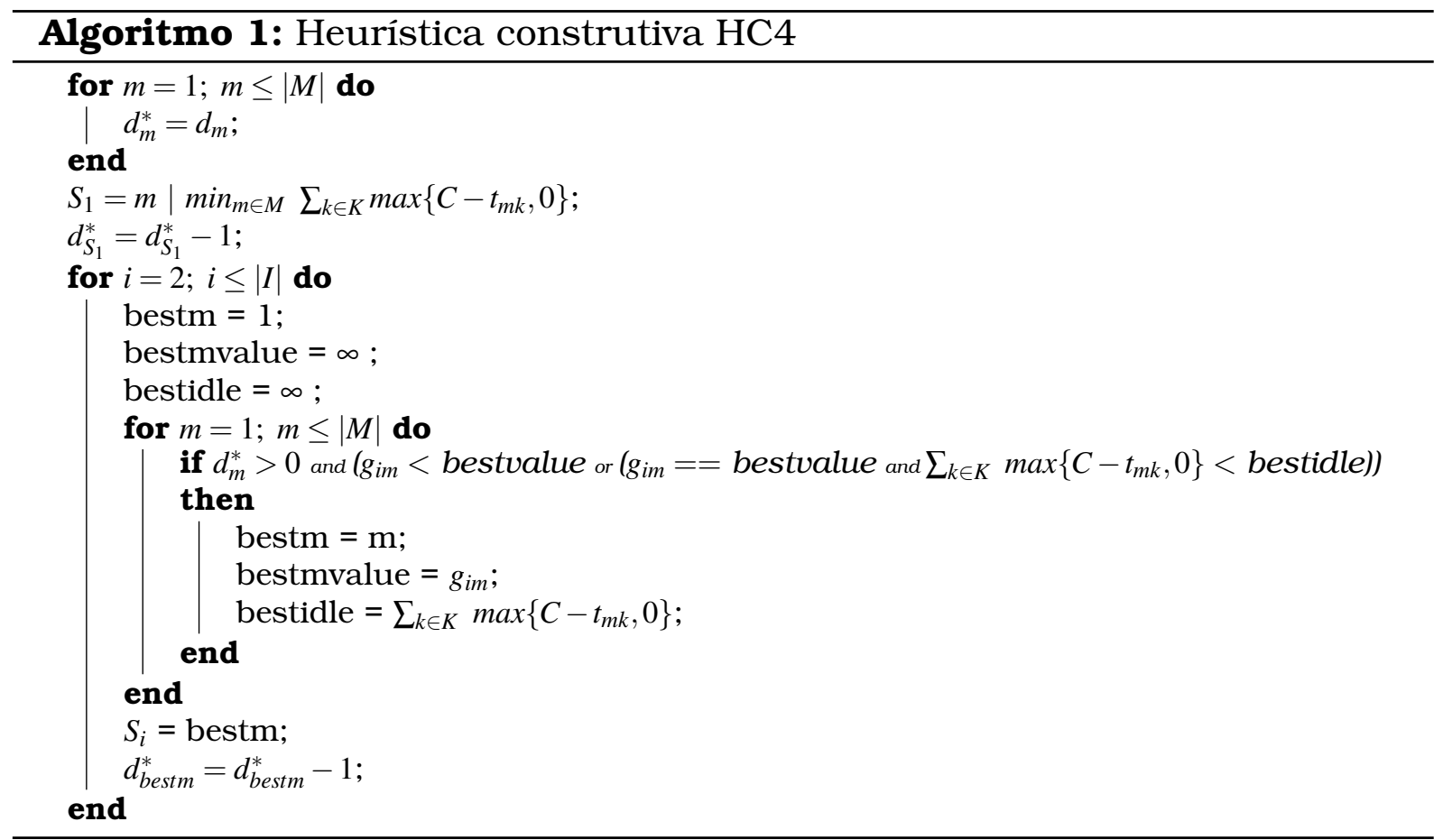

Propomos uma pequena modificação, com o intuito de tentar balancear a distribuição de modelos de forma que, durante todo o processo de construção, haja modelos com potencial tempo ocioso. Por isso, utilizamos o tempo ocioso como um critério de seleção e não de desempate, ou seja, o desperdício de tempo ocioso também é penalizado, levando a manter tais modelos para serem utilizados em posições posteriores da sequência. Além disso, operamos a construção em três "direções", iniciando a partir do modelo $m$ : 
1. com excesso de carga potencial na última posição da sequência (estratégia backward);

2. com menor tempo ocioso potencial na primeira posição da sequência (estratégia forward);

3. utilizando as duas estratégias anteriores simultaneamente.

Após testes preliminares, observamos que não fazer distinção entre o excesso de carga e tempo ocioso conduz a melhores soluções, pois há uma penalidade maior para modelos subsequentes se ambos possuem excesso de carga ou tempo ocioso. Por isso, definimos o objetivo deste método de construção como mostrado na equação (5.2), em que se penaliza qualquer desvio ao tempo de ciclo que poderia ser compensado pelo próximo modelo a ser produzido.

$$
\operatorname{Min} g_{i m}^{\prime}=\sum_{k \in K}\left|\min \left\{t_{m_{i-1} k}-C, l_{k}-C\right\}-\min \left\{C-t_{m_{i} k}, l_{k}-C\right\}\right|
$$

Para o método de construção backward, em que se inicia pela última posição, a equação é ligeiramente diferente:

$$
\operatorname{Min} g_{i m}^{\prime \prime}=\sum_{k \in K}\left|\min \left\{t_{m_{i+1} k}-C, l_{k}-C\right\}-\min \left\{C-t_{m_{i} k}, l_{k}-C\right\}\right|
$$

O Algoritmo 2 sintetiza o método de construção que utiliza as estratégias forward e backward simultaneamente.

Na Tabela 5.1 são mostradas as diferenças entre os quatro métodos propostos.

\subsubsection{Exemplo}

Exemplo 2 (Heurística HC1) Sejam os tempos de execução de cada modelo como mostrado na Tabela 5.2, $C=10, l_{k}=12, \forall k \in K$ e $d=(1,1,1)$. Mostraremos cada passo de construção de uma solução segundo a heurística HC1.

$\mathrm{O}$ modelo $m_{2}$ possui $\sum_{k \in K} \max \left\{t_{m k}-C, 0\right\}=0$. Como o excesso de carga do modelo na última posição não pode ser compensado por um item posterior, escolhe-se o modelo $m_{2}$ para ocupar essa posição. Para selecionar o modelo que deve anteceder $m_{2}$, utiliza-se a equação (5.3):

$$
\begin{aligned}
& g_{21}^{\prime \prime}=|(9-10)+(12-10)|+|(8-10)+(10-10)|, \\
& g_{23}^{\prime \prime}=|(9-10)+(9-10)|+|(8-10)+(12-10)|, \\
& \therefore \min \left\{g_{21}, g_{23}\right\}=\min \{3,2\}=2
\end{aligned}
$$

De acordo com a equação (5.3), o modelo $m_{3}$ deve anteceder o modelo $m_{2}$. Assim, a subsequência é: $(-, 3,2)$ e a demanda residual, $d^{*}=(1,0,0)$. Portanto, a sequência final é $(1,3,2)$. 


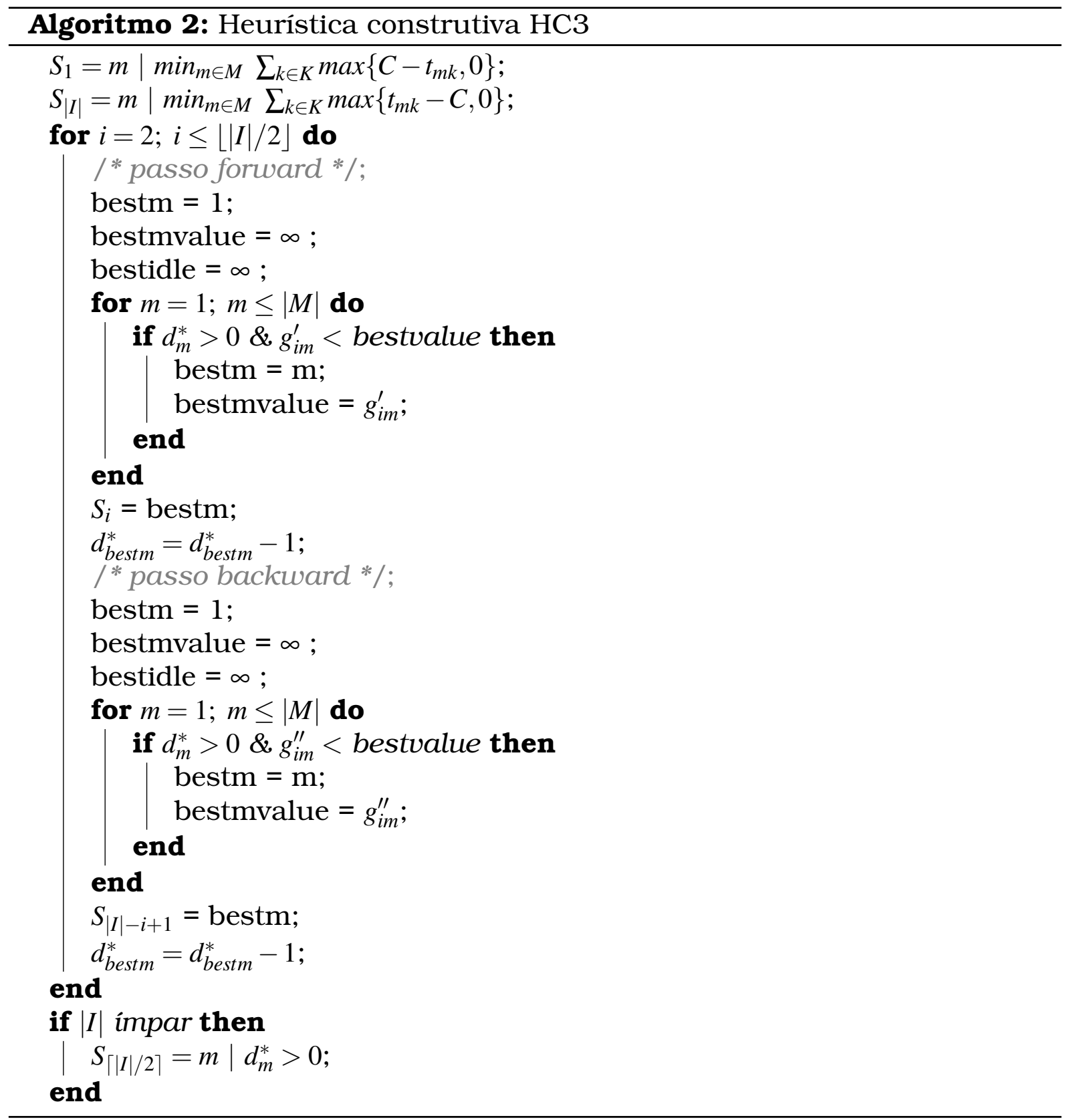

\begin{tabular}{llll} 
& & $1^{\circ}$ modelo selecionado & objetivo para selecionar \\
& posição & \multicolumn{1}{c}{ característica } & o proximo item \\
\hline \hline HC1 & $|I|$ & menor excesso de carga & $g_{i m}^{\prime \prime}$ \\
HC2 & 1 & menor tempo ocioso & $g_{i m}^{\prime}$ \\
HC3 & 1 e $|I|$ & menor tempo ocioso e exces- & $g_{i m}^{\prime}$ e $g_{i m}^{\prime \prime}$, respectivamente \\
& & so de carga, respectivamente & \\
HC4 & 1 & menor tempo ocioso & $g_{i m}$ \\
\hline \hline
\end{tabular}

Tabela 5.1: Heurísticas construtivas

Exemplo 3 (Heuristica HC4) Sejam os tempos de execução de cada modelo como mostrado na Tabela 5.2, $C=10, l_{k}=12, \forall k \in K$ e $d=(1,1,1)$. Mostraremos cada passo de construção de uma solução segundo a heurística HC4.

O modelo $m_{1}$ possui $\sum_{k \in K} \max \left\{C-t_{m k}, 0\right\}=0$. Como este tem o menor tempo ocioso, ocupará a primeira posição. Para selecionar o modelo "vizinho", utiliza- 


\begin{tabular}{c|rr}
\cline { 2 - 3 }$t_{m k}$ & $k_{1}$ & $k_{2}$ \\
\hline \hline$m_{1}$ & 12 & 10 \\
$m_{2}$ & 9 & 8 \\
$m_{3}$ & 9 & 12 \\
\hline \hline
\end{tabular}

Tabela 5.2: Tempo de execução dos modelos em cada estação

se a equação (5.1):

$g_{22}=\max \{\max \{12-10,0\}-\max \{10-9,0\}, 0\}+\max \{\max \{10-10,0\}-\max \{10-8,0\}, 0\}$, $g_{23}=\max \{\max \{12-10,0\}-\max \{10-9,0\}, 0\}+\max \{\max \{10-10,0\}-\max \{10-12,0\}, 0\}$, $\therefore \min \left\{g_{22}, g_{23}\right\}=\min \{1,1\}=1$

Como houve empate entre os dois modelos $\left(m_{2}, m_{3}\right)$, toma-se o que tem o menor tempo ocioso. Assim, a subsequência é: $(1,3)$ e a demanda residual, $d^{*}=(0,1,0)$. Portanto, a sequência final é $(1,3,2)$.

\subsection{Busca Local}

A partir de cada uma das soluções gerada pelas heurísticas construtivas, propomos sua melhoria através de um algoritmo de busca local (LS, do inglês Local Search). Este algoritmo consiste em trocar elementos distintos de posição, visando encontrar soluções melhores a partir da atual.

\subsection{Função de avaliação exata}

A partir de uma solução inicial, podemos modificar a sequência de produção, visando encontrar uma solução melhor (com menor excesso de carga). Dado que as variáveis inteiras $x_{m i}$, do modelo definido pelas equações (4.17)(4.22), foram fixadas por alguma heurística, pode-se avaliar se uma solução é melhor que a atual simplesmente resolvendo o problema linear (LP, do inglês Linear Problem) resultante.

Para facilitar a permutação dos modelos na sequência de produção, as variáveis $x_{m i}$ são representadas por um vetor de $|I|$ posições, em que cada posição $i$ armazena o $i$-ésimo modelo a ser produzido. Uma estratégia de busca seria a utilização da vizinhança all-pairs, em que todas as trocas possiveis seriam efetuadas. Entretanto, para reduzir o esforço computacional da busca, procuramos testar apenas as trocas com maior expectativa de geração de ganhos. Para isso, tomamos a posição $i^{\prime}$ da sequência para a qual $\max _{i \in I} \sum_{k \in K} y_{k i}$ procede. Além dos valores $y_{k i}$, utilizamos outra informação recebida da avaliação: o valor das variáveis $s_{k i}$. Isto permite analisar qual item (anterior ou posterior) é mais indicado a mudar de posição: 
- se $s_{k i^{\prime}}>0$ nas estações em que $t_{m_{i^{\prime}}}>C$, o modelo $m_{i^{\prime}-1}$ está forçando o atraso no início da produção do modelo $m_{i^{\prime}}$;

- senão, o modelo $m_{i^{\prime}+1}$ é um modelo que possui alta carga nas mesmas estações que $m_{i^{\prime}}$, assim, para evitar excesso de carga no modelo posterior, o trabalhador não terminou a execução do item $i^{\prime}$.

Seguindo esta idéia, definimos os custos de permanência para os itens $i^{\prime}-1$ (antecessor) e $i^{\prime}+1$ (sucessor). Deseja-se minimizar o custo de permanência de um "vizinho indesejado", portanto, o item que apresenta maior custo irá mudar de posição.

antecessor $=\sum_{k \in K} \max \left\{s_{k i^{\prime}}+t_{m_{i^{\prime}}}-l_{k}, 0\right\}$,

sucessor $=\sum_{k \in K} \max \left\{t_{m_{i^{\prime}}}-C, 0\right\}$

Se antecessor $\geq$ sucessor, significa que mesmo utilizando todo o comprimento da linha $l_{k}$, este item está começando atrasado e, por isso, não está sendo possível concluí-lo. Porém, se o maior excesso de carga está ocorrendo ainda que não consideremos a interferência do item anterior, o candidato mais indicado a trocar de posição, diminuindo a carga do item $i^{\prime}$, é o item $i^{\prime}+1$.

Considere o seguinte movimento para geração da vizinhança do algoritmo de busca local: a troca de um item $i^{\star}$ com todos os outros itens da sequência. Assim, definido o modelo da posição $i^{\star} \in\left\{i^{\prime}-1, i^{\prime}+1\right\}$ como aquele a ser trocado de posição, o melhor movimento é aquele que transforma uma solução $S$ em uma solução vizinha $(S)=S^{\prime}$ tal que $m_{i_{(S)}^{\star}}=m_{i_{\left(S^{\prime}\right)}^{\star}}, m_{i_{(S)}^{\star}}=m_{i_{\left(S^{\prime}\right)}^{\star}}, m_{i_{(S)}}=m_{i_{\left(S^{\prime}\right)}}, \forall i \in I-$ $\left\{i^{\star}, i^{\star}\right\}$ e a solução $S^{\prime}$ é de melhor qualidade que todas as outras soluções vizinhas de $S$. A Figura 5.1 ilustra um movimento realizado a partir de uma solução incumbente.

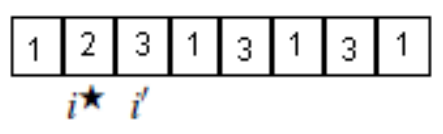

solução inicial

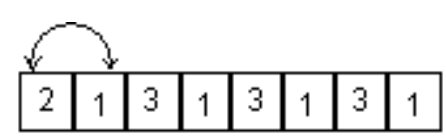

solução vizinha

Figura 5.1: Vetor solução de uma sequência: o item $i^{\star}$ deve mudar de posição

Se $f\left(S^{\prime}\right) \geq f(S)$ não é possível encontrar uma solução melhor que a atual, então o algoritmo de busca local termina retornando a solução incumbente. Outro critério de parada consiste em atingir um número máximo de iterações IT ou exceder um tempo limite de execução $t$. O Algoritmo 3 sintetiza essas informações.

A escolha da posição $i^{\prime}$ é ilustrada no Exemplo 4. Chamaremos o algoritmo descrito nessa seção, utilizando os custos de permanência para seleção da posição $i^{\star}$, de $L S^{1}$. 


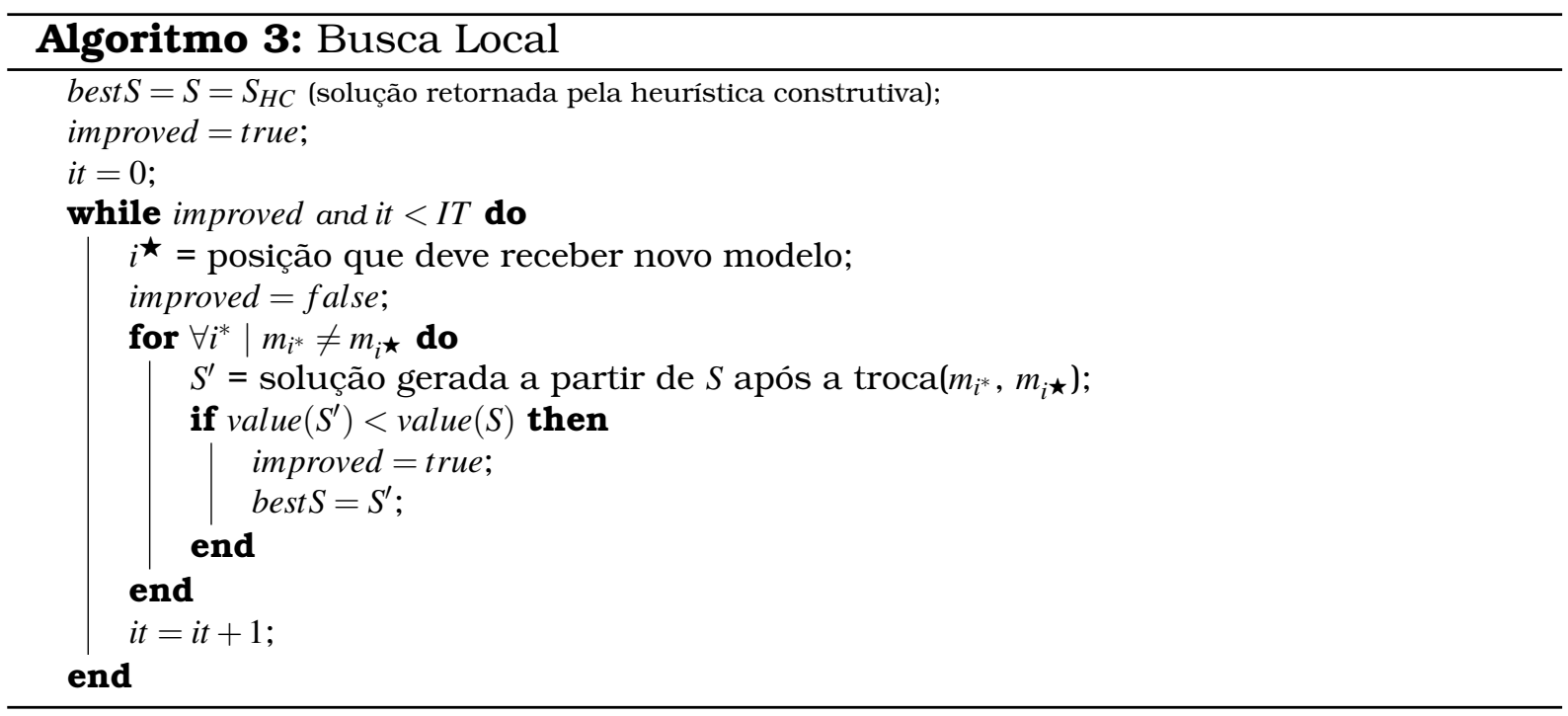

Exemplo 4 (Busca Local) Sejam os tempos de execução de cada modelo como mostrado na Tabela 2.5, $C=21, l_{k}=23, \forall k \in K$ e a solução inicial $(1,1,2,3)$.

Observe a Figura 5.2, que representa a solução fornecida pelo LP para a sequência $(1,1,2,3)$. Comparando com a solução ótima, ilustrada na Figura 2.10, esta solução apresenta maior excesso de carga não compensado na estação 2 .

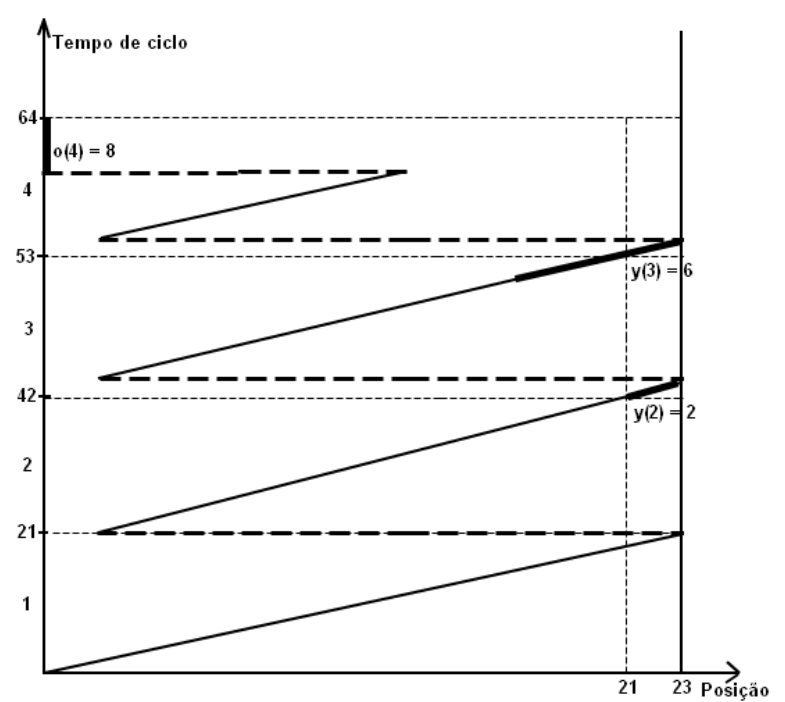

estação 1

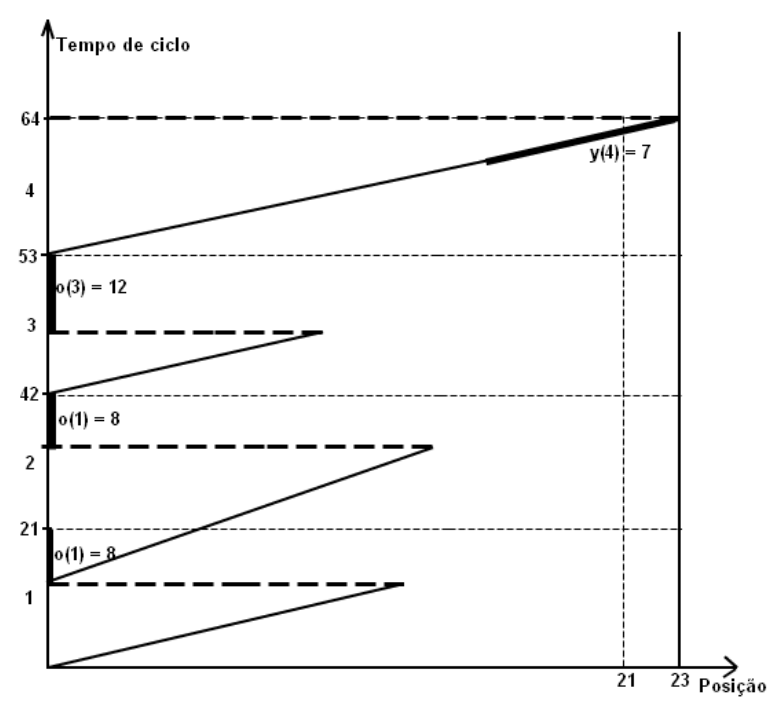

estação 2

Figura 5.2: Diagrama de movimento para o exemplo da Tabela 2.5

O modelo na posição $i^{\prime}=4$ está causando o maior excesso de carga na solução atual, pois $\max _{i \in I} \sum_{k \in K} y_{k i}=\max \{0+0,2+0,6+0,0+7\}=7$. Analisando qual item é o mais indicado a mudar de posição (anterior ou posterior), temos:

antecessor $=\sum_{k \in K} s_{k i^{\prime}}+t_{m_{i^{\prime}}}-l_{k}=\max \{2+11-23,0\}+\max \{0+28-23,0\}=5$

sucessor $=\sum_{k \in K} \max \left\{t_{m_{i^{\prime}}}-C\right\}=\max \{11-21,0\}+\max \{28-21,0\}=7$ 
O maior excesso de carga está ocorrendo ainda que não consideremos a interferência do item anterior, por isso o candidato mais indicado a trocar de posição é o item $i^{\prime}+1$. Porém tal item não existe, o que ilustra tanto a importância da heurística construtiva HC3, que visa colocar os itens mais apropriados em cada uma das extremidades da sequência, quanto a importância de considerarmos não apenas a posição com maior excesso de carga para gerar a vizinhança do algoritmo de busca local.

Investigamos o comportamento do algoritmo $L S^{1}$ com um maior espaço de busca: ao invés de selecionar apenas a posição com maior $\sum_{k \in K} y_{k i}$, seria possível tomar as $k$ posições que apresentam os maiores excessos de carga, buscando obter $k$ de forma que o maior tempo computacional dispendido seja justificado por uma melhor qualidade da solução final. Porém, o tempo computacional do algoritmo $L S^{1}$ para instâncias com mais de 100 itens já é proibitivo (uma única execução - $L S^{1}$ aplicado a apenas uma das soluções geradas pelas heurísticas construtivas - demora mais de $1 \mathrm{~h}$ ). Como instâncias menores não são de interesse prático, buscamos adaptar o método de busca visando alcançar soluções de qualidade, com boa performance.

\subsubsection{Função de avaliação aproximada}

Sabemos que selecionar o item $i^{\prime}$ não é a parte mais custosa, pois quase todo o tempo é gasto na avaliação das potenciais soluções incumbentes. A complexidade para avaliar a qualidade de cada vizinho não é linear: o número de soluções vizinhas cresce linearmente com o número de itens, mas a resolução do problema linear torna-se mais custosa quanto maior o número de itens. Portanto, obter uma estratégia de busca capaz de resolver em tempo satisfatório problemas de sequenciamento de tamanho prático, implica buscarmos uma forma de avaliar a vizinhança sem a resolução explícita do problema linear.

Como o excesso de carga não pode ser propagado indefinidamente devido ao tamanho das estações $\left(l_{k}\right)$, pode-se derivar uma medida que aproxima este valor. Ao resolver o problema de sequenciamento temos já a solução do balanceamento, por isso, o tempo de execução de cada modelo em cada estação $\left(t_{m k}\right)$ é conhecido.

Das considerações iniciais do problema, temos que nenhum trabalhador pode iniciar seu trabalho em uma posição anterior ao início da estação $\left(s_{k i} \geq\right.$ $0, \forall k \in K, \forall i \in I$ ), nem exceder o limite da estação (conjunto de restrições (4.20) do modelo definido pelas equações (4.17)-(4.22)). Com isso, consideramos o excesso de carga aproximado como o excesso de carga que seria possível compensar através do próximo item a ser produzido, ou seja: 


$$
w o_{i k}=\left\{\begin{array}{l}
0, \text { se } t_{m_{i} k}<C \\
\min \left\{t_{m_{i} k}-C, l_{k}-C\right\}, \text { se } t_{m_{i+1} k}>C \text { ou } i=|I| \\
\max \left\{\min \left\{t_{m_{i} k}-C, l_{k}-C\right\}-\min \left\{C-t_{m_{i+1} k}, l_{k}-C\right\}, 0\right\}, \text { c.c. }
\end{array}\right.
$$

Ao minimizar o excesso de carga não compensado entre modelos adjacentes estamos minimizando o excesso de carga total. Se o tempo de produção do modelo $m$ na estação $k$ for menor que o tempo de ciclo $C$, necessariamente não haverá excesso de carga, ainda que ele inicie atrasado, como define a equação (5.4) se $t_{m_{i} k}<C$. Porém, se $t_{m_{i} k}>C$ e $t_{m_{i+1} k}>C$, poderá haver um excesso de carga na produção do item $i$, na estação $k$, que poderia ser compensado se um item mais leve fosse alocado na posição $i+1$. O excesso de carga na posição $i$ e estação $k$ que é passível de ser compensado pelo próximo modelo a ser produzido, nunca será maior que $l_{k}-C$, pois o trabalhador não pode exceder o limite da estação $l_{k}$. Do mesmo modo, na equação (5.4), o tempo ocioso do item $i+1$ nunca contribui com uma parcela maior que o atraso máximo permitido ao trabalhador na produção do item $i+1$.

Analisando a equação (5.4) pode-se observar uma limitação importante: a medida aproximada considera tempo ocioso apenas o tempo de produção que é inferior ao tempo de ciclo $\left(C-t_{m_{i+1} k}\right)$. Isso exclui, por exemplo, os casos em que o modelo $i+1$ utiliza todo o tempo de ciclo, mas devido a $t_{m_{i+2} k}<C$, o item $i+1$ poderia começar atrasado, diminuindo o excesso de carga do item $i$. Descartando as variáveis que definem o início da produção de cada item $\left(s_{k i}\right)$, estamos, implicitamente, considerando que todos os itens estão sendo iniciados em $s_{k i}=0$. Desta forma, não propagamos interações entre modelos de posições não adjacentes: se itens subsequentes ao item $i+1$ têm tempo de processamento menor que o tempo de ciclo, isso não será contabilizado para diminuir o excesso de carga de um item $i$, ou seja, não permitimos que o excesso de carga de um item $i$ imponha atraso no início da execução dos itens $i+2, i+3, \cdots,|I|$.

Isto por que não estamos interessados em uma medida que melhor aproxime o valor real do excesso de carga, mas apenas obter uma medida que indique se uma solução é melhor que outra, de forma que esta medida não precise ser recalculada completamente para cada solução vizinha.

Como estamos considerando que o excesso de carga será compensado apenas pelo próximo item a ser produzido na estação, e não armazenamos o retardo de início dos itens devido ao excesso de carga de itens anteriores (variável $s_{k i}$ ), o vetor que armazena $w o_{i}=\sum_{k \in K} w o_{i k}$ apenas precisa ser atualizado nas quatro posições afetadas: ao trocar duas posições, devemos atualizar a medida que aproxima o excesso de carga dessas posições e suas antecessoras. Assim, a medida apresentada pela equação (5.4) visa indicar a qualidade 
de uma solução em comparação com as soluções vizinhas, não sendo necessário recalcular a medida para todos os itens da sequência. Os testes realizados mostram que é possível, em menos de $2 \mathrm{~s}$, melhoras consideráveis (mais de $10 \%$ ) em relação a uma solução inicialmente dada por uma das heurísticas construtivas. No restante deste trabalho, a busca local apresentada nesta seção será referenciada por $L S_{A}$ ( $L S$ aproximada).

Considerando que estamos trabalhando com uma aproximação, uma vizinhança all-pairs não fornece garantias de estar tomando sempre a melhor decisão. Portanto, gastar $|I|$ vezes mais tempo em cada iteração do método de busca não parece justificável. Assim, na implementação da $L S_{A}$, também optamos por manter a escolha do item $i^{\prime}$, que terá um novo modelo como sucessor ou predecessor na sequência de produção. A posição $i^{\prime}$ não é escolhida deterministicamente como a posição com maior excesso de carga, mas sorteada de forma que as posições com maior excesso de carga tenham maior probabilidade de seleção. Nomeamos essa seleção probabilística de "roleta", por analogia ao método da roleta muito utilizado nos algoritmos genéticos (Michalewicz, 1996).

Sempre que a $L S_{A}$ chegar em um mínimo local a partir de uma posição $i^{\prime}$, continua-se a busca sorteando (pelo método da roleta) outra posição $i^{\prime}$ com excesso de carga. Assim, para cada $i^{\prime}$ sorteada, uma busca best improvement é aplicada para escolher a melhor troca e uma busca first improvement é utilizada para escolher a posição $i^{\prime}$. Portanto, a busca local $L S_{A}$ só termina quando não há nenhuma posição $i^{\prime}$ tal que a vizinhança gerada em torno dessa posição forneça uma solução melhor que a incumbente.

A $L S_{A}$ não utiliza o recurso de escolher qual vizinho (antecessor ou sucessor) deve ser modificado, pois os valores de $s_{k i}$ não estão sendo calculados. Além disso, avaliar as soluções vizinhas através da equação (5.4) é muito fácil, desta forma, aumentamos a vizinhança da busca local com medida de avaliação aproximada para contemplar todas as trocas a partir de $i^{\prime}-1 \mathbf{e} i^{\prime}+1$.

\subsubsection{Método de busca local com mais de uma função de ava- liação}

Quando a $L S_{A}$ não é capaz de obter uma nova solução incumbente, podemos continuar a busca utilizando o valor do problema linear como função de avaliação, como descrito na Seção 5.2.1. Visando obter um melhor custo computacional, a implementação desse método de busca foi ligeiramente adaptado. A essa diferente implementação, daremos o nome de $L S$. Todos os detalhes de implementação que diferem do método descrito na Seção 5.2.1 serão descritos a seguir.

Analogamente a $L S_{A}$, não escolhemos a posição $i^{\prime}$ deterministicamente, 
sendo utilizada a mesma seleção probabilística (seleção através da "roleta"). Para uma melhor performance, ao invés de calcular o valor para todas as soluções vizinhas, geradas a partir da escolha de uma posição $i^{\prime}$, e tomar a melhor (best improvement), podemos tomar a primeira melhor solução encontrada (first improvement). Isto não se faz necessário utilizando a medida aproximada, visto a rapidez com que é possivel comparar a qualidade de todas as soluções vizinhas.

Analogamente a $L S_{A}$, a busca prossegue mesmo estando em um mínimo local em relação a vizinhança gerada a partir da troca de todos os modelos com o modelo adjacente a $i^{\prime}$. Neste caso, também pela roleta, uma outra posição $i^{\prime}$ é escolhida. A busca se encerra quando nenhuma vizinhança, considerandose todas as posições $i^{\prime}$ com excesso de carga, apresenta uma solução melhor que a incumbente, ou então, quando o limite de tempo definido pelo usuário é atingido.

Nos testes realizados, verificamos que quando a $L S$ está muito próxima de um mínimo local, há um grande esforço computacional para melhorar muito pouco a solução. Estes testes nos ajudaram a definir o limite de tempo $t$. Além de exibir os resultados para a $L S$, sempre aplicada sobre a solução retornada pela $L S_{A}$, definimos a busca $L S_{P}$ ( $L S$ parcial) como a $L S$ com tempo limite igual a $t / 2$. Os resultados computacionais, aplicando-se cada um dos métodos descritos nessa seção, serão apresentados na Seção 6.2.4.

\subsection{Vizinhança MIP}

Além da busca local proposta na Seção 5.2.2, propomos duas estratégias de melhoria utilizando busca local com vizinhança baseada em programação inteira mista (MIP). Mais detalhes sobre algoritmos híbridos podem ser encontrados em Maniezzo et al. (2010).

Em uma primeira abordagem, a que daremos o nome de mip $p_{1}$, após obter uma solução inteira $h$ por uma heurística qualquer $\left(h_{i}\right.$ indica o modelo alocado à posição $i$ na solução $h$ ), adicionamos ao modelo definido pelas equações (4.17)-(4.22), a seguinte restrição:

$$
\sum_{i \in I} x_{h_{i}} \geq|I|-M A X
$$

onde MAX é um valor inteiro no intervalo $[2,|I|]$.

A restrição (5.5) impõe que não mais de MAX posições poderão sofrer alteração (produzir um modelo diferente do inicialmente determinado pela solução h). Essa vizinhança MIP realiza um all-pairs implícito: se liberarmos duas posições, a solução ótima obtida pela mip $p_{1}$ é equivalente a melhor solução obtida por uma vizinhança 2-OPT. Esse método pode perder muito tempo apenas pro- 
vando a otimalidade, algo completamente desnecessário, visto que a solução obtida ao final da iteração não terá garantias de otimalidade. Podemos conseguir soluções melhores aplicando iterativamente esta estratégia, ou seja, após um certo limite de tempo ou após atingir um dado gap, aplicamos a heurística mip 1 sobre a solução obtida no passo anterior.

Uma outra forma de resolução do problema de sequenciamento utilizando vizinhança baseada em programação inteira mista é determinar quais posições serão liberadas (nomeamos essa estratégia mip 2 ). Resolvemos o problema inteiro liberando $10 \%$ das posições, ou seja, em $10 \%$ das posições as variáveis inteiras voltarão a ser desconhecidas. Para escolha das posições a serem liberadas, utilizamos duas estratégias: sorteamos ao acaso dois blocos contíguos; ou liberamos as 5\% posições com maior excesso de carga e as 5\% posições com maior tempo ocioso. Nomeamos essas estratégias de mip $p_{2 A}$ (mip $p_{2}$ aleatória) e mip $_{2 N A}$ (mip 2 não aleatória), respectivamente.

No próximo capítulo serão mostrados os resultados computacionais utilizando todos os métodos aqui propostos. 
CAPÍTULO

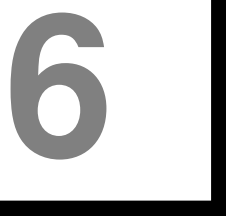

\section{Experimentos}

Neste capítulo serão discutidos os resultados experimentais obtidos a partir do modelo exato e heurísticas propostos nos capítulos anteriores. Na Seção 6.1, será descrito o processo de geração das instâncias e, na Seção 6.2, os resultados computacionais serão mostrados e discutidos.

\subsection{Geração de instâncias para o MALWABP}

Como se está abordando um problema ainda não tratado na literatura, não há disponíveis instâncias MALWABP. Os experimentos foram, então, executados sobre instâncias ALWABP modificadas: usaram-se 80 instâncias da base de dados Heskia e 80 instâncias da base de dados Roszieg, disponíveis na literatura (Chaves et al., 2007). O número de tarefas, número de trabalhadores e densidade do grafo de precedências (order strength) de cada família de instâncias é mostrada na Tabela 6.1.

\begin{tabular}{cccc}
\hline Família & $|N|$ & $|W|$ & order strength \\
\hline \hline Heskia & 28 & 4 ou 7 & 22,49 \\
Roszieg & 25 & 4 ou 6 & 71,67 \\
\hline \hline
\end{tabular}

Tabela 6.1: Características das instâncias utilizadas

Para adaptar essas instâncias precisamos fornecer os tempos de execução dos demais modelos (consideramos os tempos de execução das tarefas do primeiro modelo aqueles fornecidos pelas instâncias ALWABP). Para definir os tempos de execução dos modelos $m=2, \cdots,|M|$, multiplicamos o tempo de cada tarefa por uma constante de proporcionalidade obtida aleatoriamente como 
um inteiro no intervalo $\{0,4\}$. Essa constante de proporcionallidade pode diferir a cada tarefa e modelo, mas é comum a todos os trabalhadores. O fator multiplicativo distinto para cada par tarefa-modelo, deve-se ao fato de que uma tarefa pode demandar maior tempo de execução em um modelo do que em outros. É possível também que nem todos os modelos requeiram a execução de todas as tarefas para sua produção, o que é simulado permitindo o fator multiplicativo zero.

Utilizamos a mesma constante de proporcionalidade para todos os trabalhadores. Claro que os trabalhadores possuem aptidões muito diversas entre si, mas considera-se que os trabalhadores são igualmente capazes de operar as mesmas tarefas em qualquer dos modelos. Essa assunção se deve ao fato de que, para os diferentes modelos, uma tarefa necessita, em geral, dos mesmos recursos e equipamentos para ser realizada. Portanto, trabalhadores aptos a operar uma certa tarefa em um modelo, são igualmente aptos a operar essa tarefa em todos os outros modelos. As tarefas que cada trabalhador não está apto a executar estão definidas nas instâncias já comumente utilizadas no ALWABP.

As instâncias foram modificadas para o caso multi-modelo, considerando que há 25 modelos a serem produzidos em proporções geradas randomicamente, com demanda total de 125 itens. Os testes preliminares, aplicando apenas a busca local com função de avaliação exata $\left(L S^{1}\right)$, foram realizados em instâncias com 4 modelos a serem produzidos nas proporções de $8 \%, 20 \%$, $32 \%$ e $40 \%$, e demanda total de 25 itens. Além disso, consideramos que todos os modelos gerados a partir de uma instância possuem o mesmo grafo de precedências fornecido por esta instância ALWABP.

\subsection{Resultados computacionais}

Os modelos descritos nas Seções 4.1 e 4.2 .2 e as heurísticas descritas no Capítulo 5 foram implementados na linguagem $\mathrm{C}++$, utilizando o compilador g++ 4.4 e o pacote comercial CPLEX 12.1, no sistema operacional Ubuntu Linux 9.10. Os testes foram executados em um computador com $4 \mathrm{~GB}$ de memória RAM e processador Intel ${ }^{\circledR}$ Core $^{\mathrm{TM}} 2$ Quad de 2,66 GHz.

Apenas os resultados do problema de sequenciamento são relevantes, pois como o balanceamento foi realizado utilizando a estratégia sucessiva, nada se pode concluir sobre sua qualidade em relação à literatura citada na Seção 3.1.1.

Para o sequenciamento, consideramos que o tempo total que um item permanece em cada estação (proporcional ao tamanho e por isso designado $l_{k}$ ), é o mesmo valor para todas as estações e depende apenas do tempo de ciclo. 
Fixamos este valor em $l_{k}=1,1 C, \forall k \in K$. Foram testadas as quatro heurísticas construtivas propostas na Seção 5.1. Além do método de busca local $\left(L S^{1}\right)$ proposto na Seção 5.2.1, implementamos uma pequena variação $\left(L S^{2}\right)$ em que sempre o elemento sucessor de $i^{\prime}\left(i^{\prime}+1\right)$ é tomado como o elemento $i^{\star}$ a ser trocado de posição. Consideramos como a melhor solução heurística para cada instância, aquela obtida por uma das quatro heurísticas construtivas seguida por $L S^{1}$ e $L S^{2}$, tal que a solução apresente o menor valor para a função objetivo (minimizar a quantidade de excesso de carga não compensado).

\subsubsection{Qualidade dos limitantes}

Primeiramente, apresentamos, na Tabela 6.2, os resultados obtidos para os limitantes propostos. Na tabela apresentamos o gap médio e desvio padrão para o limitante inferior (LB) e para o limitante superior (UB). O LB proposto para o problema de sequenciamento apresenta alta variância: há instâncias em que o limitante inferior tem um gap de $69 \%$ em relação ao valor ótimo, por isso, este limitante não é apropriado para tomar conclusões sobre a qualidade das soluções heurísticas.

\begin{tabular}{lrrrr} 
& gap LB (\%) & $\sigma_{L B}(\%)$ & gap UB $(\%)$ & $\sigma_{U B}(\%)$ \\
\hline \hline Heskia & 6,97 & 5,98 & 31,39 & 7,63 \\
Roszieg & 7,52 & 7,50 & 44,96 & 12,60 \\
\hline \hline
\end{tabular}

Tabela 6.2: Qualidade dos limitantes propostos

\subsubsection{Testes iniciais: $L S^{1}$ e $L S^{2}$}

A Tabela 6.3 mostra os resultados experimentais que representam a qualidade e robustez da busca local apresentada na Seção 5.2.1. Para cada medida, é mostrado o valor retornado pela melhor solução heurística em cada instância. São mostrados o gap médio em relação ao ótimo $(\overline{g a p})$, desvio padrão do $\overline{g a p}\left(\sigma_{\overline{g a p}}\right)$, maior gap encontrado em uma instância de cada família, tempo médio total de processamento de todas as heurísticas $\left(\bar{t}_{h}\right)$, desvio padrão do $\overline{t_{h}}$ $\left(\sigma_{\overline{t_{h}}}\right)$, tempo médio de processamento da solução ótima $\left(\overline{t_{o}}\right)$ e desvio padrão do $\overline{t_{o}}\left(\sigma_{\overline{t_{o}}}\right)$.

\begin{tabular}{lrrrrrrr} 
& $\overline{g a p}(\%)$ & $\sigma_{\overline{g a p}}(\%)$ & maior gap $(\%)$ & tempo $\overline{t_{h}}(\mathrm{~s})$ & $\sigma_{\overline{t_{h}}}(\mathrm{~s})$ & tempo $\overline{t_{o}}(\mathrm{~s})$ & $\sigma_{\overline{t_{o}}}(\mathrm{~s})$ \\
\hline \hline Heskia & 0,63 & 0,65 & 3,50 & 2,50 & 1,46 & 1634 & 2180 \\
Roszieg & 1,19 & 1,18 & 6,25 & 2,69 & 1,55 & 630 & 946 \\
\hline \hline
\end{tabular}

Tabela 6.3: Qualidade das soluções e tempo computacional

Esses resultados são animadores, pois além de obtermos, com um custo computacional muito baixo, uma solução de muito boa qualidade em média, 
o desvio padrão mostra que o método é robusto, pois o gap da melhor solução heurística obtida para cada instância não varia muito acima de $1 \%$.

A Tabela 6.4 mostra em quantas instâncias, para cada família, cada heurística construtiva encontrou a melhor solução obtida pelo método heurístico após aplicação da $L S^{2}$ (o valor entre parênteses indica a quantidade em que se obteve a solução ótima). Afim de analisarmos a qualidade das heurísticas propostas, é mostrado também o gap em relação ao ótimo (e desvio padrão) de cada heurística construtiva.

Podemos observar que a heurística HC3 apresenta soluções de qualidade ligeiramente melhor, em média, o que comprova a importância de se fixar corretamente os modelos nas extremidades da sequência. Porém, a maior quantidade de soluções ótimas foram encontradas aplicando uma busca local sobre a solução inicial obtida pela $\mathrm{HC} 1$, o que mostra que esta heurística, em média, conduz a soluções mais promissoras para encontrar posteriormente um mínimo local de melhor qualidade, comportamento que deve-se às restrições que exigem a finalização do último item dentro do tempo de ciclo $\left(s_{k, I+1}=0, \forall k \in K\right)$.

\begin{tabular}{lcccc|cccc} 
& \multicolumn{4}{c}{$\mathrm{n}^{\mathbf{0}}$ melhores soluções (n } & \multicolumn{4}{c}{ gap $_{\text {HC }}\left(\sigma_{\text {gap }_{H C}}\right.$ ) (\%) } \\
& HC1 & HC2 & HC3 & HC4 & HC1 & HC2 & HC3 & HC4 \\
\hline \hline Heskia & $40(28)$ & $30(22)$ & $42(22)$ & $25(19)$ & $2,27(1,80)$ & $2,50(2,00)$ & $2,18(1,68)$ & $3,66(2,81)$ \\
Roszieg & $42(24)$ & $41(20)$ & $33(19)$ & $34(23)$ & $3,66(3,14)$ & $3,72(3,19)$ & $3,18(2,65)$ & $5,70(4,54)$ \\
\hline \hline
\end{tabular}

Tabela 6.4: Comparação entre as heurísticas construtivas

De fato, apesar da solução da $\mathrm{HC} 1$ ser já uma solução de qualidade (gap médio de $3 \%$ ), a Tabela 6.5 mostra que é possivel reduzir em até quase $20 \%$ o valor de uma solução inicial. Nas duas primeiras colunas desta tabela são mostrados o gap médio e desvio padrão, entre parênteses, após a aplicação de $L S^{1}$ e $L S^{2}$ a partir das soluções iniciais dada por cada heurística construtiva. A terceira coluna mostra a redução percentual $(\bar{R})$ do excesso de carga quando se aplica cada busca local, e a maior redução obtida $(\uparrow R$ ). A HC4 mostra uma redução percentual média superior às outras heurísticas, mas isto deve-se ao fato de que apresenta a pior qualidade de solução inicial: gap médio de 4,7\%.

Estes dados permitem concluir que a $L S^{2}$ é ligeiramente superior à $L S^{1}$. Porém em $20 \%$ das instâncias apenas a $L S^{1}$ encontrou a melhor solução heurística. Isso mostra que é possível obter uma solução de melhor qualidade se aumentarmos a vizinhança da busca local: ao invés de escolhermos um único $i^{\star}$, estender a vizinhança contendo todas as trocas de ambos os elementos $i^{\prime}+1$ e $i^{\prime}-1$ com todas as outras posições da sequência.

As heurísticas construtivas encontram o ótimo apenas quando o valor ótimo corresponde ao LB. A explicação para isso é que nesses casos os modelos apresentam conformidade entre as estações (tem alta ou baixa carga em todas as estações). Em quase todas as instâncias em que o valor ótimo é igual ao LB, 


\begin{tabular}{ccc|cc|cc}
\cline { 2 - 7 } & \multicolumn{2}{c|}{ Heskia } & \multicolumn{2}{c|}{ Roszieg } & \multicolumn{3}{c}{$\bar{R}(\uparrow R)$} \\
& $\operatorname{gap}_{L S^{1}}(\sigma)$ & $\operatorname{gap}_{L S^{2}}(\sigma)$ & $\operatorname{gap}_{L S^{1}}(\sigma)$ & $\operatorname{gap}_{L S^{2}}(\sigma)$ & $L S^{1}$ & $L S^{2}$ \\
\hline \hline HC1 & $0,69(0,68)$ & $0,63(0,65)$ & $1,33(1,26)$ & $1,19(1,18)$ & $1,82(19,35)$ & $1,92(19,35)$ \\
HC2 & $0,88(0,84)$ & $0,81(0,76)$ & $1,43(1,39)$ & $1,32(1,32)$ & $1,83(14,08)$ & $1,92(14,08)$ \\
HC3 & $0,75(0,69)$ & $0,66(0,62)$ & $1,37(1,27)$ & $1,20(1,05)$ & $1,53(11,85)$ & $1,65(11,85)$ \\
HC4 & $1,31(1,07)$ & $1,28(1,07)$ & $1,73(1,55)$ & $1,93(1,74)$ & $2,88(15,10)$ & $2,80(15,10)$ \\
\hline \hline
\end{tabular}

Tabela 6.5: Comparação entre os métodos de busca local (valores em termos percentuais $(\%))$

pelo menos uma das heurísticas construtivas fornece a solução ótima sem ser necessário aplicar uma busca local, o que demonstra o bom comportamento do algoritmo no melhor caso. Nos casos em que a solução ótima não foi encontrada pela heurística construtiva, foi obtida após a aplicação de uma busca local.

Em geral, a melhor solução heurística corresponde a solução ótima em $42,5 \%$ das instâncias, ou seja, aplicando todos os métodos heurísticos propostos, em quase metade das instâncias testadas obteve-se a solução ótima. A Tabela 6.6 mostra a quantidade de soluções ótimas encontradas por cada heurística construtiva, antes e após a aplicação de $L S^{1}$ e $L S^{2}$. Pode-se observar que a heurística $L S^{2}$ também é ligeiramente melhor no tocante a encontrar soluções ótimas.

\begin{tabular}{crrr|rrr}
\hline \hline & $\mathrm{HC} 1$ & $\mathrm{HC} 1+L S^{1}$ & $\mathrm{HC} 1+L S^{2}$ & $\mathrm{HC} 2$ & $\mathrm{HC} 2+L S^{1}$ & $\mathrm{HC} 2+L S^{2}$ \\
ótimo = LB & 12,50 & 30,00 & 32,50 & 15,00 & 25,00 & 26,25 \\
\cline { 2 - 7 } 17,5 & $\mathrm{HC} 3$ & $\mathrm{HC} 3+L S^{1}$ & $\mathrm{HC} 3+L S^{2}$ & $\mathrm{HC} 4$ & $\mathrm{HC} 4+L S^{1}$ & $\mathrm{HC} 4+L S^{2}$ \\
& 13,75 & 24,38 & 25,63 & 15,63 & 24,38 & 26,25 \\
\hline \hline
\end{tabular}

Tabela 6.6: Porcentagem de soluções ótimas (\%)

Como mostrado na Tabela 6.3, o tempo necessário para a resolução exata do problema de sequenciamento é alto, ainda que para uma pequena demanda (apenas 25 itens), mas as heurísticas propostas conseguem resolver o problema em tempo médio inferior a $3 \mathrm{~s}$, fornecendo soluções a menos de $1 \%$ do ótimo, em média. Porém os resultados não são muito animadores quando aplicados em instâncias de tamanho prático (mais de 20 modelos e 100 itens). Nos testes realizados utilizando-se os métodos $L S^{1}$ e $L S^{2}$, não foi possível obter soluções de melhor qualidade que o método exato, todos com tempo limite de $1 \mathrm{~h}$. Isso porque avaliar a qualidade de cada solução vizinha através da resolução do LP passa a ser um processo computacionalmente custoso, não permitindo uma quantidade elevada de iterações, o que é necessário para encontrar um mínimo local. 


\subsubsection{Comparação entre as heurísticas construtivas}

Nesta seção iremos comparar dentre as heurísticas construtivas, qual foi a melhor, ou seja, qual gerou a solução que mais frequentemente foi a solução com menor excesso de carga após a aplicação da busca local com vinhança baseada em MIP ( mip $\left._{1, L S_{P}, 180}\right)$, para o problema MALWABP com 25 modelos e 125 itens. A Tabela 6.7 mostra a quantidade de instâncias, para cada família, em que a solução encontrada pela heurística foi a melhor, ou uma das melhores (em caso de haver empate); e a frequência em que isso ocorre dentre as duas famílias.

\begin{tabular}{lrrrr} 
& HC1 & HC2 & HC3 & HC4 \\
\hline \hline Heskia & 18 & 28 & 19 & 14 \\
Roszieg & 19 & 28 & 30 & 9 \\
Total & $23,87 \%$ & $36,13 \%$ & $31,61 \%$ & $14,84 \%$ \\
\hline \hline
\end{tabular}

Tabela 6.7: Comparação entre as heurísticas construtivas, comparando-se as soluções após a $\operatorname{mip}_{1, L S_{P}, 180}$

De acordo com os resultados mostrados na Tabela 6.7, vemos que a solução dada pela heurística construtiva $\mathrm{HC} 2$ alcançou mais frequentemente o mínimo local. Apenas a HC4 encontrou o mínimo local com uma frequência muito menor que as outras heurísticas construtivas. Porém, em todas as instâncias em que a HC4 encontrou o mínimo local, apenas a solução inicial gerada por essa heurística construtiva obteve o menor excesso de carga após aplicada uma estratégia de melhoria. Isso evidencia a importância de se utilizar todas as quatro heurísticas construtivas a fim de alcançar bons resultados.

\subsubsection{Busca Local}

Apesar dos bons resultados aplicando-se as heurísticas $L S^{1}$ e $L S^{2}$ em pequenas instâncias, foi necessário o desenvolvimento de outras heurísticas para solucionar instâncias que se assemelham aos problemas de interesse prático. Nesta seção compararemos os resultados obtidos através dos métodos de busca local com função de avaliação aproximada e exata, discutidos nas Seções 5.2.2 e 5.2.3.

Os métodos de melhoria foram aplicados sobre as soluções retornadas por todas as heurísticas construtivas em paralelo: foram implementadas 4 threads que executam as estratégias de melhoria independentemente sobre cada uma das quatro soluções iniciais.

A busca local $L S_{A}$ é capaz de melhorar em quase $20 \%$ uma solução inicial, não demorando mais de $2 \mathrm{~s}$ para ser executada sobre uma solução gerada por qualquer das heurísticas construtivas; em média o tempo é de menos 
de 1 s para cada execução, com uma redução média do excesso de carga de $2,13 \%$. Na Tabela 6.8, os resultados referem-se à redução média do excesso de carga de um método $y$ em comparação com o método $x$ aplicado anteriormente $(y \rightarrow x)$ (tomando-se a solução da melhor heurística construtiva em cada grupo de instâncias). Como estamos realizando testes sobre 160 instâncias, para facilitar a visualização os resultados são exibidos em grupos de 10 instâncias, pois esses grupos apresentam muitas similaridades em sua geração (Chaves et al., 2007).

\begin{tabular}{lrrrrr}
\hline instâncias & $L S_{A} \rightarrow H C$ & $L S_{P} \rightarrow L S_{A}$ & $L S \rightarrow L S_{P}$ & $t_{L S_{P}}$ & $t_{L S}$ \\
\hline \hline Heskia 1-10 & 1,52 & 0,30 & 0,05 & 344 & 884 \\
Heskia 11-20 & 2,18 & 0,29 & 0,10 & 353 & 911 \\
Heskia 21-30 & 1,89 & 0,34 & 0,06 & 351 & 900 \\
Heskia 31-40 & 1,42 & 0,16 & 0,03 & 358 & 904 \\
Heskia 41-50 & 2,14 & 0,21 & 0,06 & 349 & 952 \\
Heskia 51-60 & 1,55 & 0,26 & 0,08 & 320 & 952 \\
Heskia 61-70 & 1,43 & 0,12 & 0,04 & 278 & 842 \\
Heskia 71-80 & 1,85 & 0,19 & 0,04 & 324 & 951 \\
\hline média & 1,75 & 0,23 & 0,05 & 335 & 912 \\
\hline \hline Roszieg 1-10 & 2,92 & 0,59 & 0,12 & 346 & 911 \\
Roszieg 11-20 & 2,48 & $\mathbf{1 , 5 1}$ & 0,06 & 321 & 821 \\
Roszieg 21-30 & 2,46 & 0,39 & 0,07 & 354 & 849 \\
Roszieg 31-40 & 2,95 & 0,66 & 0,12 & 366 & 911 \\
Roszieg 41-50 & 2,56 & 0,26 & 0,09 & 351 & 934 \\
Roszieg 51-60 & 1,98 & 0,29 & 0,09 & 326 & 849 \\
Roszieg 61-70 & 2,39 & 0,21 & 0,07 & 332 & 934 \\
Roszieg 71-80 & 2,41 & 0,25 & 0,09 & 341 & 934 \\
\hline média & 2,52 & 0,52 & 0,10 & 342 & 893 \\
\hline \hline média geral & 2,13 & 0,38 & 0,08 & 339 & 902 \\
\hline \hline
\end{tabular}

Tabela 6.8: Comparação entre os métodos de busca local (valores em \% e tempo em s)

Impomos um limite de tempo de $900 \mathrm{~s}$ para cada execução da $L S$. Houve instâncias em que a $L S$ encontrou um mínimo local e, portanto, o limite de tempo não foi o critério de parada aplicado. Mostramos também qual foi o tempo exato em que a $L S_{P}$ encontrou a última solução incumbente dentro do seu limite de tempo, e pode-se observar que 360 s é um tempo apropriado para a execução da $L S$.

Analisando a Tabela 6.8, vemos que é possivel ter uma diminuição média de 0,38\% do excesso de carga aplicando-se a $L S_{P}$, com tempo de execução médio inferior a 6 min. No entanto, continuando a busca após ter atingido o tempo de execução ( $t / 2)$, ou seja, utilizando a $L S$, obtem-se uma redução média do excesso de carga de apenas 0,08\%. Portanto, é mais apropriado limitar o tempo de execução em $360 \mathrm{~s}$, pois quando a $L S$ está muito próxima de um mínimo local, é necessário avaliar um número muito grande de soluções 
vizinhas para encontrar uma que seja pouco melhor que a incumbente.

\subsubsection{Vizinhança MIP}

Na Tabela 6.9 são mostrados os resultados obtidos pela busca local com vizinhança baseada em programação inteira mista mip $p_{2}$, em que liberamos 12 posições. Desta forma, resolveu-se o problema inteiro definido pelas equações (4.17)-(4.22) com $\left|I^{\prime}\right|=|I|-12$ e $M^{\prime} \in M$.

Vários testes foram realizados, tanto com blocos aleatórios ( mip $_{2, A}$ ), como escolhendo-se as posições com maior excesso de carga e maior tempo ocioso para serem liberadas $\left(\right.$ mip $\left._{2, N A}\right)$. Como cada resolução do problema inteiro exigia um tempo muito grande apenas para o CPLEX provar a otimalidade, realizamos testes com gap definido entre $\{1,4\} \%$. Realizamos testes preliminares com $\left|I^{\prime}\right|$ no intervalo $\{2,16\}$. Nenhum parâmetro conduziu a soluções significantemente melhores que a solução inicial em tempo computacional viável (como solução inicial, utilizamos as soluções retornadas pela $L S_{A}$ e $L S_{P}$ ). Pequenas melhorias são observadas apenas quando o número de posições liberadas é acima de 12 e gap definido em 0,01\%, mas o problema de sequenciamento $\operatorname{com}|M| \cdot|I|=125 \cdot 12=1500$ variáveis inteiras já exige um tempo muito alto para obter soluções com gap inferior a $0,1 \%$.

Na Tabela 6.9 é mostrado apenas a solução do método mip $_{2, A,\left|I^{\prime}\right|=12, \text { gap }=2 \% \text {, }}$ pois os resultados para outros parâmetros tampouco conduziram a melhores soluções. Vê-se que em nenhum grupo de instâncias essa estratégia híbrida conseguiu melhorar a solução inicial de forma significativa, e aplicando-se sobre a solução retornada pela $L S_{P}$, não houve qualquer melhoria. Apenas em um grupo de instâncias da família Roszieg obteve-se uma redução de 0,07\% em relação à $L S_{A}$, mas nesse mesmo grupo de instâncias, a $L S_{P}$ alcançou uma melhoria de 1,51\% (ver Tabela 6.8).

A grande dificuldade de obter sucesso com essa estratégia está no fato de, se liberarmos poucas posições, não há solução vizinha de melhor qualidade. Liberando um número significativo de posições, mais de 10\%, o tempo de execução para encontrar uma solução vizinha melhor que a incumbente é proibitivo.

Mas a estratégia de busca local com vizinhança baseada em programação inteira forneceu bons resultados utilizando-se a mip $p_{1}$, como pode-se observar analisando os resultados mostrados na Tabela 6.10. A coluna nomeada mip $_{1, L S_{A}} \rightarrow L S_{A}$ refere-se a redução do excesso de carga aplicando a mip $p_{1}$ sobre a solução retornada pela $L S_{A}$, em comparação com esta solução inicial. As colunas $L S_{P} \rightarrow L S_{A}$ e $L S \rightarrow L S_{P}$, referem-se a redução do excesso de carga obtido aplicando a $m i p_{1, L S_{P}}$ em comparação à solução retornada pela $m i p_{1, L S_{A}}$, e à comparação entre $\operatorname{mip}_{1, L S}$ e $m i p_{1, L S_{P}}$, respectivamente. Em todas as execuções, 


\begin{tabular}{lrrrrrrrr}
\hline instâncias & $m i p_{A, N A}$ & mi $_{A, A}$ & mip $_{P, N A}$ & mip $_{P, A}$ & $t_{A, N A}$ & $t_{A, A}$ & $t_{P, N A}$ & $t_{P, A}$ \\
\hline \hline Heskia 1-10 & 0,01 & 0,00 & 0,00 & 0,00 & 29 & 14 & 11 & 11 \\
Heskia 11-20 & 0,02 & 0,00 & 0,00 & 0,00 & 23 & 12 & 11 & 11 \\
Heskia 21-30 & 0,03 & 0,00 & 0,00 & 0,00 & 84 & 14 & 11 & 10 \\
Heskia 31-40 & 0,01 & 0,00 & 0,00 & 0,00 & 69 & 13 & 11 & 10 \\
Heskia 41-50 & 0,04 & 0,00 & 0,00 & 0,00 & 194 & 43 & 39 & 35 \\
Heskia 51-60 & 0,00 & 0,01 & 0,00 & 0,00 & 158 & 47 & 38 & 37 \\
Heskia 61-70 & 0,02 & 0,00 & 0,00 & 0,00 & 191 & 42 & 31 & 30 \\
Heskia 71-80 & 0,01 & 0,01 & 0,00 & 0,00 & 246 & 44 & 33 & 33 \\
\hline média & 0,02 & 0,00 & 0,00 & 0,00 & 124 & 28 & 23 & 22 \\
\hline \hline Roszieg 1-10 & 0,03 & 0,01 & 0,00 & 0,00 & 79 & 12 & 11 & 11 \\
Roszieg 11-20 & $\mathbf{0 , 0 7}$ & 0,02 & 0,00 & 0,00 & 26 & 11 & 9 & 9 \\
Roszieg 21-30 & 0,01 & 0,00 & 0,00 & 0,00 & 22 & 13 & 11 & 11 \\
Roszieg 31-40 & 0,03 & 0,01 & 0,00 & 0,00 & 84 & 13 & 10 & 10 \\
Roszieg 41-50 & 0,03 & 0,00 & 0,00 & 0,00 & 92 & 31 & 27 & 25 \\
Roszieg 51-60 & 0,03 & 0,01 & 0,00 & 0,00 & 77 & 29 & 21 & 20 \\
Roszieg 61-70 & 0,02 & 0,01 & 0,00 & 0,00 & 95 & 35 & 26 & 25 \\
Roszieg 71-80 & 0,02 & 0,01 & 0,00 & 0,00 & 163 & 32 & 25 & 24 \\
\hline média & 0,03 & 0,01 & 0,00 & 0,00 & 80 & 22 & 17 & 17 \\
\hline \hline média geral & 0,02 & 0,01 & 0,00 & 0,00 & 102 & 25 & 20 & 19 \\
\hline \hline
\end{tabular}

Tabela 6.9: Comparação entre as estratégias híbridas de busca local mip 2 (valores em \% e tempo em s)

o tempo de cada iteração da mip 1 foi limitado em $180 \mathrm{~s}$.

A mip $p_{1, L S_{A}, 180}$ forneceu resultados muito próximos aos encontrados através da $L S_{P}$, tanto em qualidade de soluções quanto no tempo de execução. Pode-se observar também que o tempo de execução da mip $p_{1}$ se mantém inalterado, independentemente da solução inicial. O maior tempo observado é exatamente o tempo necessário para obter a solução inicial (ver Tabela 6.8 em que são mostrados os tempos de execução de cada $L S$ ). A redução de quase $0,20 \%$ do excesso de carga obtido através da $\operatorname{mip}_{1, L S_{P}}$ em comparação à solução retornada pela $m i p_{1, L S_{A}}$, mostra que é positivo aplicar a mip $p_{1}$ sobre a solução retornada pela $L S_{P}$. Mas a redução de apenas 0,07\%, comparando-se mip $p_{1, L S_{P}}$ e mip $p_{1, L S}$, mostra que executar a busca local por um tempo superior a $6 \mathrm{~min}$, não fornece soluções significativamente melhores, assim como não fornece uma boa solução inicial para a mip $p_{1}$.

Os resultados da mip para diferentes limites de tempo de execução em cada iteração $(180,300$ ou 420 s) são mostrados na Tabela 6.11, com a mip aplicada sobre a solução retornada pela $L S_{P}$. A redução média percentual do excesso de carga é considerada em relação à própria solução inicial. Foram realizados testes iniciais, para avaliar a viabilidade de valores dentro do intervalo $\{3, I\}$ para o parâmetro $M A X$, definido na restrição 5.5. No entanto, apesar da solução convergir rapidamente a cada iteração quando define-se $M A X=2$, para $M A X=3$ o tempo necessário para atingir um pequeno gap é inviável. Por isso, apesar de ser interessante uma comparação acerca desse parâmetro, por limitação de tempo, não realizamos testes completos variando-se MAX. Assim, 


\begin{tabular}{lrrrrrr}
\hline instâncias & $m i p_{1, L S_{A}} \rightarrow L S_{A}$ & $t_{m i p_{1, L S_{A}}}$ & $L S_{P} \rightarrow L S_{A}$ & $t_{L S_{P}} / t_{L S_{A}}$ & $L S \rightarrow L S_{P}$ & $t_{L S} / t_{L S_{P}}$ \\
\hline \hline Heskia 1-10 & 0,21 & 276 & 0,22 & 2,40 & 0,05 & 1,92 \\
Heskia 11-20 & 0,27 & 307 & 0,18 & 2,08 & 0,09 & 2,05 \\
Heskia 21-30 & 0,21 & 327 & 0,25 & 2,25 & 0,07 & 1,90 \\
Heskia 31-40 & 0,12 & 306 & 0,10 & 2,05 & 0,04 & 1,97 \\
Heskia 41-50 & 0,19 & 338 & 0,14 & 2,26 & 0,08 & 1,95 \\
Heskia 51-60 & 0,18 & 382 & 0,20 & 1,69 & 0,07 & 2,15 \\
Heskia 61-70 & 0,09 & 344 & 0,05 & 1,66 & 0,06 & 2,10 \\
Heskia 71-80 & 0,13 & 361 & 0,15 & 1,82 & 0,03 & 2,00 \\
\hline média & 0,17 & 330 & 0,16 & 2,03 & 0,06 & 2,01 \\
\hline \hline Roszieg 1-10 & 0,54 & 366 & 0,37 & 1,92 & 0,09 & 1,96 \\
Roszieg 11-20 & 1,79 & 542 & 0,22 & 1,38 & 0,12 & 1,91 \\
Roszieg 21-30 & 0,32 & 328 & 0,20 & 2,21 & 0,10 & 1,84 \\
Roszieg 31-40 & 0,45 & 350 & 0,39 & 1,95 & 0,11 & 1,90 \\
Roszieg 41-50 & 0,21 & 360 & 0,19 & 1,98 & 0,03 & 1,85 \\
Roszieg 51-60 & 0,26 & 343 & 0,18 & 1,91 & 0,09 & 1,91 \\
Roszieg 61-70 & 0,19 & 383 & 0,13 & 1,71 & 0,07 & 2,06 \\
Roszieg 71-80 & 0,25 & 401 & 0,16 & 1,73 & 0,08 & 1,98 \\
\hline média & 0,50 & 384 & 0,23 & 1,85 & 0,09 & 1,93 \\
\hline \hline média geral & 0,34 & 357 & 0,19 & 1,94 & 0,07 & 1,97 \\
\hline \hline
\end{tabular}

Tabela 6.10: Comparação entre as estratégias híbridas de busca local mip $p_{1,180}$ para diferentes soluções iniciais (valores em \% e tempo em s)

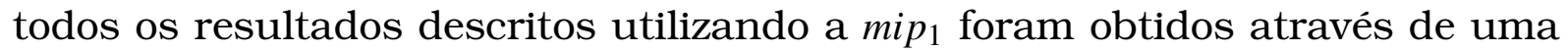
busca 2-OPT.

\begin{tabular}{lrrrrrr}
\hline instâncias & 180 & 300 & 420 & $t_{m i p_{180}}$ & $t_{m i p_{300}}$ & $t_{m i p_{420}}$ \\
\hline \hline Heskia 1-10 & 0,13 & 0,07 & 0,06 & 608 & 576 & 622 \\
Heskia 11-20 & 0,15 & 0,11 & 0,12 & 590 & 577 & 739 \\
Heskia 21-30 & 0,11 & 0,09 & 0,06 & 645 & 602 & 655 \\
Heskia 31-40 & 0,06 & 0,04 & 0,02 & 604 & 574 & 628 \\
Heskia 41-50 & 0,12 & 0,07 & 0,03 & 649 & 624 & 587 \\
Heskia 51-60 & 0,11 & 0,03 & 0,05 & 614 & 568 & 626 \\
Heskia 61-70 & 0,03 & 0,02 & 0,02 & 523 & 507 & 564 \\
Heskia 71-80 & 0,09 & 0,03 & 0,01 & 640 & 569 & 568 \\
\hline média & 0,10 & 0,06 & 0,05 & 609 & 574 & 624 \\
\hline \hline Roszieg 1-10 & 0,31 & 0,22 & 0,23 & 645 & 661 & 811 \\
Roszieg 11-20 & 0,55 & 0,59 & 0,51 & 635 & 818 & 977 \\
Roszieg 21-30 & 0,12 & 0,10 & 0,12 & 596 & 614 & 768 \\
Roszieg 31-40 & 0,18 & 0,14 & 0,13 & 641 & 637 & 714 \\
Roszieg 41-50 & 0,14 & 0,04 & 0,02 & 674 & 584 & 608 \\
Roszieg 51-60 & 0,15 & 0,08 & 0,06 & 585 & 595 & 626 \\
Roszieg 61-70 & 0,11 & 0,04 & 0,03 & 638 & 592 & 634 \\
Roszieg 71-80 & 0,12 & 0,04 & 0,02 & 658 & 596 & 637 \\
\hline média & 0,21 & 0,16 & 0,14 & 634 & 637 & 722 \\
\hline \hline média geral & 0,16 & 0,11 & 0,09 & 622 & 606 & 673 \\
\hline \hline
\end{tabular}

Tabela 6.11: Comparação entre as estratégias híbridas de busca local mip $_{1, L S_{P}}$ para diferentes limites de tempo por iteração (valores em \% e tempo em s)

Analisando os resultados mostrados na Tabela 6.11, é possível observar que, com exceção do grupo de instâncias 11-20 da família Roszieg, a mip $p_{1}$, configurada para rodar $180 \mathrm{~s}$ a cada iteração, forneceu uma solução igual ou superior à configuração de $300 \mathrm{~s}$ ou 420 s. Isso mostra que executar essa 
heurística híbrida de uma forma menos "gulosa" fornece soluções de melhor qualidade.

\subsubsection{Comparação com o CPLEX}

Nesta seção iremos comparar as soluções obtidas através dos métodos $L S_{P}$ e mip $_{1, L S_{P}, 180 s}$ com a solução obtida pelo método exato (solução do modelo definido pelas equações (4.17)-(4.22) através do software CPLEX). Para ser possível comparar a qualidade da solução obtida heuristicamente com a qualidade da solução obtida através do CPLEX após um grande tempo de execução, resolvemos o modelo exato apenas para uma instância de cada grupo, pois cada instância teve um tempo de execução de $172.800 \mathrm{~s}-2$ dias.

Na Tabela 6.12 são mostrados o gap dos métodos heurísticos $\left(L S_{P}\right.$ e mip $\left._{1, L S_{P}, 180}\right)$ em relação a melhor solução obtida pelo CPLEX em 2 dias de execução, e comparação entre os tempos de execução.

\begin{tabular}{lrrrr}
\hline instâncias & gap mip $_{1, L S_{P}, 180}(\%)$ & $t_{c p l e x} / t_{m i p_{1}}$ & gap $L S_{P}(\%)$ & $t_{c p l e x} / t_{L S_{P}}$ \\
\hline \hline Heskia 1 & $-1,72$ & 233 & $\mathbf{- 1 , 7 2}$ & 476 \\
Heskia 11 & $-1,08$ & 360 & $\mathbf{- 1 , 0 8}$ & 466 \\
Heskia 21 & $-1,78$ & 328 & $\mathbf{- 1 , 7 4}$ & 435 \\
Heskia 31 & $-2,27$ & 248 & $\mathbf{- 2 , 2 2}$ & 421 \\
Heskia 41 & $-2,36$ & 329 & $\mathbf{- 2 , 3 3}$ & 505 \\
Heskia 51 & $-0,88$ & 319 & $\mathbf{- 0 , 7 8}$ & 680 \\
Heskia 61 & $-1,66$ & 458 & $\mathbf{- 1 , 6 4}$ & 702 \\
Heskia 71 & $-1,37$ & 222 & $\mathbf{- 1 , 2 0}$ & 613 \\
\hline média & $-1,64$ & 312 & $-1,59$ & 537 \\
\hline \hline Roszieg 1 & $-0,38$ & 308 & $\mathbf{- 0 , 3 8}$ & 748 \\
Roszieg 11 & $-0,06$ & 370 & $-0,06$ & 592 \\
Roszieg 21 & $-0,14$ & 318 & $-0,14$ & 411 \\
Roszieg 31 & $-0,11$ & 308 & $-0,06$ & 437 \\
Roszieg 41 & $-0,70$ & 321 & $\mathbf{- 0 , 6 6}$ & 506 \\
Roszieg 51 & $-0,69$ & 194 & $-0,33$ & 439 \\
Roszieg 61 & $-1,04$ & 254 & $\mathbf{- 0 , 9 0}$ & 508 \\
Roszieg 71 & $-1,17$ & 236 & $\mathbf{- 1 , 0 2}$ & 427 \\
\hline média & $-0,54$ & 289 & $-0,44$ & 508 \\
\hline \hline média geral & $-1,09$ & 300 & $-1,02$ & 523 \\
\hline \hline
\end{tabular}

Tabela 6.12: Comparação com a solução obtida pelo CPLEX após 2 dias de execução

Aplicando a mip $_{1, L S_{P}, 180 s}$, obtivemos soluções sempre melhores que o CPLEX, limitado a 2 dias de execução. A própria solução inicial $\left(L S_{P}\right)$, com tempo de execução mais de 500 vezes inferior, já fornece soluções melhores que o CPLEX para todas as instâncias consideradas. A heurística $L S_{A}$, cujo tempo de execução é de poucos segundos, alcançou soluções melhores que o CPLEX nas 12 instâncias destacadas na coluna gap $L S_{P}$. 
Isso mostra que os métodos propostos são capazes de fornecer soluções de qualidade, com pequeno esforço computacional. Em especial, a busca local $L S_{P}$, aplicada sobre a $L S_{A}$, é um método muito eficiente e capaz de alcançar soluções de qualidade em apenas 6 min.

\subsection{Sumário dos resultados}

A partir dos resultados mostrados no Capítulo 6, pode-se concluir que a medida de avaliação aproximada proposta é adequada, pois em poucos segundos a busca local $L S_{A}$ é capaz de melhorar em até $20 \%$ uma solução inicial, reduzindo o excesso de carga em mais de $2 \%$, em média. Verificou-se também a possibilidade de continuar a busca, utilizando a solução do LP como medida de avaliação da vizinhança. Os testes mostram que é possível melhorar, em média, 0,23\% e 0,52\% a solução dada pela $L S_{A}$ nas famílias Heskia e Roszieg, respectivamente; com tempo de execução inferior a $360 \mathrm{~s}$. Continuando a busca local por aproximadamente mais $6 \mathrm{~min}$, é possível melhorar, em média, $0,05 \%$ e $0,10 \%$ a solução dada pela $L S_{P}$ nas famílias Heskia e Roszieg, respectivamente.

Propomos também duas estratégias híbridas: as buscas locais com vizinhança baseada em programação inteira mista mip $p_{1}$ e mip $p_{2}$. Esta última não forneceu soluções de qualidade, pois para obter uma ampla vizinhança, capaz de englobar soluções melhores que a incumbente, é necessária a liberação de um número muito grande de variáveis inteiras, sendo, portanto, um problema de difícil resolução.

Com a estratégia $m i p_{1}$ aplicada sobre a solução retornada pela $L S$ obteve-se um ganho de apenas 0,07\%, com tempo de execução em torno de 20 min. Aplicando a mip $_{1}$ sobre a $L S_{P}$, a estratégia híbrida obteve melhores resultados que a busca local: a mip $_{1, L S_{P}, 180}$ é em média $0,05 \%$ melhor que a $L S$ nas instâncias da família Heskia, e 0,11\% melhor nas instâncias da família Roszieg, e ainda com menor custo computacional. Todas essas comparações foram realizadas sobre a solução retornada pela melhor heurística construtiva (heurística que gerou a solução de melhor qualidade após a aplicação da mi $p_{1, L S_{P}, 180}$ em cada grupo de instâncias). Portanto, executar a busca local $L S$ por um tempo superior a 360 s não fornece uma boa solução, nem uma boa solução inicial à mip 1 .

Apenas aplicando-se a busca local $L S_{P}$, já é possível obter soluções melhores que o CPLEX com tempo limite de 2 dias. Com tempo computacional superior em apenas $5 \mathrm{~min}$, a mip $_{1, L S_{P}, 180}$ fornece um gap médio 0,07\% menor que a $L S_{P}$ (gap médio calculado sobre todas as 16 instâncias consideradas e quatro heurísticas construtivas). 


\section{- 7 \\ Conclusões e Trabalhos Futuros}

Através de uma revisão bibliográfica sistemática, obteve-se uma visão geral dos trabalhos recentes sobre os problemas MALBP e ALWABP. Isso foi essencial para o desenvolvimento de modelos e heurísticas para o problema MALWABP.

Foi proposto um modelo matemático para resolução do problema de balanceamento MALWABP, a partir da adaptação dos modelos matemáticos dos problemas de balanceamento ALWABP e MALBP. Outros dois modelos matemáticos foram propostos para a resolução do problema de sequenciamento MALWABP, sendo o segundo uma adaptação do primeiro com menor número de variáveis inteiras. Diversas heurísticas foram desenvolvidas para resolução desse segundo modelo.

Primeiramente desenvolveram-se quatro heurísticas construtivas, a partir da adaptação de uma heurística construtiva para resolução do MALBP, proposta por Scholl et al. (1998). Como uma estratégia de melhoria baseada em uma vizinhança all-pairs seria muito custosa, desenvolveu-se também um critério de geração de vizinhança baseado nas posições com maior excesso de carga, sendo possivel avaliar a vizinhança gerada através da resolução do LP resultante da fixação das variáveis inteiras, para instâncias de pequeno porte. Testou-se a aplicação dessa busca local para resolução de instâncias que se assemelham a problemas práticos (grande quantidade de diferentes modelos e demanda total), e os testes iniciais mostraram a inviabilidade de resolução do problema linear para obter a qualidade de cada solução vizinha, em cada iteração da busca bocal. Por isso, desenvolveu-se uma medida que aproxima o valor do LP e pode ser recalculada muito rapidamente.

Sabendo-se qual trabalhador $w_{k}$ foi alocado a cada estação $k$ e dada uma 
sequência de modelos (inicialmente obtida por uma das quatro heurísticas construtivas), pode-se aproximar o excesso de carga total através da análise do tempo de execução de modelos adjacentes. Se um modelo $m_{i+1}$ pode ser executado em um tempo menor que o tempo de ciclo, subtraí-se do possível excesso de carga do modelo $m_{i}$ o tempo ocioso do modelo $m_{i+1}$, ou seja, estima-se separadamente para cada posição da sequência, o quanto o item $i$ excede o tempo de ciclo e o quanto isso pode ser compensado parcial, ou completamente, pelo tempo ocioso do próximo item a ser produzido na estação $k$. Desta forma, podem-se privilegiar sequências em que modelos de alta carga são seguidos por modelos de baixa carga nas mesmas estações.

A medida assim derivada mostrou-se muito eficiente em resolver o problema de sequenciamento proposto. Dentre as 16 instâncias resolvidas através do software CPLEX (com tempo limite de 2 dias e aplicado sobre o modelo definido pelas equações (4.17)-(4.22)), em apenas quatro, a $L S_{A}$ não foi capaz de encontrar soluções melhores que o CPLEX. Mas refinando-se sua solução, utilizando a busca local com medida de avaliação calculada através da resolução do problema linear $\left(L S_{P}\right)$, foram obtidos resultados melhores que o CPLEX em todas as instâncias consideradas.

Propomos também duas estratégias híbridas de busca local. Nenhuma melhoria significativa foi obtida aplicando a busca local com vizinhança baseada

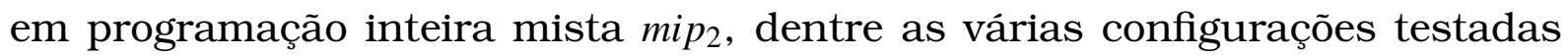
para número de posições a serem liberadas e gap tolerado em cada iteração. O problema resultante tem uma vizinhança muito restrita se liberarmos poucas variáveis inteiras, que definem qual modelo será alocado a cada posição da sequência. Mas ao liberarmos mais de $10 \%$ das posições $(0,1 \cdot|I| \cdot|M|$ variáveis inteiras), era necessário definir um gap muito pequeno para que uma solução melhor que a incumbente fosse encontrada, implicando em um alto custo computacional.

Analisando a qualidade da $L S_{P}$ e da mip $p_{1}$ sobre a solução retornada pela $L S_{A}$, vemos que a $L S_{P}$ é ligeiramente melhor que a mi $p_{1}$. Porém a estratégia híbrida mip $_{1}$ é muito eficiente como estratégia de melhoria a ser aplicada sobre a solução fornecida pela $L S_{P}$, pois obtém soluções melhores que a busca local com maior tempo limite de execução $(L S)$. Isso mostra que no início da execução, a busca local com função de avaliação exata é capaz de obter melhorias significativas, sendo inclusive, ligeiramente melhor que a estratégia baseada em vizinhança MIP. No entanto, quando se está muito próximo de um ótimo local, a estratégia de vizinhança MIP é capaz de obter resultados melhores que a busca local $L S$ (a partir da solução retornada pela $L S_{P}$ ).

Isso mostra que é possivel obter soluções de melhor qualidade aplicando-se os três métodos propostos em sequência: busca local com medida aproximada 
$\left(L S_{A}\right)$, busca local com medida de avaliação através da resolução do problema linear $\left(L S_{P}\right)$, e busca local com vizinhança baseada em programação inteira mista $\left(\right.$ mip $\left._{1, L S_{P}, 180}\right)$. Apenas aplicando-se a $L S_{P}$ (sobre a solução retornada pela $L S_{A}$ ), obtêm-se soluções de qualidade superior ao CPLEX executado por 2 dias, em todas as 16 instâncias consideradas, o que sugere que as heurísticas construtivas e métodos de busca local propostos neste trabalho são capazes de resolver adequadamente o problema de sequenciamento.

Nesse trabalho, concentrou-se em resolver o problema de sequenciamento, já que para obter conclusões sobre a qualidade do balanceamento, deve-se ter a sua solução. No tocante a trabalhos futuros, vemos duas linhas claras: considerar o problema de balanceamento para o problema MALWABP, e estudar o problema de sequenciamento MALWABP considerando que também os trabalhadores de apoio podem ser deficientes.

Primeiramente, com o êxito obtido neste problema e guiados pelo trabalho de Emde et al. (2010), pode-se buscar identificar se o comportamento das funções de antecipação sobre a qualidade do balanceamento no problema MALBP é observado também no problema MALWABP. O melhor método proposto $\left(\right.$ mip $_{1, L S_{P}, 180}$ ) poderá também ser submetido a problemas maiores, pois nestes mesmos experimentos, Emde et al. (2010) comparam a qualidade do balanceamento frente a incertezas na demanda (demanda total de até 500 itens) e variação na quantidade de modelos a serem produzidos (10, 75 e 150 modelos distintos).

Na Seção 4.2.2, a limitação do modelo de sequenciamento simplificado, proposto para o sequenciamento MALWABP, foi discutida. No modelo de sequenciamento proposto não é necessário especificar qual trabalhador de apoio atuará em cada posição da sequência e estação, visto que todos os trabalhadores de apoio são igualmente eficientes. Mas se a equipe de apoio for composta por trabalhadores com diferentes habilidades, é preciso especificar quais tarefas $y_{m i j}$ serão executadas por cada trabalhador, como definido no modelo (4.6)-(4.15), para obter o real excesso de carga. Porém, quando se definem quais tarefas $y_{m i j}$ os trabalhadores de apoio devem realizar, retira-se a liberdade dos trabalhadores operarem em qualquer momento da produção do item $i$ na estação $k$, devido às relações de precedência entre as tarefas. Neste caso, reduzir o tempo total empregado pelos trabalhadores de apoio não é equivalente a reduzir o número de trabalhadores necessários à equipe de apoio.

Assim, em uma segunda continuação possível desse trabalho, poder-se-ia desenvolver um novo modelo matemático e heurísticas para o problema de sequenciamento MALWABP que considerasse os diferentes tempos de execução das tarefas, inclusive para os trabalhadores de apoio. Isto permitiria a aplicação dos modelos e métodos desenvolvidos em CTD’s, sem a necessidade de 
contratação de trabalhadores não deficientes. Esta extensão, extremamente desafiadora tecnicamente, justifica-se dada a importância social dos CTD’s. 


\section{Referências Bibliográficas}

Ahmadi, R. H. e Wurgaft, H. (1994). Design for synchronized flow manufacturing. Management Science, 40(11):1469-1483. Citado na página 25.

Akgündüz, O. S. e Tunali, S. (2010). An adaptive genetic algorithm approach for the mixed-model assembly line sequencing problem. International Journal of Production Research, 48(17):5157-5179. Citado na página 28.

Alpay, S. (2009). Grasp with path relinking for a multiple objective sequencing problem for a mixed-model assembly line. International Journal of Production Research, 47(21):6001-6017. Citado na página 28.

Araújo, F. F. B., Costa, A. M., e Miralles, C. (2010). Linhas de produção com trabalhadores deficientes e máquinas paralelas. In Proceedings of the 5th Americas International Conference on Production Research. Citado na página 30.

Bautista, J. e Cano, J. (2008). Minimizing work overload in mixed-model assembly lines. International Journal of Production Economics, 112(1):177-191. Citado na página 13.

Bissoli, L. (2005). Sinal verde para a competência. UOL sentidos. Último acesso em 16 de Janeiro de 2012. Citado na página 2.

Bock, S., Rosenberg, O., e van Brackel, T. (2006). Controlling mixed-model assembly lines in real-time by using distributed systems. European Journal of Operational Research, 168(3):880 - 904. Balancing Assembly and Transfer lines. Citado na página 26.

Boysen, N., Fliedner, M., e Scholl, A. (2009a). Assembly line balancing: Joint precedence graphs under high product variety. IIE Transactions, 41:183193. Citado nas páginas 2 e 24 . 
Boysen, N., Fliedner, M., e Scholl, A. (2009b). Production planning of mixedmodel assembly lines: overview and extensions. Production Planning \& Control, 20:455-471. Citado na página 28.

Boysen, N., Fliedner, M., e Scholl, A. (2009c). Sequencing mixed-model assembly lines: Survey, classification and model critique. European Journal of Operational Research, 192:349-373. Citado na página 11.

Boysen, N., Kiel, M., e Scholl, A. (2010). Sequencing mixed-model assembly lines to minimise the number of work overload situations. International Journal of Production Research, online first. DOI: 10.1080/00207543.2010.507607. Citado nas páginas 14 e 28.

Bureau of Labor Statistics, E. (2010). New monthly data series on the employment status of people with a disability. Último acesso em 08 de Janeiro de 2011. Citado na página 1.

Chaves, A. A., Lorena, L. A. N., e Miralles, C. (2009). Hybrid metaheuristic for the assembly line worker assignment and balancing problem. Lecture Notes on Computer Science, 5818:1-14. Citado nas páginas 29 e 30.

Chaves, A. A., Miralles, C., e Lorena, L. A. N. (2007). Clustering search approach for the assembly line worker assignment and balancing problem. In 37th International Conference on Computers and Industrial Engineering, pages 1469-1478, Alexandria, Egypt. Citado nas páginas 51 e 57.

Cohen, S. L. e Pine II, B. J. (2007). Mass customizing: The training industry. T and $D, 61(6): 50-54+5$. Citado na página 2.

Costa, A. M. e Miralles, C. (2009). Job rotation in assembly lines employing disabled workers. International Journal of Production Economics, 120(2):625632. Citado na página 30.

Dong, J., Xiao, T., Fan, S., e Giang, L. (2002). Mixed-model assembly line sequencing with hybrid genetic algorithm and simulation. pages 541-545. Citado na página 28.

Emde, S., Boysen, N., e Scholl, A. (2010). Balancing mixed-model assembly lines: a computational evaluation of objectives to smoothen workload. International Journal of Production Research, 48:3173-3191. Citado nas páginas 27 e 65.

Erel, E. e Gökçen, H. (1999). Shortest-route formulation of mixed-model assembly line balancing problem. European Journal of Operational Research, 116:194-204. Citado nas páginas 11 e 24. 
Gouveia, L. e Voß, S. (1995). A classification of formulations for the (timedependent) traveling salesman problem. European Journal of Operational Research, 83(1):69-82. Citado na página 28.

Gutjahr, A. L. e Nemhauser, G. L. (1964). An algorithm for the line balancing problem. Management Science, 11:308-315. Citado na página 24.

Hwang, R. e Katayama, H. (2010). Integrated procedure of balancing and sequencing for mixed-model assembly lines: A multi-objective evolutionary approach. International Journal of Production Research, 48(21):6417-6441. Citado na página 26.

Hyun, C. J., Kim, Y., e Kim, Y. K. (1998). A genetic algorithm for multiple objective sequencing problems in mixed model assembly lines. Computers and Operations Research, 25(7-8):675-690. Citado na página 28.

IBGE (2000). Censo demográfico. Último acesso em 08 de Janeiro de 2011. Citado na página 1 .

IBGE (2005). Ibge and corde open international meeting on disability statistics. Social Communication. Último acesso em 13 de Março de 2011. Citado na página 1.

Jaime, L. R. e Carmo, J. C. (2005). A inserção da pessoa com deficiência no mundo do trabalho: o resgate de um direito de cidadania. Editora dos autores, São Paulo. Citado na página 2.

Kara, Y. (2008). Line balancing and model sequencing to reduce work overload in mixed-model u-line production environments. Engineering Optimization, 40(7):669-684. Citado na página 26.

Kara, Y., Özcan, U., e Peker, A. (2007). Balancing and sequencing mixedmodel just-in-time $\mathrm{u}$-lines with multiple objectives. Applied Mathematics and Computation, 184(2):566-588. Citado na página 26.

Kim, Y. K., Hyun, C. J., e Kim, Y. (1996). Sequencing in mixed model assembly lines: A genetic algorithm approach. Computers \& Operations Research, 23(12): 1131 - 1145. Citado na página 28.

Kim, Y. K., Kim, J. Y., e Kim, Y. (2006). An endosymbiotic evolutionary algorithm for the integration of balancing and sequencing in mixed-model ulines. European Journal of Operational Research, 168(3):838-852. Citado na página 26. 
Leu, Y., Matheson, L. A., e Rees, L. P. (1996). Sequencing mixed-model assembly lines with genetic algorithms. Computers and Industrial Engineering, 30(4):1027-1036. Citado na página 28.

Maniezzo, V., Stützle, T., e Voß, S., editors (2010). Matheuristics - Hybridizing Metaheuristics and Mathematical Programming, volume 10 of Annals of Information Systems. Springer. Citado na página 49.

Mansouri, S. A. (2005). A multi-objective genetic algorithm for mixed-model sequencing on jit assembly lines. European Journal of Operational Research, 167(3):696-716. Citado na página 28.

Matanachai, S. A. I. e Yano, C. A. (2001). Balancing mixed-model assembly lines to reduce work overload. IIE Transactions - Institute of Industrial Engineers, 33(1):29-42. Citado na página 27.

McMullen, P. R. (2001). An ant colony optimization approach to addressing a jit sequencing problem with multiple objectives. Artificial Intelligence in Engineering, 15(3):309-317. Citado na página 28.

McMullen, P. R. (2010). Jit mixed-model sequencing with batching and setup considerations via search heuristics. International Journal of Production Research, 48(22):6559-6582. Citado na página 28.

McMullen, P. R. e Frazier, G. V. (2000). A simulated annealing approach to mixed-model sequencing with multiple objectives on a just-in-time line. IIE Transactions (Institute of Industrial Engineers), 32(8):679-686. Citado na página 28.

McMullen, P. R. e Tarasewich, P. (2006). Multi-objective assembly line balancing via a modified ant colony optimization technique. International Journal of Production Research, 44:27-42. Citado na página 27.

Merengo, C., Nava, F., e Pozzetti, A. (1999). Balancing and sequencing manual mixed-model assembly lines. International Journal of Production Research, 37(12):2835-2860. Citado na página 26.

Michalewicz, Z. (1996). Genetic algorithms + data structures = evolution programs (3rd ed.). Springer-Verlag, London, UK. Citado na página 48.

Miltenburg, J. (2002). Balancing and scheduling mixed-model u-shaped production lines. International Journal of Flexible Manufacturing Systems, 14(2):123-155. Citado na página 26.

Miralles, C., Garcia-Sabater, J. P., Andrés, C., e Cardos, M. (2007). Advantages of assembly lines in Sheltered Work Centres for Disabled. A case study. 
International Journal of Production Economics, 110:187-197. Citado nas páginas 18, 20, 29, e 30 .

Miralles, C., Garcia-Sabater, J. P., Andrés, C., e Cardos, M. (2008). Branch and bound procedures for solving the Assembly Line Worker Assignment and Balancing Problem: Application to Sheltered Work centres for Disabled. Discrete Applied Mathematics, 156:352-367. Citado na página 29.

Moreira, M. C., Costa, A. M., Ritt, M., e Chaves, A. A. (2012). Simple heuristics for the assembly line worker assignment and balancing problem. Journal of Heuristics, pages 1-20. Citado na página 30.

Moreira, M. C. O. (2011). Balanceamento de linhas de produção com trabalhadores deficientes. Dissertação de Mestrado, Universidade de São Paulo. Citado na página 7.

Moreira, M. C. O. e Costa, A. M. (2009). A minimalist yet efficient tabu search for balancing assembly lines with disabled workers. In Anais do XLI Simpósio Brasileiro de Pesquisa Operacional, Porto Seguro. Citado nas páginas 20 e 30 .

Moreira, M. C. O., Santos, L. M. R., e Costa, A. M. (2009). Trabalhadores com deficiência em linhas de produção: modelo, resultados e discussões. In Anais da XIV Escuela Latinoamericana de Investigacion Operativa, El Fuerte, México. Citado nas páginas 1 e 30.

Office for National Statistics Labour Force Survey, U. K. (2009). Disability and employment statistics. Shaw Trust - Ability at work. Último acesso em 15 de Março de 2011. Citado na página 1.

Özcan, U., Kellegöz, T., e Toklu, B. (2011). A genetic algorithm for the stochastic mixed-model $\mathrm{u}$-line balancing and sequencing problem. International Journal of Production Research, 49(6):1605-1626. Citado na página 26.

Pastor, R., Andrés, C., Duran, A., e Pérez, M. (2002). Tabu search algorithms for an industrial multi-product and multi-objective assembly line balancing problem, with reduction of the task dispersion. Journal of the Operational Research Society, 53:1317-1323. Citado na página 27.

Patterson, J. H. e Albracht, J. J. (1975). Assembly-Line Balancing: zero-one Programming with Fibonacci Search. Operations Research, 23:166 - 172. Citado na página 10.

Ponnambalam, S. G., Aravindan, P., e Subba Rao, M. (2003). Genetic algorithms for sequencing problems in mixed model assembly lines. Computers and Industrial Engineering, 45(4):669-690. Citado na página 28. 
Rao, Y., Wang, B., e Shao, X. (2009). Lot sizing and scheduling for mixedmodel fabrication/assembly systems. pages 2404-2409. Citado na página 26.

Roberts, S. D. e Villa, C. D. (1970). On a multiproduct assembly line balancing problem. AIIE Transactions, 2:361-364. Citado nas páginas 23 e 24.

Salveson, M. E. (1955). The assembly line balancing problem. Journal of Industrial Engineering, 6:18-25. Citado na página 23.

Sawik, T. (2009). Monolithic versus hierarchical approach to integrated scheduling in a supply chain. International Journal of Production Research, 47(21):5881-5910. Citado na página 26.

Scholl, A. (1999). Balancing and sequencing of assembly lines. Physica-Verlag. Citado nas páginas $5,7,8,9,11,12,16,17,34$, e 36.

Scholl, A. e Becker, C. (2006). State-of-the-art exact and heuristic solution procedures for simple assembly line balancing. European Journal of Operational Research, 168:666-693. Citado nas páginas 8 e 9.

Scholl, A., Klein, R., e Domschke, W. (1998). Pattern based vocabulary building for effectively sequencing mixed-model assembly lines. Journal of Heuristics, 4(4):359-381. Citado nas páginas 28, 39, 40, e 63.

Shao, X., Wang, B., Rao, Y., Gao, L., e Xu, C. (2010). Metaheuristic approaches to sequencing mixed-model fabrication/assembly systems with two objectives. International Journal of Advanced Manufacturing Technology, 48(912):1159-1171. Citado na página 28.

Simonelli, A. P., Rodrigues, D. S., e Soares, L. (2006). Caracterização do perfil de trabalhadores afastados e de pessoas com deficiência no mercado de trabalho do municipio de São Carlos. In Anais das XIV Jornadas de Jovens pesquisadores da Associação de Universidades do Grupo Montevidéu. Citado na página 2 .

Thomopoulos, N. T. (1970). Mixed model line balancing with smoothed station assignments. Management Science, 16(9):593-603. Citado na página 24.

Tseng, H., Chen, M., Chang, C., e Wang, W. (2008). Hybrid evolutionary multi-objective algorithms for integrating assembly sequence planning and assembly line balancing. International Journal of Production Research, 46(21):5951-5977. Citado na página 26. 
van Zante-de Fokkert, J. I. e de Kok, T. G. (1997). The mixed and multi model line balancing problem: a comparison. European Journal of Operational Research, 100(3):399 - 412. Citado na página 10.

Vilarinho, P. M. e Simaria, A. S. (2002). A two-stage heuristic method for balancing mixed-model assembly lines with parallel workstations. International Journal of Production Research, 40:1405-1420. Citado na página 27.

Vilarinho, P. M. e Simaria, A. S. (2006). Antbal: An ant colony optimization algorithm for balancing mixed-model assembly lines with parallel workstations. International Journal of Production Research, 44(2):291-303. Citado na página 27.

Visich, J. K., Khumawala, B. M., e Diaz-Saiz, J. (2010). An empirical comparison of improvement heuristics for the mixed-model u-line balancing problem. International Journal of Manufacturing Technology and Management, 20(1-4):25-45. Citado na página 27.

Wang, B. (2010). Sequencing mixed-model production systems by modified multi-objective genetic algorithms. Chinese Journal of Mechanical Engineering (English Edition), 23(5):537-546. Citado na página 28.

Xiaobo, Z. e Ohno, K. (1997). Algorithms for sequencing mixed models on an assembly line in a jit production system. Comput. Ind. Eng., 32:47-56. Citado na página 28.

Zhang, W., Gen, M., e Lin, L. (2008). A multiobjective genetic algorithm for assembly line balancing problem with worker allocation. In Systems, Man and Cybernetics, 2008. SMC 2008. IEEE International Conference on, pages 3026 -3033. Citado na página 26. 